ZEBEDEU FERNANDES DE SOUZA

A IMPORTÂNCIA DA REAÇÃO DA DEMANDA NA FORMAÇÃO DOS PREÇOS DE CURTO PRAZO EM MERCADOS DE ENERGIA ELÉTRICA 
ZEBEDEU FERNANDES DE SOUZA

\title{
A IMPORTÂNCIA DA REAÇÃO DA DEMANDA NA FORMAÇÃO DOS PREÇOS DE CURTO PRAZO EM MERCADOS DE ENERGIA ELÉTRICA
}

\begin{abstract}
Dissertação apresentada à Escola Politécnica da Universidade de São Paulo para obtenção do título de mestre em Engenharia Elétrica
\end{abstract}

Área de Concentração:

Sistemas de Potência

Orientador:

Prof. Dr. Dorel Soares Ramos

São Paulo 
Este exemplar foi revisado e alterado em relação à versão original, sob responsabilidade única do autor e com a anuência de seu orientador.

São Paulo, 23 de março de 2010.

Assinatura do autor

Assinatura do orientador

Souza, Zebedeu Fernandes de

A importância da reação da demanda na formação dos preços de curto prazo em mercados de energia elétrica / Z.F. de Souza. -- ed.rev. -São Paulo, 2010.

$118 \mathrm{p}$.

Dissertação (Mestrado) - Escola Politécnica da Universidade de São Paulo. Departamento de Engenharia de Energia e Automação Elétricas.

1.Sistemas elétricos de potência 2.Energia elétrica 3.Planejamento energético 4.Distribuição de energia elétrica 5.Geração de energia eletrica 6.Demanda energética 7.Economia de energia 8.Microeconomia 9.Preço I.Universidade de São Paulo. Escola Politécnica. Departamento de Engenharia de Energia e Automação Elétricas Il.t. 


\section{DEDICATÓRIA}

À minha companheira Valéria, por seu carinho e compreensão. Ao Fernando, meu filho querido, e aos meus pais e irmãs, que sempre me inspiram a continuar a jornada. 


\section{AGRADECIMENTOS}

À minha companheira Valéria, por seu carinho e apoio em todos os momentos.

Ao meu querido filho Fernando, por ser força tão grande de inspiração.

Aos meus pais e às minhas irmãs, Sandra e Silvania, que sempre estiveram presentes em minha vida, ainda que fisicamente distantes.

Ao Professor Dorel Soares Ramos, por ter me acolhido como orientado e por todo o suporte que forneceu durante toda a elaboração deste trabalho, sempre com muito profissionalismo e dedicação.

Ao Professor Hernan Prieto Schimidt, por sua orientação durante grande parte do desenvolvimento do meu programa de mestrado.

Aos professores Donato da Silva Filho e Fernando Amaral de Almeida Prado, membros das bancas de qualificação e defesa, que sugeriram importantes melhorias neste trabalho.

Aos grandes amigos da Assessoria Técnica e Econômica do Conselho da CCEE, Evelina Neves, Katia Ogawa, Leandro Tsuneshiro e Luiz Pazzini, os quais me contagiam todos os dias com seus espíritos sempre voltados ao aprimoramento e à inovação.

Aos companheiros da Coordenação de Preços, pelo suporte constante.

A todos os meus amigos. 
"O importante é continuar aprendendo, desfrutar os desafios e tolerar a ambigüidade, pois, em definitivo, não existem certezas." (Marina Horner) 


\section{RESUMO}

Uma condição fundamental para que um mercado seja competitivo é que existam muitos compradores e, em especial, compradores que possam responder aos preços. Os consumidores reagem para se ajustarem aos preços de acordo com sua disposição em consumir um determinado bem. À medida que o preço se eleva, os consumidores tendem a reduzir a quantidade demandada e, quando o preço cai, os consumidores tendem a aumentar o volume demandado. A sensibilidade dos consumidores às mudanças de preços é caracterizada pela elasticidade-preço da demanda. Contudo, nos desenhos de mercados de energia elétrica, é comum a concentração de atenção no lado do suprimento, assumindo-se, implicitamente, que toda a demanda é inelástica. $O$ presente trabalho contempla uma análise dos mecanismos de formação de preços de curto prazo adotados em mercados de energia elétrica (i.e. formação baseada em custos e formação baseada em ofertas) e, a partir desse contexto, avalia os benefícios da introdução de mecanismos de incentivo à participação da demanda na determinação dos preços do mercado de curto prazo como forma de elevar sua eficiência econômica.

Palavras-chave: Mercados de Energia Elétrica. Preços de Curto Prazo. Sinal Econômico. Resposta da Demanda. 


\begin{abstract}
Given an economic environmental, a fundamental condition for a market be suitable to competition is that must has a plenty of buyers and, in special, those who can react to price signals. The consumers' reaction aims at to adjust their energy requirements to the prices according to their disposal to access a certain product or service. As the price increases, the consumers tend to reduce the demanded volume and, on the other hand, when the prices decreases, the consumers increase the demanded volume. The consumers' reaction to the price changes is characterized by the price elasticity of demand. However, in the electric energy market design, it is common to pay attention to the supply side, taking into account, implicitly, that all demand is inelastic. This work performs an analysis of mechanisms of spot price formation adopted by electric energy markets (i.e. cost based and bid based prices) and, from this context, evaluates the benefits of incentive mechanisms to the demand participation in determining short-term market price as an option to improve the economic efficiency.
\end{abstract}

Key-words: Electricity Market. Short-Term Price. Spot Price. Economic Signal. Demand Response. 


\section{LISTA DE ILUSTRAÇÕES}

Figura 2.1 - Mecanismo de mercado 20

Figura 2.2 - Mudanças de equilíbrio de mercado - deslocamento da oferta 21

Figura 2.3 - Mudanças de equilíbrio de mercado - deslocamento da demanda ... 21

Figura 2.4 - Demanda perfeitamente inelástica, ou perfeitamente rígida 23

Figura 2.5 - Demanda perfeitamente elástica 24

Figura 2.6 - Receita marginal e custo marginal e maximização do lucro da firma . 27

Figura 3.1 - Esquema de despacho e formação de preços por otimização dos custos de operação 32

Figura 4.1 - Relação entre os tipos de tarifas e a percepção do consumidor aos preços de curto prazo 54

Figura 4.2 - Valoração do benefício da resposta da demanda 59

Figura 4.3 - Capacidade de resposta da demanda e incentivo ao exercício de poder de mercado 60

Figura 4.4 - Efeitos da reação da demanda sobre os preços em diferentes níveis 62

Figura 5.1 - O planejamento da operação eletroenergética 78

Figura 5.2 - Decisão da utilização dos recursos hidrelétricos no presente versus armazenamento de água 78

Figura 5.3 - Minimização do custo total de geração 80 
Figura 5.4 - Definição do CMO conforme o recurso utilizado

Figura 5.5 - Processo de planejamento da operação e cálculo do CMO/PLD 82

Figura 5.6 - Formação de preços a partir da introdução da CAR 83

Figura 5.7 - Formação de preços a partir da introdução da CAR e dos níveis-meta. 85 


\section{LISTA DE GRÁFICOS}

Gráfico 5.1 - Histórico do PLD (janeiro de 2003 a julho de 2009) 75

Gráfico 5.2 - Efeitos da introdução da Redução Voluntária de Carga no longo prazo 91

Gráfico 5.3 - Efeitos da introdução da Redução Voluntária de Carga no longo prazo 92

Gráfico 5.4 - Histograma dos CMOs calculados a partir do NEWAVE 94

Gráfico 5.5 - Histograma dos CMOs calculados a partir do NEWAVE 95

Gráfico 5.6 - Custo Marginal de Operação do Sudeste - série histórica crítica 96

Gráfico 5.7 - Variação percentual do PLD entre períodos consecutivos 102

Gráfico 5.8 - Variação do PLD em R $\$ / M W h$ 103 


\section{LISTA DE TABELAS}

Tabela 4.1 - Benefícios da resposta da demanda 44

Tabela 4.2 - Participação dos Consumidores nos programas de incentivo à resposta da demanda - EUA 51

Tabela 4.3 - Opções oferecidas aos consumidores pelo PowerShare Pricing Program - alternativa CallOption 69

Tabela 4.4 - Critérios de verificação de redução efetiva de carga 74

Tabela 5.1- Usinas termelétricas virtuais introduzidas no NEWAVE para representar a Redução Voluntária de Carga 90

Tabela 5.2 - Valores médios do CMO, considerando todo o horizonte de estudo 93

Tabela 5.3 - Valores médios anuais dos CMOs simulados, calculados a partir dos valores esperados mensais 93

Tabela 5.4 - Curva do custo do déficit de energia elétrica 96

Tabela 5.5 - Freqüência de ocorrência de déficits para as séries simuladas 98

Tabela 5.6 - Resultados das simulações (PLDs calculados com o modelo DECOMP com e sem a incorporação da RVC) 99

Tabela 5.7- Resultados das simulações (PLDs calculados com o modelo DECOMP com e sem a incorporação da RVC 100

Tabela 5.8 - CMO's médios por patamar de carga 103

Tabela 5.9 - Volatilidade do PLD para as séries simuladas 105 


\section{LISTA DE ABREVIATURAS E SIGLAS}

$\begin{array}{ll}\text { ANEEL } & \text { Agência Nacional de Energia Elétrica } \\ \text { BPA } & \text { Boneville Power Administration } \\ \text { CCEE } & \text { Câmara de Comercialização de Energia Elétrica } \\ \text { CEPEL } & \text { Centro de Pesquisas de Energia Elétrica } \\ \text { CMO } & \text { Custo Marginal de Operação } \\ \text { CMSE } & \text { Comitê de Monitoramento do Setor Elétrico } \\ \text { CVU } & \text { Custo Variável Unitário } \\ \text { DEMX } & \text { Demand Exchange } \\ \text { GCPS } & \text { Grupo Coordenador do Planejamento dos Sistemas Elétricos } \\ \text { IESO } & \text { Independent Electricity System Operator } \\ \text { IBGE } & \text { Instituto Brasileiro de Geografia e Estatística } \\ \text { MW } & \text { Megawatt } \\ \text { MWh } & \text { Megawatt-hora } \\ \text { ONS } & \text { Operador Nacional do Sistema Elétrico } \\ \text { PIB } & \text { Produto Interno Bruto } \\ \text { PJM } & \text { PJM Interconection } \\ \text { PLD } & \text { Preço de Liquidação de Diferenças } \\ \text { SIN } & \text { Sistema Interligado Nacional } \\ \text { WVPA } & \text { Wabash Valley Power Association }\end{array}$




\section{LISTA DE SÍMBOLOS}

$\begin{array}{ll}\boldsymbol{C}(\boldsymbol{q}) & \text { Curva de custo } \\ \boldsymbol{C M} & \text { Custo marginal } \\ \boldsymbol{C P} & \text { Custo de produção } \\ \boldsymbol{D} & \text { Curva de demanda } \\ \boldsymbol{E}_{\boldsymbol{p}} & \text { Elasticidade-preço da demanda } \\ \boldsymbol{O} & \text { Curva de oferta } \\ \boldsymbol{P} & \text { Preço } \\ \boldsymbol{P} & \text { Preço } \\ \boldsymbol{P C} & \text { Preço do contrato } \\ \boldsymbol{Q} & \text { Quantidade } \\ \boldsymbol{q} & \text { Quantidade } \\ \boldsymbol{Q E} & \text { Quantidade de energia fornecida } \\ \boldsymbol{R}(\boldsymbol{q}) & \text { Curva de receita } \\ \boldsymbol{R M} & \text { Receita marginal } \\ \boldsymbol{T} & \text { Lucro de uma empresa }\end{array}$




\section{SUMÁRIO}

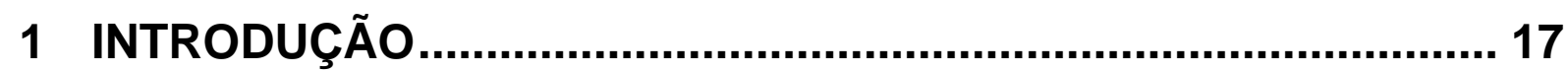

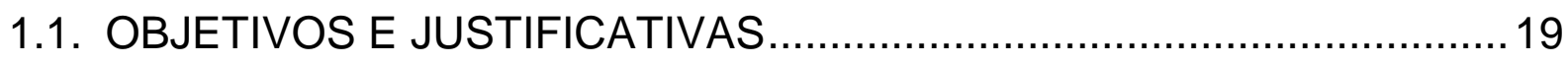

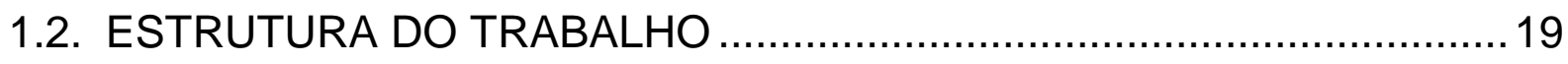

2 MERCADOS E PREÇOS: TEORIA ECONÔMICA ......................... 20

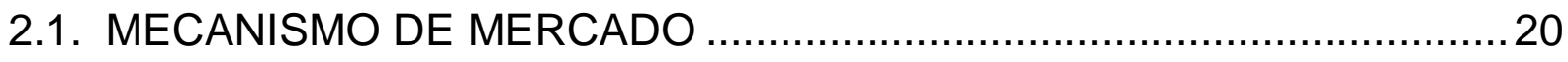

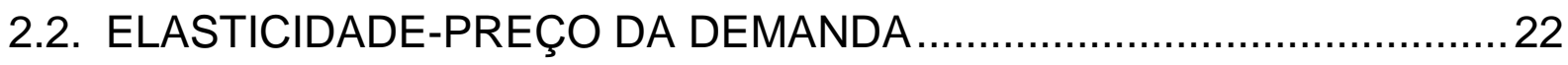

2.3. DETERMINAÇÃO DE PREÇOS EM CONCORRÊNCIA PERFEITA ......25

2.3.1. Concorrência perfeita: conceituação....................................................25

2.3.2. Determinação de preços com base na maximização do lucro ..................26

2.4. DETERMINAÇÃO DE PREÇOS EM AMBIENTE OLIGOPOLISTA ........28

3 FORMAÇÃO DE PREÇOS EM MERCADOS DE ENERGIA ELÉTRICA .............................................................................. 30

3.1. REQUISITOS BÁSICOS NA FORMAÇÃO DE PREÇOS.......................30

3.2. FORMAÇÃO DE PREÇOS BASEADA NAS VERTENTES DE CUSTO E DE OFERTA: CARACTERIZAÇÃO CONCEITUAL ............................... 31

3.3. ASPECTOS RELEVANTES DOS AGENTES PRODUTORES NA FORMAÇÃO DE PREÇOS POR OFERTA ….................................... 34

3.3.1. Formação de preços por oferta e poder de mercado ................................34

3.3.2. Oferta estratégica dos geradores em esquemas de formação de preços por oferta 
3.3.3. Influência do nível de contratação sobre a estratégia dos geradores em esquemas de formação de preços por oferta

3.3.4. Análise da adoção da formação de preços por ofertas no mercado de energia elétrica brasileiro

4 IMPORTÂNCIA DA PARTICIPAÇÃO DA DEMANDA NA DETERMINAÇÃO DOS PREÇOS DE CURTO PRAZO

4.1. CONSIDERAÇÕES GERAIS

4.2. CLASSIFICAÇÃO DOS MECANISMOS DE RESPOSTA DA DEMANDA

4.2.1. Programas de resposta da demanda baseados em preços.

4.2.1.1. RTP (Real-time pricing). .49

4.2.1.2. Time-of-use (TOU) .50

4.2.1.3. Critical Peak Pricing (CPP) .52

4.2.2. Discussão: influência da estrutura tarifária das distribuidoras sobre a capacidade de reação da demanda aos preços de curto prazo .52

4.2.3. Programas de resposta da demanda baseados em incentivo financeiro56

4.2.3.1. Direct load control (DLC) .56

4.2.3.2. Interruptible / Curtailable (I/C) Service .56

4.2.3.3. Emergency Demand Response Programs .56

4.2.3.4. Demand-Side Bidding .57

4.3. O CUSTO DA REDUÇÃO DE CARGA PARA O CONSUMIDOR 58

4.4. RESPOSTA DA DEMANDA E PODER DE MERCADO. .59

4.5. RESPOSTA DA DEMANDA E VOLATILIDADE DOS PREÇOS 61 
4.6. RESPOSTA DA DEMANDA E SEGURANÇA DE ABASTECIMENTO ...62

4.7. INFLUÊNCIA DO NÍVEL DE CONTRATAÇÃO SOBRE A CAPACIDADE DE REAÇÃO DA DEMANDA

4.8. EXPERIÊNCIA INTERNACIONAL 65

4.8.1. Boneville Power Administration - BPA .67

4.8.2. Cinergy (atual Duke Kentucky). .68

4.8.3. Wabash Valley Power Association (WVPA) .69

4.8.4. Independent Electricity System Operator - IESO, Ontário (Canadá) .......71

4.8.5. PJM Interconection . .72

5 METODOLOGIA PARA IMPLEMENTAÇÃO DE OFERTA DE REDUÇÃO DE CARGA

5.1. CONSIDERAÇÕES GERAIS 75

5.2. OPÇÃO DE IMPLEMENTAÇÃO DA OFERTA DE REDUÇÃO DE CARGA PARA O CASO BRASILEIRO 76

5.3. MECANISMO ATUAL DE FORMAÇÃO DE PREÇOS NO MERCADO BRASILEIRO 78

5.3.1. Planejamento da operação eletroenergética .78

5.3.2. Os modelos computacionais NEWAVE e DECOMP .81

5.3.3. Determinação do Preço de Liquidação de Diferenças - PLD .82

5.4. ESTUDO DE CASO. 86

5.4.1. Avaliação dos efeitos da Redução Voluntária de Carga sobre o PLD no longo prazo .88 
5.4.1.1. Análise dos resultados - Efeito no horizonte de longo prazo............90

5.4.1.2. Análise dos resultados - Simulação da RVC no período crítico........95

5.4.2. Cálculo do PLD considerando a Redução de Carga no modelo de curto prazo (DECOMP) .98

5.4.3. Efeitos da Redução Voluntária de Carga sobre a volatilidade do PLD..100

5.4.3.1. Definição de volatilidade 100

5.4.3.2. Análise dos resultados - Efeito sobre a volatilidade nos preços de curto prazo. 101

6 CONCLUSÕES E TRABALHOS FUTUROS 105

6.1. CONCLUSÕES 105

6.2. TRABALHOS FUTUROS. 107

7 REFERÊNCIAS BIBLIOGRÁFICAS 109

APÊNDICE A - REDUÇÃO DO ACOPLAMENTO ENTRE DESPACHO FíSICO E FORMAÇÃO DE PREÇOS - A PROPOSTA DO COMITÊ DE REVITALIZAÇÃO 116 


\section{INTRODUÇÃO}

Os preços de curto prazo exercem papel fundamental no funcionamento de qualquer mercado de energia elétrica. O arranjo comercial adotado deve ter como princípio basilar o fornecimento de sinais econômicos capazes de manter o equilíbrio entre oferta e demanda, tanto no curto quanto no longo prazo.

No Brasil, o preço de curto prazo é denominado Preço de Liquidação de Diferenças, ou simplesmente PLD. Geradores, distribuidores e consumidores - livres e cativos são afetados pelo PLD. No curto prazo, na precificação de suas parcelas de produção ou consumo descontratadas e, no médio e longo prazos, pelos efeitos da sinalização econômica sobre a decisão de novos investimentos.

Supondo o despacho do tipo centralizado, os preços de curto prazo podem ser determinados por ordem de mérito de custos ou pela participação direta dos agentes de geração e consumo em um sistema de livre oferta. No primeiro caso, o preço de curto prazo, ou preço spot, toma por base o custo marginal de operação (CMO), fornecido como subproduto do modelo de despacho e que reflete a taxa de incremento do custo operativo do sistema em relação a um incremento da demanda. No segundo caso, o preço spot é determinado pelo equilíbrio entre oferta e demanda, através de um despacho baseado nas ofertas de preços dos agentes.

No Brasil, o PLD não abrange toda a gama de variação do CMO, sendo limitado por um preço máximo (teto) e mínimo (piso) vigentes para cada período de apuração e para cada submercado ${ }^{1}$.

\footnotetext{
1 Submercado é uma região do sistema elétrico em que não subsistem restrições estruturais importantes de transmissão internamente às suas fronteiras. Por outro lado, distintos submercados são interligados entre si por redes de interconexão de capacidade de intercâmbio limitada e de
} 
Para permitir que a energia comercializada seja considerada igualmente disponível em todos os pontos de consumo de um submercado e que, conseqüentemente, o preço seja único dentro de cada uma dessas regiões, não são consideradas as restrições de transmissão internas no cálculo do PLD.

Em condições de competição perfeita, a formação de preços por oferta dos agentes produtores ou por otimização centralizada dos custos de produção levaria à mesma eficiência econômica do despacho. Entretanto, os mercados de energia elétrica se aproximam mais a oligopólios do que à competição perfeita e os dois sistemas possuem intrinsecamente características bastante distintas.

Na perspectiva da precificação em mercados de energia elétrica, a introdução de mecanismos de incentivo à resposta da demanda aos preços de curto prazo se afigura de capital importância, na medida em que permite (i) elevar o nível de competição, (ii) reduzir a volatilidade dos preços, bem como (iii) alavanca o uso mais eficiente dos recursos de geração.

O presente trabalho tem por objetivo analisar os mecanismos de formação de preços de curto prazo adotados em mercados de energia elétrica, sejam baseados nas ofertas dos agentes, sejam na otimização centralizada dos custos de produção.

A partir desse contexto, buscou-se avaliar os benefícios da introdução de mecanismos de incentivo à participação da demanda no processo de formação dos preços do mercado de energia elétrico brasileiro, como forma de elevar sua eficiência econômica.

caráter estrutural, isto é, limitações de natureza permanente em que não há justificativa econômica para se promover a expansão da respectiva interligação. 


\subsection{OBJETIVOS E JUSTIFICATIVAS}

Considerando as particularidades do sistema elétrico brasileiro, como a forte componente hidráulica e a conseqüente necessidade do uso eficiente dos recursos disponíveis ao menor custo possível, o objetivo desse estudo é analisar os mecanismos de formação de preços adotados em mercados de energia elétrica (formação por custos versus por oferta) e investigar os benefícios potenciais da participação da demanda na determinação dos preços de curto prazo como instrumento importante para o aumento de eficiência na utilização dos recursos de produção.

\subsection{ESTRUTURA DO TRABALHO}

O capítulo 1 apresenta uma breve introdução das questões associadas ao trabalho. Tomando como ponto de partida a importância do reconhecimento dos conceitos econômicos que fundamentam o tema da pesquisa, o capítulo 2 dedica-se a uma exposição sintética da teoria econômica correlata, como os princípios básicos sobre os mecanismos de mercado e o comportamento estratégico das firmas em esquemas competitivos. O capítulo 3 analisa as principais características dos dois principais modelos de formação de preços adotados em mercados de energia elétrica (por oferta e por custos), destacando suas vantagens e pontos de atenção. No âmbito do objetivo principal desse estudo, o capítulo 4 avalia a importância da participação da demanda na determinação dos preços de curto prazo, os principais mecanismos de incentivo à resposta da demanda e seus efeitos sobre a eficiência de mercado. Finalizando o estudo, o capítulo 5 apresenta a metodologia adotada e um correspondente estudo de caso. 


\section{MERCADOS E PREÇOS: TEORIA ECONÔMICA}

\subsection{MECANISMO DE MERCADO}

Por definição, um mercado é um grupo de compradores e vendedores que, por meio de suas interações, determinam o preço de um produto ou um conjunto de produtos. Assim, a curva de oferta deve informar a quantidade de mercadoria que os produtores estão dispostos a vender a determinado preço, representando uma relação entre quantidade ofertada e preço. Analogamente, a curva de demanda deverá informar a quantidade que os consumidores desejam comprar à medida que muda o preço unitário (PINDYCK; RUBINFELD, 2005).

O cruzamento entre as duas curvas - oferta e demanda - determina o preço de equilíbrio ou de balanceamento do mercado. Nesse nível de preços, as quantidades ofertada e demandada são exatamente iguais, como demonstra a Figura 2.1.

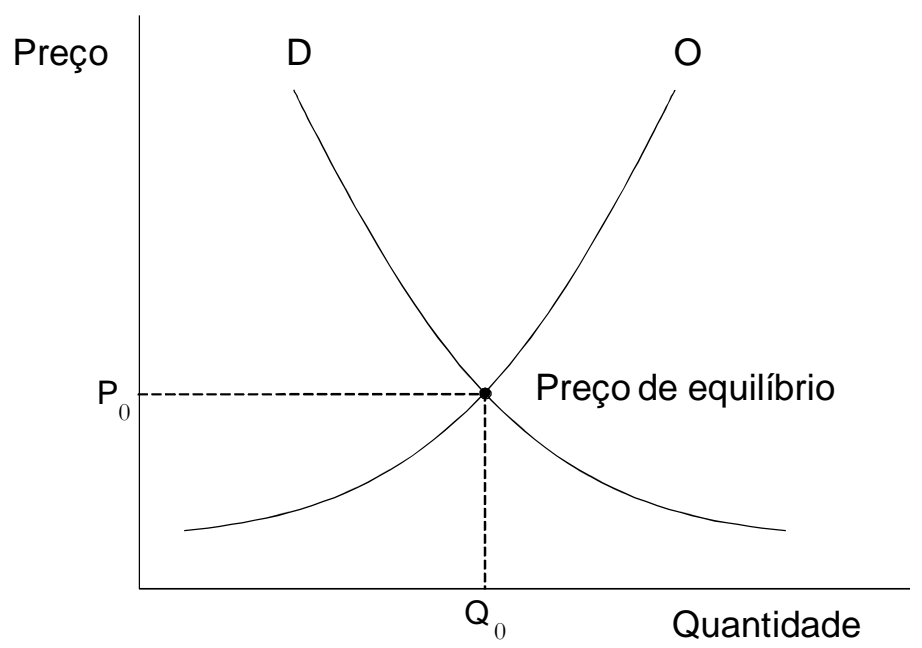

Figura 2.1 - Mecanismo de mercado.

Denomina-se mecanismo de mercado a tendência, em mercados livres, de que o preço se modifique até que o mercado se torne balanceado, ou seja, até que a quantidade ofertada e a quantidade demandada sejam iguais. 
Nesse ponto, não há escassez nem excesso de oferta, de tal forma que não existe pressão para que o preço continue se modificando (PINDYCK; RUBINFELD, 2005).

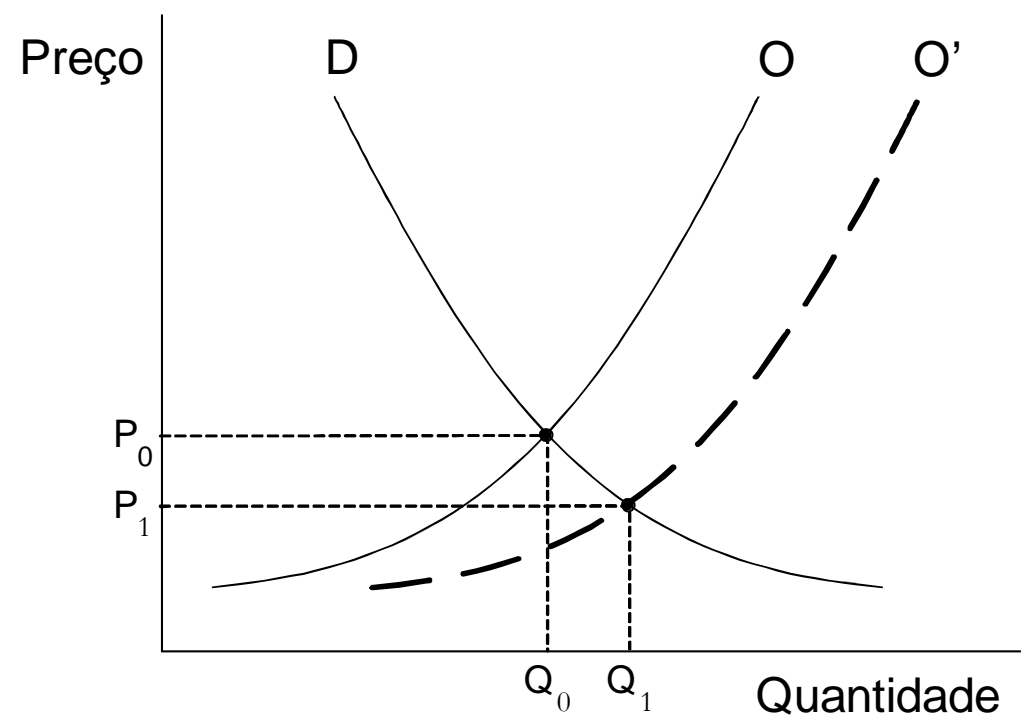

Figura 2.2 - Mudanças de equilíbrio de mercado - deslocamento da oferta.

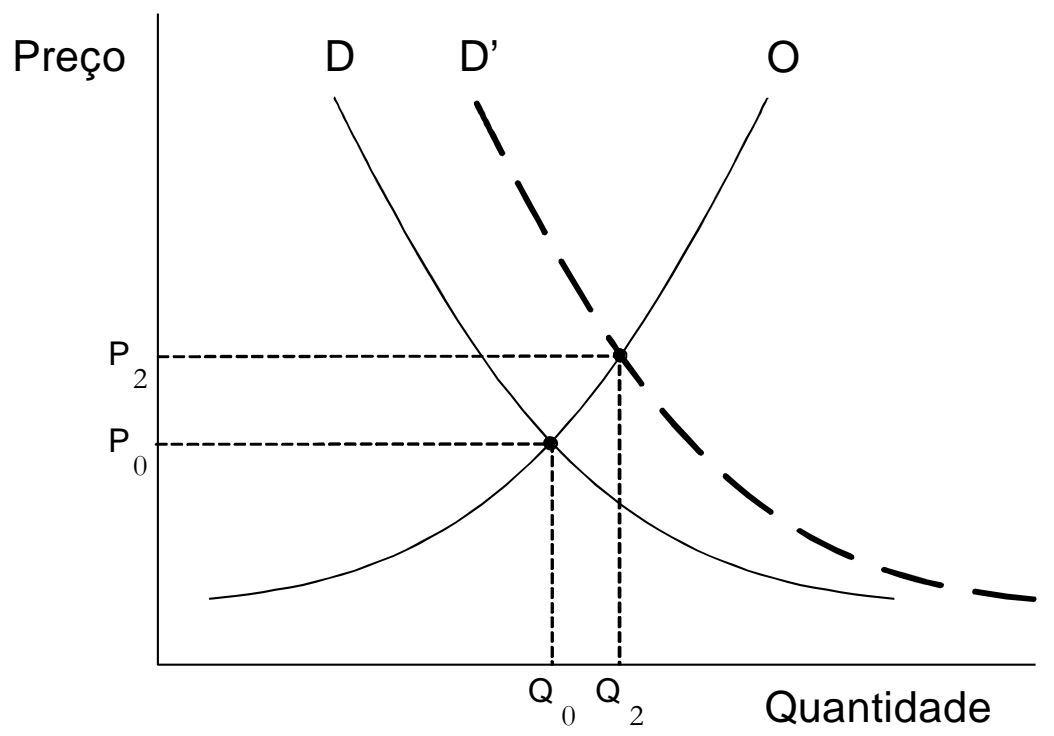

Figura 2.3 - Mudanças de equilíbrio de mercado - deslocamento da demanda. 
Oferta e demanda podem não estar em equilíbrio e, em alguns mercados, o balanceamento pode demorar quando as condições são modificadas repentinamente. Porém, segundo Pindyck e Rubinfeld (2005), a tendência é de que os mercados se tornem balanceados.

\subsection{ELASTICIDADE-PREÇO DA DEMANDA}

A demanda pode ser definida como uma relação que demonstra a quantidade de um bem ou serviço que os compradores estariam dispostos a adquirir a diferentes preços de mercado. Assim, a função procura (ou função demanda) representa a relação entre o preço de um bem e a quantidade procurada, mantendo-se todos os outros fatores constantes.

Quase todas as mercadorias obedecem à lei da procura decrescente, segundo a qual a quantidade procurada diminui quando o preço aumenta (PINDYCK; RUBINFELD, 2005).

A teoria econômica encontra duas razões para esta correlação negativa entre quantidade procurada e preço. A primeira delas é o efeito substituição, que reflete a substituição de um bem por outro similar quando o preço do primeiro aumenta. A segunda tem relação com a renda do consumidor, que traduz a perda de poder econômico quando o preço do bem aumenta (KNOOW, 2009).

A elasticidade-preço da demanda mede a variação percentual da quantidade demandada em conseqüência de uma variação percentual do preço. Indicando como $Q$ a quantidade de uma mercadoria e como $P$ seu preço, define-se a elasticidade-preço da demanda, $E_{p}$, como: 


$$
E_{p}=\frac{\Delta Q / Q}{\Delta P / P Q}
$$

Uma demanda é considerada perfeitamente inelástica, ou perfeitamente rígida, quando uma variação qualquer no preço não resulta em variação na quantidade demandada. Ou seja, independentemente do preço de mercado a quantidade se mantém constante.

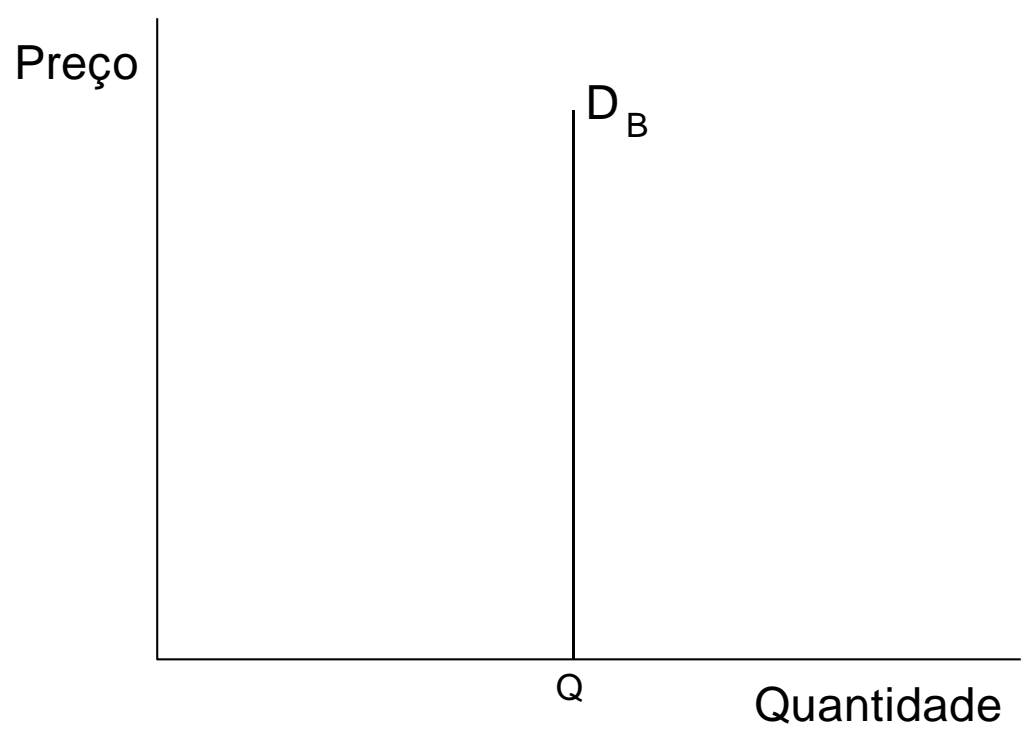

Figura 2.4 - Demanda perfeitamente inelástica, ou perfeitamente rígida.

A figura 2.5 apresenta uma curva que reflete uma demanda infinitamente elástica. Nessa condição, os consumidores adquirem a quantidade que puderem ao preço $\mathrm{P}$. No caso de qualquer aumento de preço acima desse nível, a quantidade demandada cai a zero. 


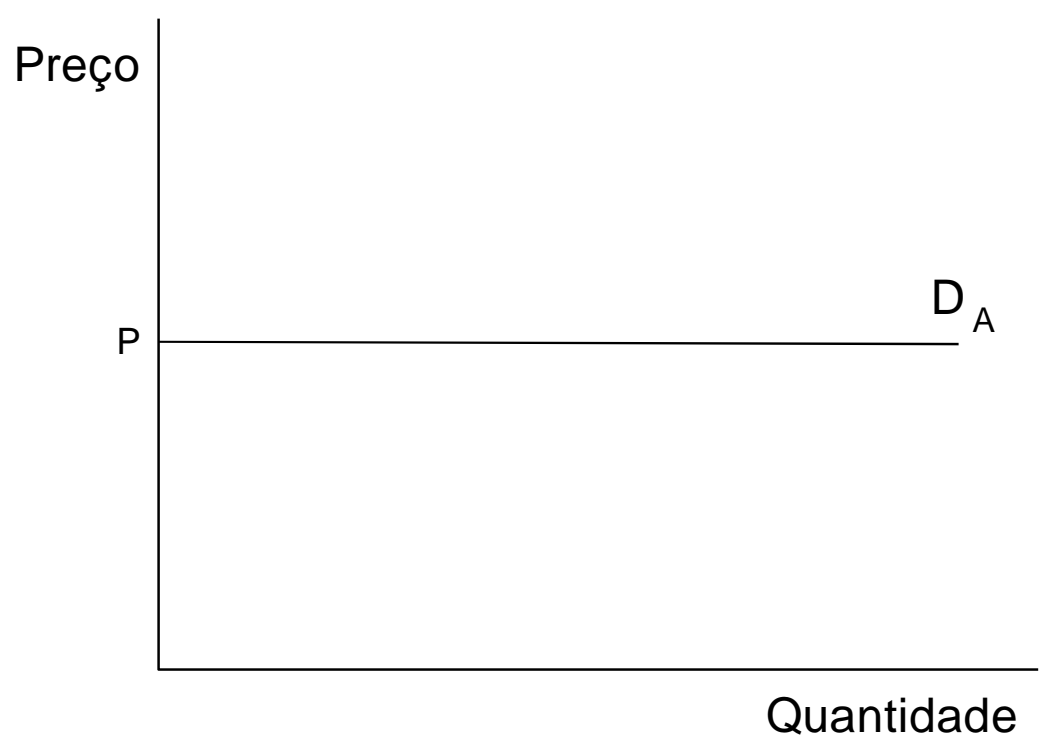

Figura 2.5 - Demanda perfeitamente elástica.

De modo semelhante, a elasticidade-preço da oferta corresponde à variação percentual da quantidade ofertada em conseqüência do aumento de um ponto percentual no preço. Essa elasticidade é normalmente positiva, pois preços mais altos incentivam os produtores a aumentarem a produção.

Em mercados de energia elétrica, a demanda tende a ser mais elástica no longo prazo, em função da possibilidade de os consumidores substituírem equipamentos ineficientes por tecnologias de menor consumo. No curto prazo, a demanda tende a ser pouco elástica, ou rígida, o que se deve aos fatos de que a energia elétrica é um bem não estocável (pelo menos de forma economicamente viável) e seu fornecimento em tempo real está sujeito a restrições técnicas.

Esta característica torna de fundamental importância a criação de mecanismos de incentivo à reação da demanda aos preços de curto prazo em mercados de energia 
elétrica, uma vez que a rigidez da demanda pode resultar, em muitos casos, em elevações súbitas de preços.

\subsection{DETERMINAÇÃO DE PREÇOS EM CONCORRÊNCIA PERFEITA}

\subsubsection{Concorrência perfeita: conceituação}

Em Knoow (2009), concorrência perfeita é definida como "uma situação limite em que nenhuma empresa e nenhum consumidor têm poder suficiente para influenciar o preço de mercado". Segundo o autor, é necessária a verificação de determinadas condições para que um mercado possa se caracterizar como perfeitamente competitivo, quais sejam:

- Existência de um grande número de empresas a produzir o mesmo produto ou serviço (bem) e com dimensão e estrutura de custos semelhante;

- Existência de um grande número de consumidores e todos com a mesma informação disponível sobre a oferta existente no mercado (simetria de informação);

- Existência de homogeneidade nos produtos ou serviços oferecidos no mercado;

- Inexistência de barreiras à entrada ou à saída de empresas no mercado.

Sob tais condições, cada uma das empresas concorrentes enfrenta uma curva da procura horizontal, ou seja, perfeitamente elástica. Dessa forma, não há incentivo para que um produtor pratique um preço diferente do preço de mercado. Com efeito, se uma empresa, individualmente, praticar um preço mais elevado do que o preço de mercado, perderá imediatamente sua fatia do mercado, uma vez que os produtos 
e serviços são perfeitamente homogêneos e os consumidores têm informação perfeita sobre a oferta existente.

Na concorrência perfeita, o preço de mercado corresponde a uma situação de lucro econômico nulo e, caso uma empresa decida praticar um preço inferior ao preço de mercado, a mesma não resistirá, dado que um preço mais baixo que o de mercado provocará acumulo de prejuízo, não sustentável no longo prazo (KNOOW, 2009).

\subsubsection{Determinação de preços com base na maximização do lucro}

Supondo que o nível de produção de uma empresa seja $q$ e que esta empresa obtenha a receita $R$, essa receita é igual ao preço do produto, $P$, multiplicado pelo número de unidades vendidas: $R=P q$. $O$ custo de produção, $C$, também depende do nível de produção.

O lucro da empresa, $\pi$, é a diferença entre receita e seu custo de produção:

$$
\pi(q)=R(q)-C(q)
$$

Para maximizar lucros, a empresa opta pelo nível de produção para o qual a diferença entre receita e custo seja máxima. Este princípio é ilustrado na figura 2.6.

A curva de receita, $R(q)$, é uma linha curva, que reflete o fato de que uma empresa só consegue vender um nível maior de produto reduzindo o preço. A inclinação dessa curva é a receita marginal, que mostra em quanto varia a receita quando o nível de produção aumenta uma unidade. 


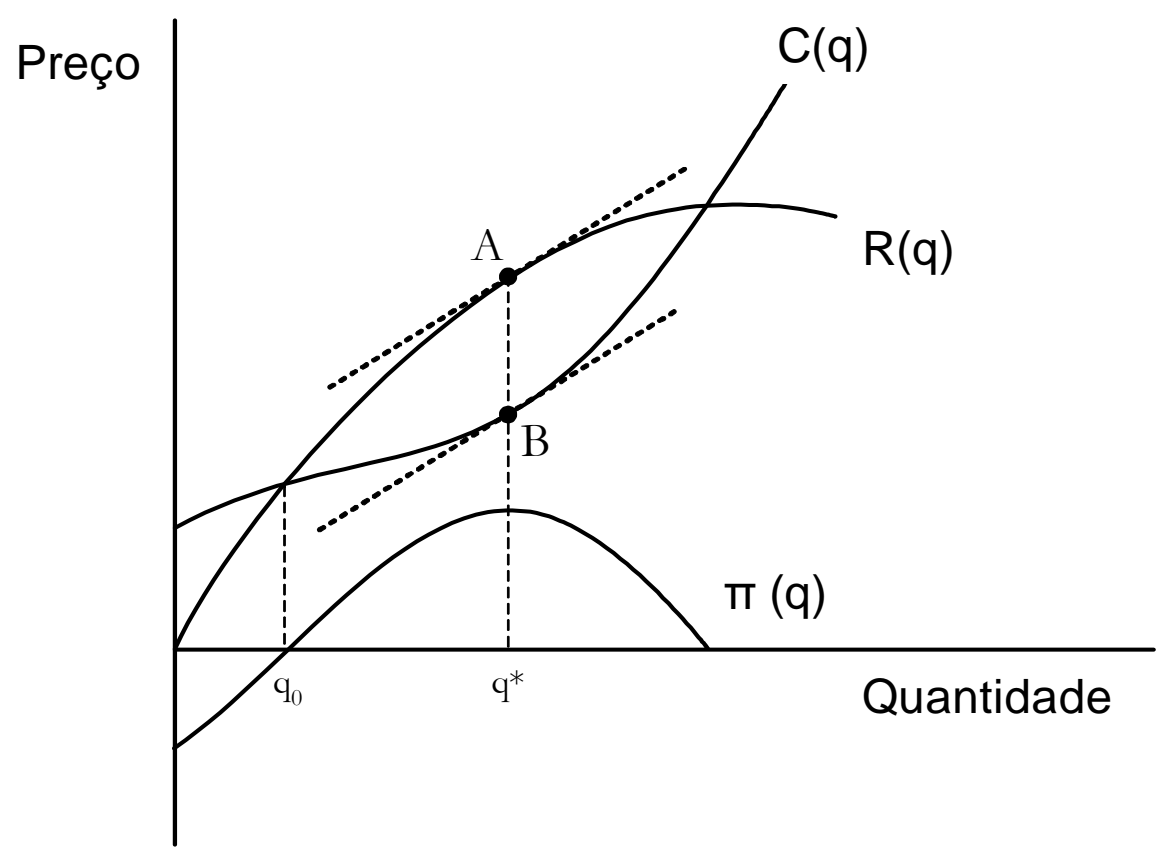

Figura 2.6 - Receita marginal e custo marginal e maximização do lucro da firma

A inclinação da curva de custo total, $C(q)$, mede o custo adicional da produção de uma unidade a mais de produto, ou custo marginal ${ }^{2}$. Nota-se que o custo total, $C(q)$, é positivo quando o produto é zero, porque há custos fixos no curto prazo.

Para a empresa ilustrada na figura 2.6, o lucro é negativo em níveis baixos de produção, pois a receita é insuficiente para cobrir os custos fixos e variáveis. À medida que o nível de produção aumenta, a receita aumenta mais rapidamente que o custo, pelo que o lucro inevitavelmente torna-se positivo a partir de determinado nível de produção.

\footnotetext{
${ }^{2}$ Custo Marginal ou custo incremental é o aumento de custo ocasionado pela produção de uma unidade adicional de produto. Uma vez que o custo fixo não apresenta variação quando ocorrem alterações no nível de produção, o custo marginal é apenas o aumento no custo variável ocasionado por uma unidade extra de produto. O custo marginal informa quanto custará aumentar a produção em uma unidade (PINDYCK; RUBINFELD, 2005).
} 
O lucro continua a crescer até que o nível de produção chegue a $q^{*}$ unidades. Nesse ponto, a receita marginal e o custo marginal são iguais e a distância vertical entre a receita e o custo, $A B$, atinge seu comprimento máximo. $O$ produto $q^{*}$ é o nível que torna o lucro máximo.

Nota-se que para níveis de produção acima de $q^{*}$ o lucro torna-se menor que o máximo possível (PINDYCK; RUBINFELD, 2005).

Conclui-se dessa forma que, sob condições de competição perfeita, o preço $(P)$ que maximiza o lucro de uma firma equivale ao ponto em que sua receita marginal (RM) se iguala ao custo marginal (CM).

$$
\mathrm{P}=\mathrm{RM}=\mathrm{CM}
$$

\subsection{DETERMINAÇÃO DE PREÇOS EM AMBIENTE OLIGOPOLISTA}

O oligopólio corresponde a uma estrutura de mercado de concorrência imperfeita, uma vez que o mercado é dominado por um número pequeno de produtores e uma empresa, individualmente, é capaz de influenciar o preço. Nessa condição, os bens ou serviços podem ser homogêneos ou não. Outra característica dos oligopólios é a forte barreira à entrada ao mercado, sejam por elevados custos de entrada, limitações legais, entre outras (KNOOW, 2009).

Em mercados oligopolistas, uma empresa determina seus preços e volumes com base, pelo menos em parte, em considerações estratégicas relativas ao comportamento de seus concorrentes (PINDYCK; RUBINFELD, 2005). 
Ao mesmo tempo, as decisões dos concorrentes dependerão das decisões tomadas pela própria empresa. Para descobrir os preços e quantidades de equilíbrio em mercados oligopolistas, é necessário um princípio subjacente que descreva o equilíbrio quando as empresas tomam decisões que, explicitamente, levam em consideração o comportamento das outras empresas (PINDYCK; RUBINFELD, 2005). Embora não seja examinada neste trabalho, cabe destacar que a abordagem adotada para descrever o equilíbrio em mercados oligopolistas é a Teoria dos Jogos, a qual busca analisar a estratégia de concorrência e cooperação entre um grupo de empresas. 


\section{FORMAÇÃO DE PREÇOS EM MERCADOS DE ENERGIA ELÉTRICA}

\subsection{REQUISITOS BÁSICOS NA FORMAÇÃO DE PREÇOS}

Para Stoft (2002), os preços de energia elétrica devem prover o mercado dos seguintes benefícios:

- No curto prazo

(i) Eficiência da demanda: o preço deve sinalizar ao consumidor o uso eficiente da energia elétrica, devendo o mesmo reduzir o consumo no momento de escassez ou elevá-lo na conjuntura inversa.

(ii) Eficiência do suprimento: o preço deve sinalizar a eficiência dos custos de produção, de forma que o máximo seja produzido com a mínima quantidade de recursos.

- No longo prazo

(iii) Eficiência nos investimentos: o preço deve sinalizar adequadamente aos investidores a viabilidade de expansão da oferta (avaliação da remuneração do produtor) ou da demanda (exemplo: avaliação do impacto do custo futuro da energia elétrica sobre uma determinada atividade industrial).

A formação de preços em mercados de energia elétrica desregulamentados está intrinsecamente relacionada ao processo de despacho da geração. 
Dessa forma, os preços devem refletir o nível de utilização dos recursos disponíveis como água armazenada nos reservatórios, levando ainda em consideração, no processo de formação, o custo dos combustíveis, disponibilidade das usinas, limites de transmissão entre regiões elétricas, entre outros.

Para que se atinja a eficiência adequada, tanto do lado da demanda quanto do lado do suprimento, a escolha do mecanismo adequado para a formação dos preços de curto prazo deve levar em consideração aspectos da estrutura do mercado de energia elétrica como a quantidade de concorrentes, a distribuição de propriedade ou equilíbrio estrutural entre oferta e demanda.

\subsection{FORMAÇÃO DE PREÇOS BASEADA NAS VERTENTES DE CUSTO E DE OFERTA: CARACTERIZAÇÃO CONCEITUAL}

Conforme mencionado anteriormente, em condição de competição perfeita, os mecanismos de formação de preços por custos ou por ofertas levariam à mesma eficiência econômica. De fato, num mercado perfeitamente competitivo, os agentes de geração seriam incentivados a ofertar pelos seus custos marginais de produção,

o que resultaria em um despacho que minimizaria os custos e, paralelamente, estimularia o aumento de eficiência e produtividade por parte dos geradores.

Entretanto, os mercados de energia elétrica possuem caráter tipicamente oligopolista e os dois modelos de formação de preços devem funcionar de formas bem diferentes, apresentando vantagens e desvantagens.

Com efeito, na adoção de mecanismos de mercado para formação dos preços de curto prazo (i.e. formação de preços por oferta), é de fundamental importância a 
incorporação de instrumentos de mitigação de poder de mercado ${ }^{3}$. Tal mitigação pode ser promovida pelo incentivo ao aumento da competição ou por políticas de second best (intervenção regulatória), quando o próprio mercado (first best) não é capaz de conduzir à eficiência econômica.

A alternativa tradicional ao esquema de oferta de preços é o despacho por custo. Neste caso, um agente central procura atender ao consumo previsto com o menor custo possível, o que implica em acionar os geradores em ordem crescente de custo variável de produção (declarados pelos geradores em $\$ / M W h$ ) até que a geração total seja igual à demanda. O preço de curto prazo, então, é determinado pelo custo marginal de operação $(\mathrm{CMO})$, que representa o custo de atender um $\mathrm{MWh}$ adicional de demanda (COMITÊ DE REVITALIZAÇÃO DO MODELO DO SETOR ELÉTRICO, 2002).

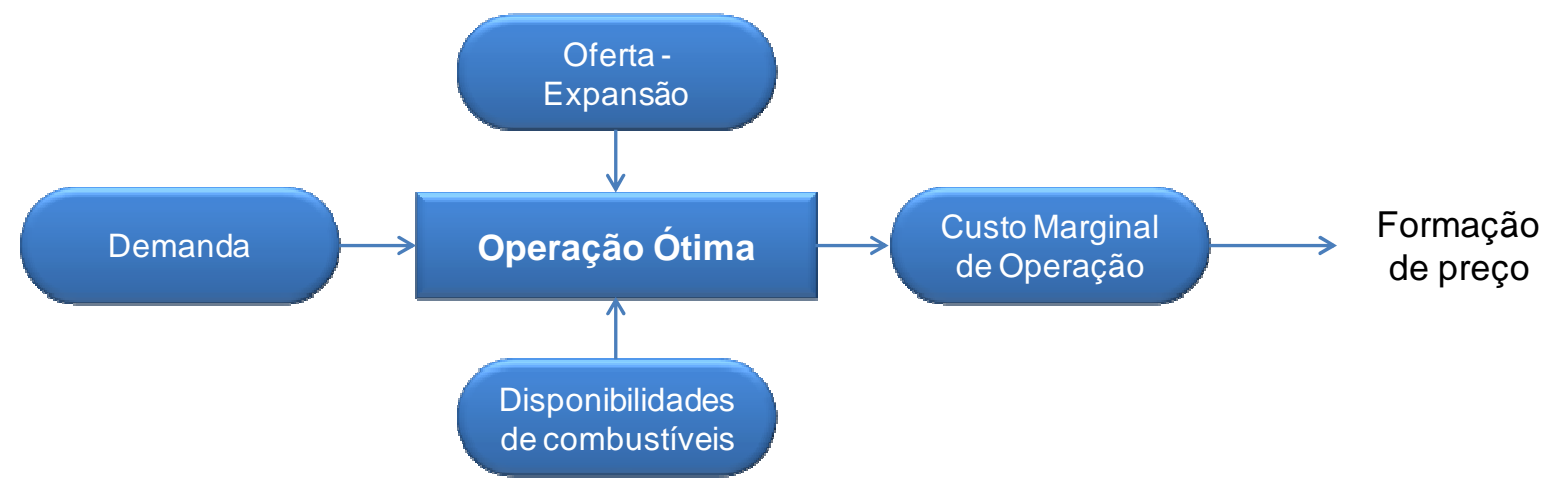

Figura 3.1 - Esquema de despacho e formação de preços por otimização dos custos de operação.

Em situação de mercado perfeitamente competitivo e onde não subsistam externalidades ou distorções em outras partes da economia, impedindo seu

\footnotetext{
${ }^{3} \mathrm{O}$ exercício de poder de mercado pode ser interpretado como qualquer ação voluntária por parte de um agente de mercado a qual seja capaz de modificar os preços em função dos interesses desse agente.
} 
funcionamento em condições isonômicas, o ponto que maximiza a soma de excedente dos consumidores e produtores ${ }^{4}$ é aquele no qual o preço do bem ou serviço se iguala ao custo marginal. Nesse sentido, a determinação dos preços pelo custo marginal simularia um mercado sob condição de competição perfeita e seria a política ótima para a sociedade (ARAÚJO, 2001) 5 .

Por outro lado, na formação de preços por custos, os agentes de geração hidrelétricos deixam de ter o controle sobre o valor da energia produzida, pois o custo de oportunidade ${ }^{6}$ da geração hidráulica é calculado, centralizadamente, pelo modelo que determina o despacho.

Um inconveniente reconhecido no despacho por custo é o gerenciamento centralizado de uma grande quantidade de informações sobre cada um dos agentes e da arbitragem de parâmetros críticos, necessários ao processo decisório do despacho, como o custo do déficit ${ }^{7}$.

$\mathrm{Na}$ formação de preços por oferta, o preço da energia é resultado da interação direta entre oferta e demanda e reflete o equilíbrio de mercado. Dessa forma, a diversidade de percepções dos agentes, compradores e vendedores, em relação às incertezas

\footnotetext{
${ }^{4}$ Excedente do Consumidor: diferença entre o montante que o consumidor estaria disposto a pagar por determinada quantidade de um bem e o montante que efetivamente paga.

Excedente do Produtor: diferença entre o preço que o produtor recebe e o custo de produção por unidade.

5 Cabe ressaltar que a recomendação de se precificar o mercado de curto prazo brasileiro pelo custo marginal teve como base "a dificuldade em descentralizar o cálculo do valor da água em um sistema grande, predominantemente hidrelétrico e com um número limitado de plantas termelétricas." (COOPERS\&LYBRAND, 1997).

6 Custo de Oportunidade: é o custo associado às oportunidades perdidas por não alocar os recursos da empresa na melhor alternativa de uso (PINDYCK; RUBINFELD, 2005).

${ }^{7}$ O custo do déficit é calculado de maneira a refletir o custo social da escassez de energia elétrica e sua determinação é não trivial, tanto em termos metodológicos quanto de dados (COMITÊ DE REVITALIZAÇẨO DO MODELO DO SETOR ELÉTRICO, 2002).
} 
futuras sobre as condições de mercado é considerada no processo de formação do preço (DAVID et al., 2003).

Barroso et al. (2005) analisaram variados aspectos relacionados ao desenho de mercado de energia elétrica adotado em diversos países, por meio de um questionário respondido por 23 países $^{8}$, totalizando 27 mercados e cobrindo todos os continentes. Os autores constataram que a formação de preços por oferta é o mecanismo utilizado na maioria desses mercados. Nos sistemas com base hidráulica são adotadas diferentes soluções para a programação do despacho e formação dos preços de curto prazo: Noruega e Colômbia (mais de 70\% hidráulica), por exemplo, adotam o esquema de ofertas tanto para a programação do despacho quanto para a formação dos preços.

A seguir, são apresentados alguns aspectos relevantes sobre o modelo de formação de preços por ofertas.

\subsection{ASPECTOS RELEVANTES DOS AGENTES PRODUTORES NA FORMAÇÃO DE PREÇOS POR OFERTA}

\subsubsection{Formação de preços por oferta e poder de mercado}

Evans e Green (2005) argumentam que um mercado de energia elétrica que apresente preços constantemente altos é um mercado que necessita de ajustes. Para estes autores, dentre as causas de preços altos inclui-se capacidade de geração insuficiente, regras de mercado inapropriadas e poder de mercado estimulado por excesso de concentração de propriedade entre os agentes produtores.

\footnotetext{
${ }^{8}$ Polônia, Portugal, Suíça, Brasil, Bélgica, Japão, Estados Unidos (Califórnia e PJM), Noruega, Argentina, Canadá, Romênia, China, República Tcheca, Espanha, Coréia do Sul, África do Sul, Holanda, Rússia, França, Austrália, Peru, Colômbia e Irlanda.
} 
Para Wolak $(2008)^{9}$, um mercado de energia elétrica baseado em oferta apresenta dificuldades que devem ser consideradas, sobretudo no que se refere à vulnerabilidade ao exercício de poder de mercado por agentes que controlem parcelas significativas do segmento de geração, de forma que uma eventual retração de produção force um aumento no preço. Ressalta ainda que, em certas condições do sistema, o comportamento estratégico dos geradores pode resultar em ofertas de preços muito acima dos custos marginais de produção das unidades geradoras, o que pode implicar em preços de mercado muito acima do nível de eficiência.

Além disso, esquemas competitivos podem permitir transferências significativas de renda dos consumidores para os geradores em um curto período de tempo, como resultado da exploração de falhas no desenho de mercado pelos agentes. Citando o caso da Califórnia, Wolak (2008) estima que foram transferidos cerca de U\$ 5 bilhões dos consumidores finais para os geradores em apenas seis meses, em virtude de falhas de mercado que propiciaram o exercício de poder de mercado por parte dos geradores.

Assim, Wolak (2008) enfatiza que, mesmo com a adoção de regras de mercado que proíbam e/ou penalizem o abuso de poder de mercado, podem ocorrer transferências de renda em sistemas de formação de preços baseado em ofertas, o que decorre da dificuldade do regulador em distinguir o que é abuso ilegal de poder de mercado e exercício legal de poder de mercado.

\footnotetext{
${ }^{9}$ WOLAK, F. A. Options for short-term price determination in the Brazilian wholesale electricity market. Relatório preparado para a Câmara de Comercialização de Energia Elétrica (CCEE), 2008, São Paulo. Não publicado.
} 
Para o autor, na prática, o que pode ser considerado por alguns agentes como abuso de poder de mercado pode ser visto por outros agentes como habilidade empresarial.

Com efeito, as proibições sobre a manipulação de mercado previnem somente as formas mais agressivas de exercício de poder de mercado. Isso torna fundamental a adoção de salvaguardas regulatórias no sentido de mitigar abusos de poder de mercado quando na adoção de um sistema de preços baseado em ofertas, o que pode incluir mecanismos de monitoramento de mercado capazes de avaliar as estratégias e o nível de participação (market-share) de determinados agentes.

\subsubsection{Oferta estratégica dos geradores em esquemas de formação de preços por oferta}

Como analisado anteriormente, sob condições de competição perfeita o lucro de uma firma é maximizado no ponto em que sua receita marginal se iguala ao seu custo marginal de produção. Desta forma, o lucro é maximizado no ponto em que um incremento adicional no nível de produção mantém o lucro inalterado (PINDYCK, RUBINFELD; 2005).

Sob estas condições, os geradores seriam incentivados a ofertar pelos seus custos marginais de produção, o que levaria a um despacho que minimizaria os custos e, paralelamente, a uma busca pelo aumento de eficiência e produtividade por parte dos geradores.

Por outro lado, como os mercados de energia elétrica se aproximam mais a oligopólios do que de mercados de competição perfeita, os geradores podem ofertar 
preços muito acima de seus custos marginais, comprometendo, dessa forma, a eficiência alocativa ${ }^{10}$ do sistema.

Ao simular o problema de estabelecimento de estratégias ótimas de oferta de preços para o Sistema Interligado Nacional - SIN, Oliveira (2003) identificou a possibilidade de geradores hidrelétricos tentarem maximizar sua receita imediata, independentemente das conseqüências futuras de suas decisões e concluiu que este comportamento poderia levar a situações críticas de suprimento, estando esta forma de poder de mercado presente em todos os subsistemas do SIN.

Para Patrick e Wolak (1997), o fato de que os geradores, em média, ofertam preços acima de seus custos marginais de produção não deve ser considerado uma surpresa. Os autores explicam que, caso o custo fixo de uma empresa geradora represente uma parcela significativa do seu custo total, o custo marginal de produção pode ser inferior ao custo médio de produção em determinada faixa de geração, onde a oferta pelo custo marginal resultaria em prejuízo para o gerador.

\subsubsection{Influência do nível de contratação sobre a estratégia dos geradores em esquemas de formação de preços por oferta}

Como é amplamente conhecido, os contratos de energia elétrica funcionam como instrumentos de proteção (hedge) contra o risco de variação dos preços de curto prazo, assegurando às partes a previsibilidade e estabilidade de receita, no caso do produtor, ou de custo de aquisição, o caso do comprador.

Em esquemas competitivos (i.e. com formação de preços baseada em ofertas), os contratos implicam em forte incentivo aos geradores para que os mesmos ofertem a

\footnotetext{
${ }^{10}$ Eficiência alocativa: habilidade de combinar insumos e produtos em proporções ótimas, dados os seus preços.
} 
preços abaixo de seus custos marginais de produção, de forma a garantirem o despacho de suas usinas e atenderem seus contratos. Ou, caso não venham a ser despachados, adquiram no mercado de curto prazo o volume equivalente a um preço inferior ao seu custo de produção.

Os fundamentos que sustentam tal argumentação, elaborados por Wolak (1999a), são descritos a seguir.

i. Usualmente, um contrato de energia elétrica permite à parte compradora o exercício do direito de adquirir uma quantidade fixa de energia elétrica (com algum percentual de flexibilidade para mais ou para menos) a ser entregue em uma determinada região elétrica, a um preço pré-negociado.

ii. O compromisso de suprimento leva o vendedor a se proteger da volatilidade dos preços de curto prazo, na proporção da quantidade contratada.

iii. Ao produzir a energia necessária ao atendimento de seus contratos, o vendedor se protege da volatilidade dos preços de curto prazo. Nesse caso, o gerador garante o recebimento da diferença entre o Preço do Contrato (PC) e seu Custo de Produção (CP) para a Quantidade de Energia fornecida (QE).

Para Wolak (1999a), tal lógica leva à consideração de outro importante aspecto relacionado ao nível de contratação de um gerador e o respectivo reflexo sobre sua estratégia de oferta: prover o montante de energia contratado a partir de ativos próprios nem sempre é a melhor estratégia em termos de maximização dos lucros, se comparada à aquisição, no mercado de curto prazo, do montante a ser fornecido. 
Assim, os geradores comprometidos com contratos de venda, que possuam capacidade de influenciar o preço de curto prazo (i.e. geradores grandes o suficiente para serem formadores de preço, ou price makers), possuem forte incentivo para submeterem ofertas de preço abaixo de seus custos de produção. Caso os preços de curto prazo se verifiquem inferiores ao custo de produção, torna-se mais competitivo atender ao contrato por meio da aquisição de energia elétrica no mercado de curto prazo do que via produção própria.

Considere-se o seguinte exemplo apresentado por Wolak (1999a):

Seja $\operatorname{DR}(p)$ a curva de demanda residual ${ }^{11}$ apresentada ao gerador, o qual possui a obrigação contratual $\mathrm{QC}$ ao preço $\mathrm{PC}$ e custo marginal igual a $\mathrm{CM}$.

Assume-se, por simplificação, que a curva de custo marginal da firma seja constante, simplificação a qual não afeta as conclusões da análise.

O lucro variável ${ }^{12}$ da firma durante um período de contabilização será igual a:

$$
\Pi(p)=(D R-Q C)(p-C M)+(P C-C M) Q C
$$

O primeiro termo na equação acima é igual ao lucro ou prejuízo resultante da compra ou venda de energia elétrica no mercado de curto prazo ao preço p. $\mathrm{O}$ segundo termo equivale ao lucro variável resultante da venda da quantidade contratada, QC, ao preço do contrato, PC.

Ao ofertarem no mercado de curto prazo, os geradores têm como objetivo a determinação de um preço de mercado, p, que maximize $\pi$.

\footnotetext{
${ }^{11}$ Demanda residual: participação do produtor no atendimento da demanda total.

${ }^{12}$ Lucro Variável: Soma dos lucros de cada unidade adicional produzida por uma empresa, isto é, o lucro descontado o custo fixo (PINDYCK; RUBINFELD, 2005).
} 
Do ponto de vista de oferta no mercado de curto prazo, um gerador considera (PC CM) x QC como um pagamento fixo que irá receber, independente do preço de curto prazo, p. Conseqüentemente, a única forma do gerador afetar o resultado do primeiro termo da equação (1) é sua estratégia de oferta.

Como DR é uma curva com inclinação decrescente, se o preço de mercado "p" estiver alto, é possível que o gerador produza menos energia que o montante comprometido em contrato, QC. Contudo, se o preço spot, p, for superior ao seu custo marginal, CM, enquanto a demanda residual, DR, for menor que a quantidade contratada QC, o gerador sofrerá prejuízo equivalente ao produto de (QC - DR) pela diferença entre p e CM.

Com efeito, um gerador contratado tem forte incentivo para submeter ofertas de forma a influenciar o mercado para que o preço de curto prazo seja inferior ao seu custo marginal, caso creia que DR será menor que QC. Isso decorre do gerador ser, efetivamente, um comprador líquido de QC - DR, pois o mesmo deverá honrar o volume QC no qual já está comprometido.

Conseqüentemente, a maximização dos lucros de um gerador que precise atender a uma demanda líquida (QC - DR) se dará ao menor custo possível, que poderá ser o resultado da produção da energia adicional a partir de seus próprios ativos ao seu custo marginal, CM, ou da compra da energia adicional no mercado de curto prazo ao preço p.

Se o gerador puder influenciar o preço do mercado de curto prazo, para que se mantenha abaixo de seu custo marginal, a maximização dos lucros se dará pelo atendimento do montante contratado através da compra da respectiva quantidade no 
"spot", em substituição ao custo de sua produção. Desta forma, se um gerador está substancialmente comprometido com contratos de venda, o mesmo será incentivado a influenciar o preço de curto prazo para que este se mantenha abaixo do seu custo marginal, enquanto seu nível de produção for inferior às suas obrigações contratuais.

Segundo Wolak (1999a), em função dos efeitos positivos que os contratos exercem sobre o mercado de curto prazo, a maioria dos mercados atacadistas de energia elétrica inicia suas operações com uma grande parcela da demanda coberta por contratos de longo prazo.

\subsubsection{Análise da adoção da formação de preços por ofertas no mercado de energia elétrica brasileiro}

Conforme avaliado pela Coopers \& Lybrand (1997), para a adoção de um esquema competitivo (i.e. baseado em ofertas) no mercado de energia elétrica brasileiro, os seguintes aspectos específicos devem ser equacionados:

(i) possibilidade da oferta de preços levar a vertimentos localizados, que poderiam ser aproveitados para produção a custo de operação mínimo;

(ii) conciliação do esquema de oferta com direitos já estabelecidos com base no Mecanismo de Realocação de Energia - MRE;

(iii) conciliação das ofertas de preço com o uso múltiplo da água;

(iv) implementação de competição efetiva no caso de agentes dominantes nos respectivos submercados, de forma a não potencializar a formação de grupos de concentração de poder econômico (oligopólios); 
(v) Por fim, o esquema de ofertas poderia incorrer na possibilidade de "desotimizar" a utilização dos recursos hídricos, em função de estratégias de oferta relacionadas a necessidades de fluxo de caixa de curto prazo dos agentes.

Decker et al. (2003) argumentam que a presença de grandes reservatórios no sistema brasileiro faz com que uma decisão tomada em determinado momento tenha impactos sobre o futuro, o que torna o problema não separável no tempo e a incerteza quanto às afluências futuras torna o problema inerentemente estocástico. Nesse sentido, o autor enfatiza que a existência de usinas hidrelétricas numa mesma cascata, associada ao uso múltiplo da água, leva à necessidade de uma operação centralizada. Em alternativa, se poderia introduzir um esquema bastante complexo, em que a operação física se mantém centralizada e otimizada, enquanto que a operação comercial do mercado se mantém completamente desacoplada do despacho físico.

Nessa perspectiva, a energia afluente ao sistema passa a ser rateada entre os agentes geradores proporcionalmente à sua energia assegurada (como no caso do rateio da produção efetiva no âmbito do MRE - Mecanismo de Realocação de Energia), sendo creditada em uma espécie de "conta corrente" de energia alocada, cuja movimentação é definida por oferta de preços, estabelecendo transações meramente comerciais que não afetam a operação ótima do sistema (esta alternativa é apresentada em detalhes no Apêndice A). 


\section{IMPORTÂNCIA DA PARTICIPAÇÃO DA DEMANDA NA DETERMINAÇÃO DOS PREÇOS DE CURTO PRAZO}

\subsection{CONSIDERAÇÕES GERAIS}

Como mencionado no Capítulo 2, os consumidores reagem aos preços de acordo com sua disposição em consumir um bem (ou serviço). À medida que o preço se eleva, os consumidores tendem a reduzir a quantidade demandada e vice-versa, quando o preço cai, os consumidores tendem a aumentar o volume demandado.

Siddiqui (2003) argumenta que o funcionamento eficiente de qualquer mercado de energia elétrica desregulamentado depende da habilidade dos agentes responderem (rapidamente) às variações dos preços. Contudo, segundo o autor, muitos desses mercados já enfrentaram situações de elevação de preços em função de insuficiência de oferta associada a uma baixa capacidade de resposta da demanda.

Em se tratando de energia elétrica, a resposta da demanda se refere à capacidade de um consumidor modificar sua carga por razões econômicas (em resposta aos preços de energia elétrica ou por algum incentivo financeiro) ou por razões emergenciais (segurança na operação do sistema elétrico) (U.S.A., 2008). A modificação no perfil de consumo por razões econômicas, alterando a elasticidade preço da demanda por energia elétrica, pode ser atingida pela racionalização do consumo, pela modulação da carga (i.e. deslocamento de consumo de um período de tempo para outro), pela instalação de sistemas de gerenciamento de demanda ou por autoprodução.

$\mathrm{Na}$ literatura correlata, são descritos inúmeros benefícios que a resposta da demanda pode trazer para um mercado de energia elétrica, dos quais se destacam: 
- $\quad$ Aumento da eficiência de mercado: melhor aproveitamento dos recursos de produção; mitigação de poder de mercado; e manifestação das preferências dos consumidores.

- Maior segurança do sistema: Aumento da confiabilidade no nível de suprimento, na medida em que se reduz o risco de racionamento.

- $\quad$ Redução da volatilidade de preço: redução de risco de preço a ser gerenciado.

A tabela 4.1 agrupa os benefícios da resposta da demanda, de acordo com o tipo de agente do mercado.

Tabela 4.1 - Benefícios da resposta da demanda: baseada em Andersen et al. (2006)

\begin{tabular}{lll}
\hline \multicolumn{1}{c}{ Agente / horizonte } & \multicolumn{1}{c}{ Curto prazo } & \multicolumn{1}{c}{ Longo prazo } \\
\hline Consumidor & $\begin{array}{l}\text { Manifestação de suas preferências; } \\
\text { Redução de preço; } \\
\text { Redução da volatilidade de preço. }\end{array}$ & $\begin{array}{l}\text { Gerenciamento de risco; } \\
\text { Segurança de abastecimento. }\end{array}$ \\
Produtor / Investidor & Redução da volatilidade. & Redução dos custos de hedging. \\
Sociedade & Mitigação de poder de mercado. & $\begin{array}{l}\text { Melhor utilização dos recursos; } \\
\text { Segurança de abastecimento; } \\
\end{array}$ \\
& & Diminuição de externalidades. \\
\hline
\end{tabular}

Cabe distinguir dois tipos diferentes de participação da demanda: (i) o deslocamento de carga (load shifting) e (ii) o desligamento ou redução de carga (load shedding) (NEW ZEALAND, 2007).

O deslocamento de carga resulta na diminuição da carga durante certo período de tempo, porém, em aumento durante outro período de tempo. As indústrias que 
ajustam seus processos produtivos de forma a reduzirem o consumo em reação aos sinais econômicos dos preços (ou tarifas), por exemplo, do horário de ponta do sistema, são exemplos de resposta da demanda por meio do deslocamento de demanda (load shifting).

Já o desligamento ou redução de carga (load shedding ou load reduction) resulta em um nível mais baixo de demanda sem um correspondente aumento em outro período de tempo. A redução de carga pode ocorrer durante as horas do dia (entre horários de ponta e fora de ponta), como também ao longo do ano (entre período seco e período úmido), ou enquanto os preços do mercado de curto prazo encontram-se altos como em períodos em que as afluências ou os níveis dos reservatórios estão baixos.

No longo prazo, a resposta da demanda por redução de carga também pode ocorrer em função do aumento de eficiência do consumo ou pela substituição do insumo energético (NEW ZEALAND, 2007).

Conforme Cavalcanti (2006), permitindo-se que os consumidores tenham condições de ajustarem o seu consumo em reação aos preços, a curva de demanda resulta inclinada (i.e. elástica) e a quantidade de energia requisitada pelos consumidores naturalmente diminui conforme os preços aumentam.

Lafferty et al. (2001) ratificam esse posicionamento e destacam que os consumidores de energia elétrica, de uma forma geral, podem responder aos preços com os quais se defrontam.

Segundo Cavalcanti (2006), em mercados cuja formação de preços baseia-se no mecanismo de ofertas, quando os consumidores não reagem aos preços, a fixação 
do preço depende exclusivamente dos geradores (formadores de preço), que exercem seu poder de mercado. Assim, a resposta da demanda aumenta a competição e pode contribuir para que o preço se desloque para o ponto de equilíbrio de mercado.

Para Mattos (2004), aumentos (reduções) nos preços de energia elétrica, coeteris paribus, provocam redução (aumentos) na quantidade consumida, indicando relação inversa entre as duas variáveis. Tais alterações fazem como que os consumidores procedam de duas formas: alterando a utilização dos equipamentos já existentes, ou adquirindo novos e mais eficientes.

No curto prazo, estes agentes limitam-se em utilizar a infra-estrutura existente para reagirem às mudanças de preço, por exemplo, por meio da substituição de combustível (efeito substituição).

Sobre este efeito (substituição de combustível), Bjorner apud Mattos (2004), argumenta que, em se tratando da demanda industrial, a energia elétrica pode ser considerada como um fator de produção, assim como os fatores trabalho e capital. Considerando os preços da energia e de outros fatores como exógenos, a demanda pode ser expressa em função do valor adicionado pela empresa e do preço da energia em relação aos fatores trabalho e capital. De acordo com essa especificação, a demanda não seria influenciada pelo preço de outros tipos de energia.

Contudo, Silk e Joutz apud Mattos (2004) não concordam, por considerarem a dependência em relação aos preços de seus substitutos, mesmo reconhecendo as restrições ao uso desses substitutos. 
Analisando a indústria brasileira, Mattos (2004) chega a resultados que demonstram que a demanda de energia elétrica é mais influenciada pelo próprio preço do que pelo preço do fator substituto. O autor optou por excluir de seu estudo a variável "preço do substituto", considerando não haver um substituto próximo para a energia elétrica, o que, segundo o autor, não implicou em erro de especificação do modelo.

Sobre o problema da estimação do potencial de resposta da demanda aos preços de energia elétrica, o Berkeley Lab (2006) analisou vários estudos sobre o tema e elencou quatro abordagens distintas:

- Customer Survey: levanta-se junto aos consumidores finais a taxa de participação e a expectativa de redução de carga e, a partir dessa expectativa, estima-se a potencial resposta da demanda.

- Benchmarking: aplicam-se para uma determinada amostragem de consumidores as taxas de participação e níveis de redução de carga observados em outras regiões.

- Engineering Approach: baseia-se na metodologia bottom-up ${ }^{13}$, similar à utilizada nos estudos de potencial de eficiência energética.

- Elasticity Approach: esta abordagem envolve a estimativa da elasticidadepreço da demanda a partir de dados sobre o uso de energia elétrica de consumidores expostos a programas de resposta da demanda e/ou a precificação dinâmica. Depois de determinado um nível esperado de participação, são aplicadas elasticidades-preço à população de interesse para

\footnotetext{
${ }^{13}$ A partir da metodologia bottom - up, cria-se uma descrição quantitativa da estrutura tecnológica do uso da energia, o que se inicia com a estimativa da demanda desagregada por uso final (Jannuzzi, et al.).
} 
estimar o impacto da carga sob uma determinada faixa de preços ou nível de incentivo financeiro para a redução de carga.

\subsection{CLASSIFICAÇÃO DOS MECANISMOS DE RESPOSTA DA DEMANDA}

Uma forma de classificar os vários tipos de mecanismos de resposta da demanda se refere estímulo subjacente, que pode ser baseado em preços ou em incentivos financeiros (U.S.A, 2006). Estes dois mecanismos podem ser definidos da seguinte forma:

- Resposta da demanda baseada em preços ou tarifas: refere-se às mudanças (voluntárias) de padrão de consumo em função das variações dos preços de energia elétrica, atrelados à estrutura tarifária. Propicia uma captura da resposta do consumidor tanto cativo, quanto livre.

- Resposta da demanda baseada em incentivo financeiro: este tipo de programa oferece incentivos aos consumidores para reduzir carga em situações em que o operador do sistema considera as condições de segurança do sistema comprometidas ou verifica que os preços de curto prazo encontram-se muito elevados. Normalmente, nesse tipo de programa é estabelecido um nível base de consumo que serve de referência para a medição da resposta da demanda. Os contratos podem prever penalidades para os casos de descumprimentos dos volumes de redução comprometidos.

Os itens a seguir sumarizam os principais programas de resposta da demanda baseados em preços (via estrutura tarifária) e baseados em incentivos financeiros atualmente em uso. 


\subsubsection{Programas de resposta da demanda baseados em preços}

\subsubsection{RTP (Real-time pricing)}

Na precificação em tempo real (Real Time Pricing - RTP), os preços pagos pelos consumidores refletem as condições de oferta e demanda do sistema a cada período de tempo, de acordo com o intervalo de precificação (horário, diário, semanal etc.) e, dessa forma, esses preços fornecem sinalização econômica precisa para o mercado (BORENSTEIN, 2005).

Sob esse tipo de tarifação, os consumidores são incentivados a modificar seus padrões de consumo em resposta aos preços, o que contribui para o equilíbrio de mercado, para o aumento da segurança do sistema e para a diminuição dos picos de preços.

Para que se obtenha a resposta da demanda por meio da precificação em tempo real não é necessário que os consumidores estejam totalmente expostos aos preços de curto prazo.

Os contratos de médio e longo prazo são de extrema importância tanto para consumidores quanto para produtores, funcionando como instrumento de hedge, estabilizando os custos de aquisição ou os preços de venda de energia elétrica.

Uma parcela marginal descontratada pode ser suficiente para que um consumidor responda aos preços de curto prazo.

Vale salientar que no caso brasileiro, sob a égide do marco regulatório em vigor, a aplicação dessa modalidade de precificação poderia ser estabelecida apenas no 
mercado livre, por acordo entre consumidor livre e a comercializadora que o estiver representando perante a CCEE.

Sobre os cuidados a serem tomados na implantação de um programa de precificação (tarifação) em tempo real, Lafferty et al. (2001) argumentam que os consumidores, de uma forma geral, são avessos a riscos, o que implica cuidado especial para se adotar um esquema adequado de mitigação à exposição às variações dos preços de curto prazo. Para proteger a conta de energia de um consumidor submetido à tarifação em tempo real, o faturamento pode ser dividido em duas partes: consumo de base e desvios em relação à base (consumo marginal) ${ }^{14}$.

\subsubsection{Time-of-use (TOU)}

Outra forma de incentivo à resposta da demanda, menos dinâmica que a RTP, é a precificação (tarifação) do tipo Time of Use (TOU). Nesse sistema, os consumidores pagam preços diferenciados para períodos de tempo pré-definidos (horas do dia, dias da semana, estações do ano). O objetivo desse mecanismo é a criação de sinais econômicos por meio da precificação da energia elétrica de acordo com o nível de consumo em relação à capacidade instalada.

Assim, os preços tendem a ser mais elevados durante o dia e mais baixos durante a noite, por exemplo.

\footnotetext{
${ }^{14}$ A Comercializadora se responsabilizaria totalmente pelo lastro do Consumidor Livre junto à CCEE, registrando um contrato que considere $100 \%$ do consumo da unidade consumidora, enquanto que entre a Comercializadora e o comprador da energia vigoraria um contrato bilateral distinto dos usuais. Nesse contrato, haveria um preço fixo para um volume contratado junto à Comercializadora, definido como consumo base, enquanto se praticaria um preço baseado no mercado de curto prazo para o volume complementar, denominado de consumo marginal. Quando os preços "spof" estiverem muito elevados, posto que as regras de mercado garantem que o Consumidor Livre vende automaticamente seus excedentes de contrato ao preço de curto prazo, quando reduz consumo, o incentivo a reduzir implicitamente existe também para a parcela do volume contratado a preço fixo (consumo de base).
} 
De acordo com a Energy and Environmental Economics, Inc. (ENERGY AND ENVIRONMENTAL ECONOMICS, INC; 2006 apud SANTOS, 2008), as tarifas do tipo TOU são as mais utilizadas em programas de resposta da demanda, tanto para consumidores residenciais quanto para consumidores comerciais ou industriais. Uma pesquisa realizada nos Estados Unidos, no ano de 2006, com as cinqüenta maiores empresas americanas de energia e com quinze grandes empresas de energia de outros países verificou que $93 \%$ das empresas pesquisadas possuíam algum programa de resposta da demanda. Nesta pesquisa, o TOU preponderou com $78 \%$ e $96 \%$ entre os programas de resposta da demanda voltados para consumidores residenciais e comerciais / industriais, respectivamente, conforme a Tabela 4.2 que se segue.

Tabela 4.2 - Participação dos Consumidores nos programas de incentivo à resposta da demanda - EUA

\begin{tabular}{cccc}
\hline & \multicolumn{3}{c}{ Programas de Resposta da Demanda } \\
\hline Tipo de consumidor & OOU $^{15}$ & $R T P^{16}$ & $C P P^{1 /}$ \\
Residencial & $78,5 \%$ & $3,1 \%$ & $9,2 \%$ \\
Comercial / Industrial & $96,0 \%$ & $48,0 \%$ & $8,0 \%$ \\
\hline
\end{tabular}

De acordo com Borenstein (2005), nos programas do tipo TOU, normalmente os ajustes dos preços são feitos uma, duas ou três vezes ao ano, o que contribui para a estabilidade e previsibilidade de custos para o consumidor.

Por outro lado, como os preços são os mesmos para um dado período do dia, da semana, dos meses ou das estações durante o período para o qual tiveram sua

\footnotetext{
15 TOU: Time-of-Use

${ }^{16}$ RTP: Real-time Pricing

17 CPP: Critical peak pricing
} 
validade definida, estes podem não refletir exatamente as condições de oferta e demanda em tempo real.

No caso brasileiro, a TOU aplicada denomina-se "Tarifa Horo-sazonal" e é reajustada anualmente em nível (usualmente ajuste linear para todos os horários e períodos do ano, para uma dada classe de consumo), com ajuste da relatividade sem periodicidade definida.

\subsubsection{3. $\quad$ Critical Peak Pricing (CPP)}

O Critical Peak Pricing (CPP) é um modelo de precificação híbrido dos programas de TOU e RTP - sendo que a estrutura básica da tarifa é a da TOU - porém com a adição de mais uma tarifa aplicada em condições críticas de pico do sistema, notificadas em curtíssimo prazo pela distribuidora. Tipicamente, nesse tipo de programa há uma limitação de 50 a 100 períodos críticos por ano (BORENSTEIN; 2005).

No caso brasileiro, não se visualiza, pelo menos em médio prazo, algum atrativo nesse tipo de tarifação, posto que o pico de demanda coincidente não tem sido condicionante seja para a operação, seja para a expansão do sistema.

\subsubsection{Discussão: influência da estrutura tarifária das distribuidoras sobre a capacidade de reação da demanda aos preços de curto prazo}

Von der Fehr e Wolak (2003) defendem que as tarifas das distribuidoras brasileiras deveriam refletir as condições do sistema, o que seria uma forma imediata de incentivar a demanda a responder aos preços de curto prazo.

Os autores argumentam que, em função da predominância hidráulica do sistema de geração brasileiro, não ocorrem grandes variações de preços ao longo de um dia e, 
conseqüentemente, não haveria necessidade de investimentos altos em sistemas de medição sofisticados, com capacidade de coleta de dados horários, para que os consumidores fossem cobrados de acordo com as condições do mercado.

Do ponto de vista de estrutura tarifária, uma tarifa estática (ou flat) é economicamente ineficiente, uma vez que oculta dos consumidores a volatilidade dos preços de mercado.

À medida que se avança das tradicionais tarifas estáticas para outras opções mais flexíveis como TOU, CPP e RTP, os sinais de preços do mercado atacadista são transmitidos para os consumidores, os quais passam a ter incentivos para responderem, por meio da modificação do perfil de carga, às diferenças de preços entre os períodos (THE BRATTLE GROUP, 2008).

A figura 4.1 ilustra uma região de opções de tarifas flexíveis de acordo com o nível de percepção do consumidor aos preços de curto prazo.

Como ilustra a referida figura, um consumidor sob a condição de precificação em tempo real (RTP) tem um incentivo muito maior para reduzir carga durante períodos de preços altos do que outro consumidor em condição de precificação flat, o qual provavelmente nem terá ciência da elevação dos preços.

Nesse sentido, tarifas dinâmicas ou mais flexíveis promovem eficiência econômica no consumo de energia elétrica, exatamente pelo fato de criarem um vínculo entre preços de curto prazo e tarifas (THE BRATTLE GROUP, 2008).

Para cada uma das tarifas ilustradas na figura 4.1, há um diferente custo de hedge associado, dependendo de quanto a distribuidora paga pela minimização de 
exposição à volatilidade de preços. Tal custo é inversamente relacionado à exposição dos consumidores aos preços de curto prazo.

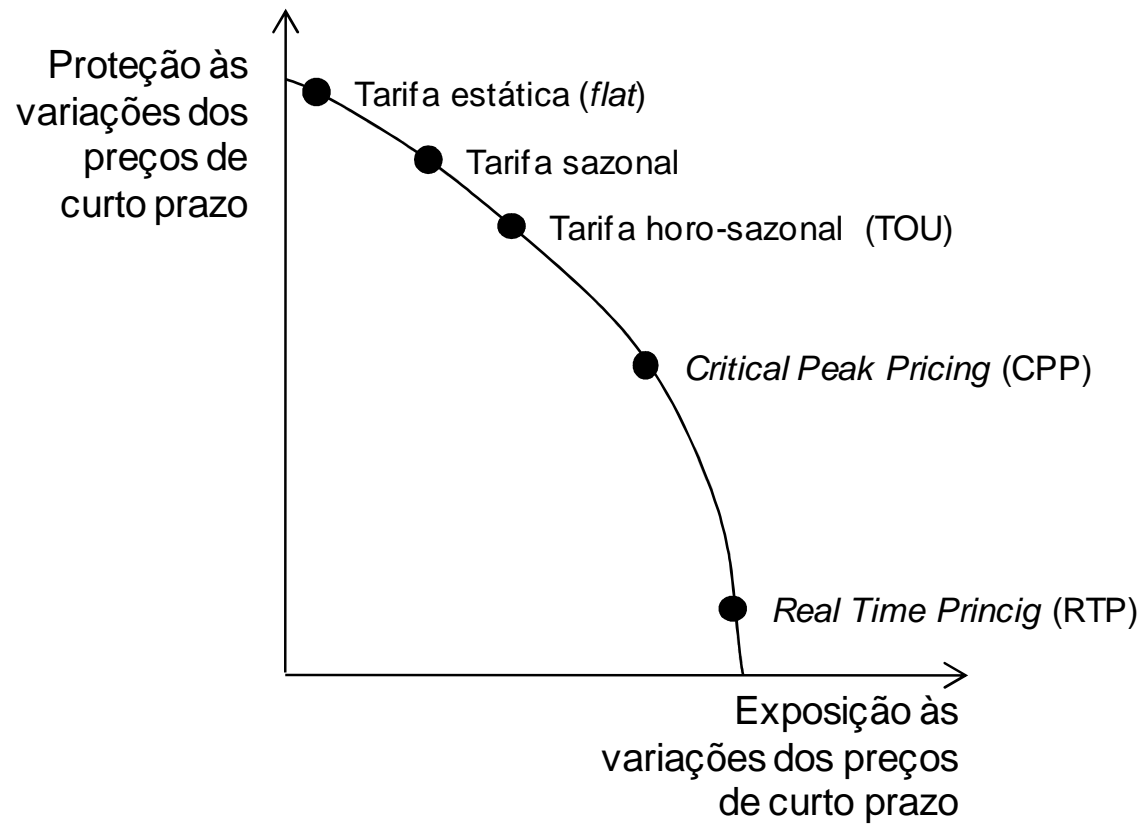

Figura 4.1 - Relação entre os tipos de tarifas e a percepção do consumidor aos preços de curto prazo - adaptada de The Brattle Group (2008).

Por exemplo, se todos os consumidores de uma distribuidora são atendidos por meio de tarifas que não refletem os sinais dos preços de curto prazo, toda a volatilidade é assumida pela distribuidora, o que maximiza sua obrigação de contratar instrumentos de hedge.

Conforme as tarifas se tornam mais dinâmicas, o custo de hedge diminui e, no extremo, na tarifação real-time (RTP), esse custo é nulo. Cabe ressaltar que o custo de contratação de instrumento de hedge por parte das distribuidoras é, em geral, pago pelos consumidores (THE BRATTLE GROUP, 2008). 
Ainda segundo essa mesma Referência mais de trinta anos de pesquisas tem demonstrado que consumidores industriais, comerciais e residenciais aceitam opções de tarifas flexíveis e podem responder aos preços de energia elétrica.

Sob a tarifação CPP ou RTP, os consumidores reagem aos sinais de preços por meio do deslocamento de carga dos períodos em que os preços se verificam altos para períodos de preços mais baixos, ou simplesmente reduzindo carga.

Nesse sentido, a precificação em tempo real (RTP) representa um vínculo direto entre os preços de curto prazo e as tarifas de distribuição. Esse tipo de tarifação reduz a necessidade de contratação de hedge pela distribuidora, já que o risco de variação do preço de curto prazo é transferido integralmente para o consumidor final na parcela de seu consumo que se definir exposta aos preços de curto prazo.

A tarifa do tipo TOU também provê incentivo aos consumidores para que desloquem suas cargas do horário de pico. Contudo, a tarifa TOU é estabelecida antecipadamente e não em função dos preços em tempo real. Ou seja, as tarifas são definidas por períodos desvinculados aos da precificação em tempo real (horária, por exemplo).

$\mathrm{Na}$ ótica do modelo institucional brasileiro vigente, em que se privilegia a contratação de longo prazo e as distribuidoras são obrigadas a contratar integralmente o montante previsto para seu mercado cativo, com 5 anos de antecedência, a implementação da recomendação de Von der Fehr e Wolak (2003) não se aplica, embora se possa reconhecer que existem vantagens em permitir a aplicação de tarifas que reflitam preços de mercado para a energia, mesmo para consumidores cativos. 
No futuro, com a possível evolução do mercado livre de modo a abranger um volume cada vez maior do mercado total $^{18}$, a aplicação desses conceitos pode ser visualizada no âmbito das Comercializadoras, como forma de reduzir a sua própria exposição ao mercado de curto prazo.

\subsubsection{Programas de resposta da demanda baseados em incentivo financeiro}

\subsubsection{Direct load control (DLC)}

No DLC, o operador do programa (operador do sistema ou distribuidora) desliga ou modifica remotamente a carga de um conjunto de equipamentos do consumidor (i.e. ar condicionado, aquecedor de água). Os programas DLC são direcionados inicialmente para consumidores residenciais ou comerciais de pequeno porte (U.S.A., 2006).

\subsubsection{Interruptible / Curtailable (I/C) Service}

Opções de redução de carga integradas às tarifas que provêm uma taxa de desconto ou créditos nas faturas de energia dos consumidores que aderem ao programa e reduzem carga durante contingências no sistema. Podem ser aplicadas penalidades nos casos de falhas no corte de carga. Os programas interruptíveis têm sido tradicionalmente oferecidos a grandes consumidores (industriais ou comerciais) (U.S.A., 2006).

\subsubsection{Emergency Demand Response Programs}

Estes programas incentivam a resposta da demanda por meio de pagamento aos consumidores por reduções de carga durante períodos em que as reservas de capacidade do sistema encontram-se baixas (U.S.A., 2006).

\footnotetext{
${ }^{18}$ Desde que se encontre solução plausível para a questão da inexistência de condicionante de lastro de longo prazo para o segmento de consumo quando participante do mercado livre.
} 


\subsubsection{Demand-Side Bidding}

O Demand-side Bidding, ou oferta de redução de carga, é um tipo de programa de resposta da demanda, normalmente oferecido a grandes consumidores, os quais ofertam redução de carga baseados nos preços do mercado atacadista.

$\mathrm{Na}$ oferta de redução de carga a demanda é envolvida diretamente no processo de determinação de preços, informando ao operador do mercado curvas de disposição de consumo (no formato preço $\mathrm{x}$ montante de energia). Com a oferta de redução de carga, o processo de determinação do preço de curto prazo passa a contar com uma demanda capaz de responder aos preços, demanda a qual muitas vezes é tratada como sendo totalmente inelástica.

Segundo (PATRICK, WOLAK; 2001), todos os mercados competitivos de energia elétrica em operação nos Estados Unidos permitem a oferta de redução de carga, tanto no mercado do dia seguinte (day-ahead market), quanto no mercado em tempo real (real-time market).

$\mathrm{Na}$ visão de (VINHAES; 2003), a oferta de redução de carga apresenta duas principais vantagens. Reduz volatilidade dos preços e poder de mercado, tendo em vista que a demanda passa a fazer parte do processo de formação dos preços e, dessa forma, reduz margem de manobra dos geradores. A autora destaca, ainda, que esta redução de volatilidade emite sinais positivos para novos investimentos.

Em mercados cuja determinação de preços baseia-se na consideração de uma demanda perfeitamente inelástica, como no caso brasileiro, a introdução da demanda no processo de determinação dos preços de curto prazo, via oferta de redução de carga, pode se mostrar uma opção válida para reduzir, em certo grau, a 
rigidez da demanda, na medida em que permite aos consumidores responderem aos preços.

Em um mercado de energia elétrica com preços formados com base em ofertas, a não incorporação da oferta de redução de carga no processo de determinação dos preços de curto prazo pode potencializar o exercício de poder de mercado por parte dos geradores, uma vez que a capacidade dos consumidores influenciarem os preços de mercado é reduzida.

No caso de mercados com formação de preços baseada em custos, como o brasileiro, a oferta de redução de carga pode ter um importante papel na mitigação de picos de preços.

\subsection{O CUSTO DA REDUÇÃO DE CARGA PARA O CONSUMIDOR}

Enquanto o preço da energia atendida é determinado pelas condições do mercado $\left(P_{1}\right.$ na Figura 4.1), em uma situação limite, em que as plantas térmicas já se encontram despachadas e o valor da água já reflete a iminência de racionamento, o valor de redução da demanda é definido pelo custo da energia não suprida. Este custo pode ser interpretado como uma medida de como os consumidores valoram a confiabilidade do suprimento de energia elétrica, ou o quanto os consumidores estariam dispostos a pagar para evitarem a interrupção do consumo (U.S.A., 2006).

Entre os custos computados no custo da energia não suprida estão incluídos (i) a inconveniência ou desconforto; (ii) a perda de vendas ou produtividade; (iii) os custos relacionados à retomada de produção; (iv) e o tempo adicional para a recuperação de produção (U.S.A., 2006). 
Uma forma de representar o benefício da resposta da demanda é pelo produto do custo da energia não suprida pelo montante esperado de energia não suprida representa o custo da redução de carga (U.S.A., 2006). Este custo é representado pelo retângulo em cinza na figura 4.2, onde a redução da demanda (D2 - D1) corresponde exatamente ao montante esperado de energia não suprida.

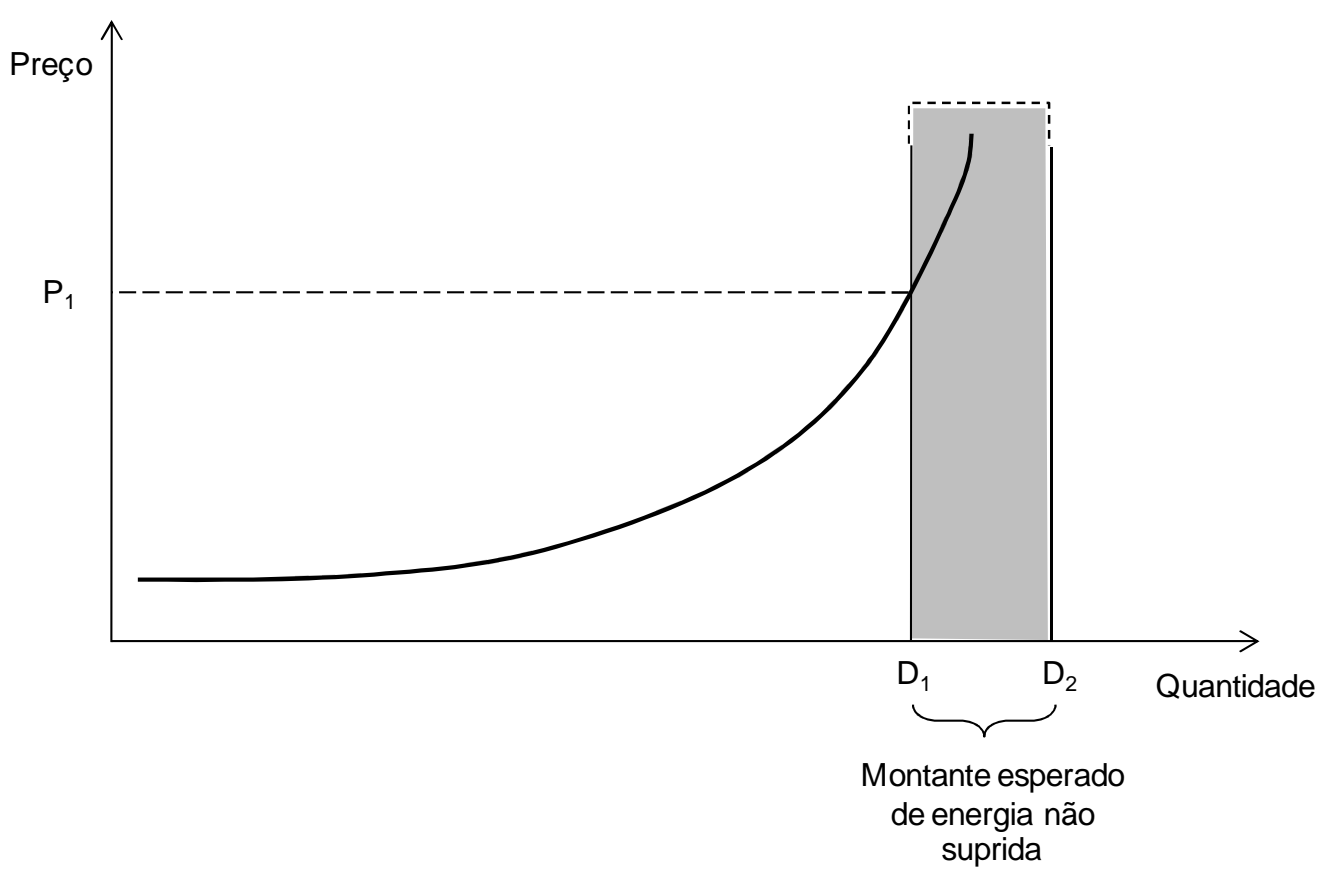

Figura 4.2 - Valoração do benefício da resposta da demanda - adaptação (U.S.A., 2006).

\subsection{RESPOSTA DA DEMANDA E PODER DE MERCADO}

O exercício de poder de mercado pode ser interpretado como qualquer ação voluntária por parte de um agente de mercado, ação esta que seja capaz de modificar os preços em função dos interesses do agente. 
A figura 4.3 exemplifica o exercício de poder de mercado por meio da retenção de capacidade de produção. Nota-se que, quando as curvas de demanda são verticais (i.e. inelásticas), a retenção de capacidade provoca o deslocamento da curva de oferta para a esquerda cujo efeito é o aumento do preço de $\mathrm{P}^{*}$ para $\mathrm{P}$ " para o atendimento da quantidade $\mathrm{q}^{*}$, o que gera um excedente adicional para os produtores equivalente a $q^{*} \times\left(P^{\prime \prime}-P^{*}\right)$. Por outro lado, havendo flexibilidade no consumo, a demanda reduz para q' e o aumento de preço se limita a P', gerando um excedente adicional menor para os produtores e, dessa forma, reduzindo o incentivo ao exercício de poder de mercado (ANDERSEN et al.,2006).

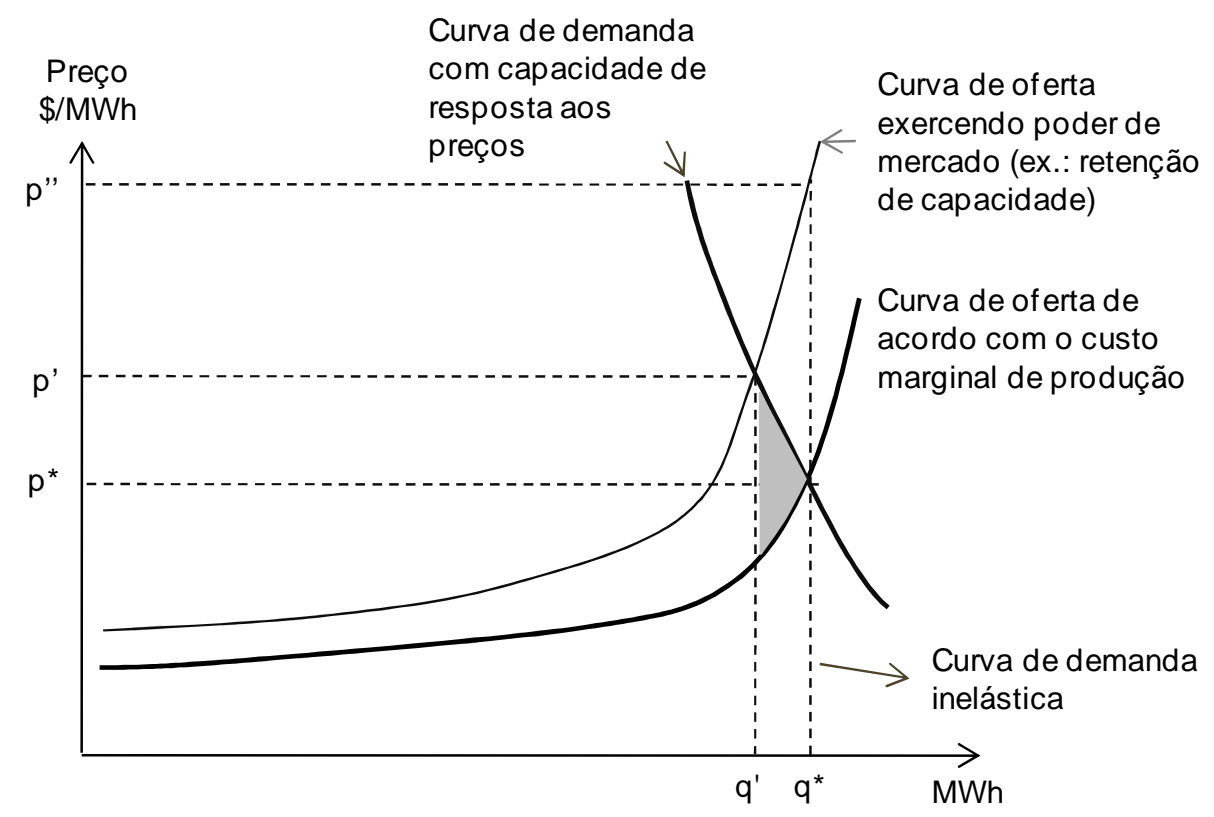

Figura 4.3 - Capacidade de resposta da demanda e incentivo ao exercício de poder de mercado - adaptada de Andersen et al. (2006).

Com base neste mesmo exemplo, (ANDERSEN ET AL., 2006) analisam um importante aspecto da resposta da demanda. Como a demanda é reduzida e o benefício final é apenas uma redistribuição de renda, o resultado final é negativo (representado pela área cinza da figura 4.3). 
Nesse caso, o valor final da resposta da demanda é a redução da necessidade de investimentos em unidades geradoras voltadas ao atendimento de cargas de pico, o que pode ser valorado em função do custo marginal de expansão, ou seja, o custo de se construir nova capacidade de geração. Em geral, a resposta da demanda é mais barata do que a construção de novas usinas exclusivamente para o atendimento de demanda de pico.

\subsection{RESPOSTA DA DEMANDA E VOLATILIDADE DOS PREÇOS}

Para Lafferty et al. (2001), a adoção de mecanismos adequados que permitam aos consumidores responderem aos preços pode reduzir o nível e a volatilidade destes no mercado de curto prazo durante períodos críticos do sistema. Tal efeito é ilustrado na figura 4.4 .

A referida ilustração demonstra que um mesmo volume de deslocamento da demanda provoca efeitos diferentes sobre o preço, dependendo do nível em que a demanda se encontra em relação à curva de oferta. Nota-se que, sendo D1'-D1 = D2'-D2, a redução de preço provocada por D1'-D1, representada por p1'-p1 é muito inferior à redução de preços provocada por D2'-D2, representada por p2'-p2. Tal diferença é explicada pela não linearidade da curva de oferta.

Na medida em que o nível da demanda se eleva, usinas com custo de operação mais elevado precisam ser acionadas, provocando a elevação do preço de curto prazo e, dada a descontinuidade da curva de oferta, para certos níveis de demanda o preço de curto prazo pode se comportar de forma extremamente volátil (como exemplificado na forte variação entre p2 e p2'). 


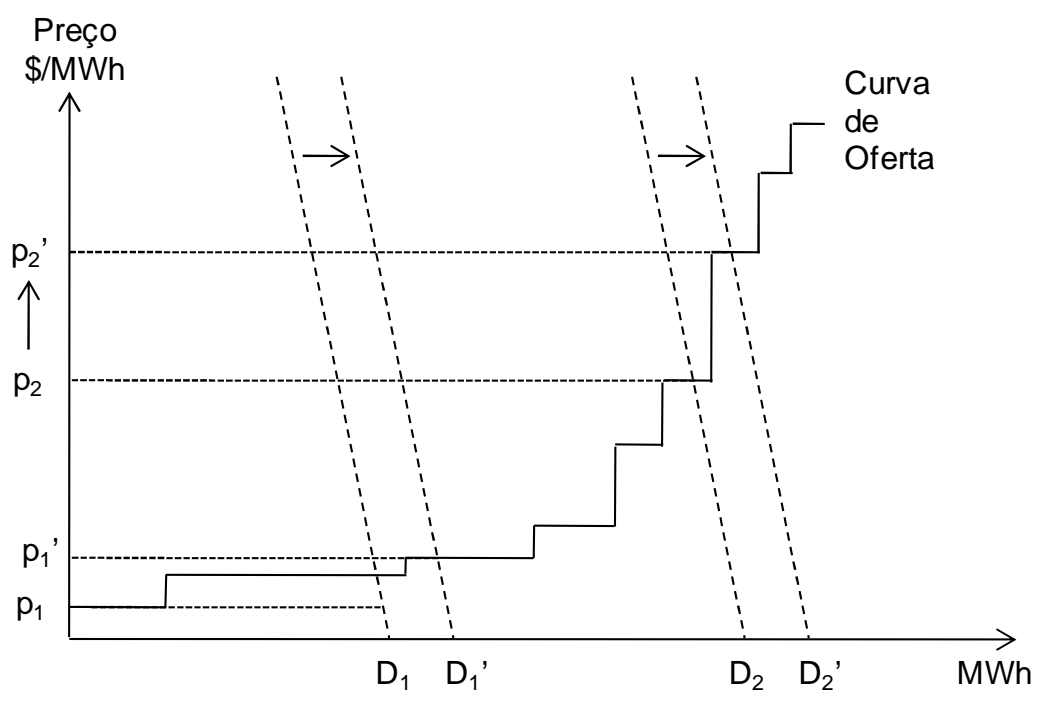

Figura 4.4 - Efeitos da reação da demanda sobre os preços em diferentes níveis.

Conforme ilustrado, a capacidade de reação da demanda pode reduzir de forma considerável a volatilidade dos preços de curto prazo, desde que tal resposta seja considerada no processo de cálculo desses preços.

\subsection{RESPOSTA DA DEMANDA E SEGURANÇA DE ABASTECIMENTO}

Se a demanda não variasse ao longo do tempo, a solução ótima seria simplesmente construir capacidade suficiente para atender toda a carga (VON DER FEHR; WOLAK, 2003). No, entanto, segundo estes autores, carga e suprimento de energia elétrica variam inevitavelmente entre os períodos (às vezes de forma imprevisível).

Assim, dependendo da relação entre oferta e demanda, existe a possibilidade de a capacidade total não ser suficiente para atender toda a carga (VON DER FEHR; WOLAK, 2003).

Um déficit de capacidade pode ser provocado por um choque de demanda resultante, por exemplo, de um comportamento incomum da carga no horário de ponta. 
Contudo, os déficits de capacidade são mais freqüentemente relacionados a choques de oferta, como em casos de falhas em unidades geradoras ou no sistema de transmissão, do que por choques de demanda (VON DER FEHR; WOLAK, 2003).

Dada uma determinada capacidade de geração, existem, em princípio, duas formas de eliminar um déficit de oferta. A primeira é pela elevação dos preços até o nível que provoque um choque na demanda (i.e. balanceamento de mercado).

Como segunda opção, no extremo, se a oferta não for suficiente para atender toda a demanda, não haverá balanceamento de mercado e, não havendo reação voluntária da demanda, a solução se dará pela desconexão emergencial de carga (i.e. racionamento da demanda).

Com relação aos sistemas predominantemente hidrelétricos, como o brasileiro, (VON DER FEHR E WOLAK, 2003) argumentam que os déficits de oferta estão normalmente relacionados à insuficiência de energia, quando o nível dos reservatórios encontra-se abaixo do necessário para o atendimento adequado da demanda durante certo período de tempo, e não à insuficiência de capacidade para o atendimento de picos de demanda.

Este aspecto é suma importância para o estudo de alternativas de incorporação da demanda no processo de formação ou determinação dos preços de curto prazo no mercado brasileiro, uma vez que o problema a ser abordado é relativamente diferente ao de outros mercados de energia elétrica, cujos programas de resposta da demanda têm por objetivo principal o aumento de reserva de capacidade. 


\subsection{INFLUÊNCIA DO NÍVEL DE CONTRATAÇÃO SOBRE A CAPACIDADE DE REAÇÃO DA DEMANDA}

Em mercados sujeitos a grande volatilidade de preços, é comum a utilização de instrumentos financeiros de proteção (hedge) como forma de gerenciamento do risco de variação do preço do ativo.

Nos mercados de energia elétrica desregulamentados, uma forma de hedging consiste no estabelecimento de instrumentos contratuais, com preços e volumes pré-negociados, como forma de proteção contra a volatilidade dos preços de curto prazo. Dessa forma, as partes envolvidas nesses contratos mitigam (ou eliminam, dependendo da formatação de preço estabelecida em contrato) a exposição à variação de preços nos montantes contratados.

A variabilidade dos preços possui o papel fundamental de sinalizar para os agentes as condições do mercado. Assim, quando há escassez de recursos, os preços devem se elevar, de forma a representar tal condição e, analogamente, quando há abundância de recursos, os preços devem ser reduzidos.

Na opinião de (SIDDIQUI, 2003), a estabilidade de preços que muitos consumidores se defrontam não oferece razões econômicas para que reduzam o consumo em situações de elevação do preço de curto prazo.

Assim, mais capacidade de geração é necessária para atender aos picos de demanda e, conseqüentemente, os consumidores futuros arcarão com o custo de implantação desta capacidade adicional por meio de tarifas mais elevadas.Por outro lado, a resposta da demanda aos preços de curto prazo não está necessariamente vinculada à existência de alguma parcela do consumo exposta às variações dos 
preços de curto prazo (i.e. descontratada). Mesmo que um consumidor esteja com toda sua carga atendida por contratos, ainda assim poderá ter incentivo para reduzir consumo - como reação aos preços de curto prazo -, desde que os preços sejam suficientemente elevados para que compensem sua decisão de diminuir produção em função da venda das sobras contratuais no mercado de curto prazo.

Para melhor compreender este mecanismo, suponha-se um consumidor que tenha comprado um volume de $100 \mathrm{MWh}$ em um contrato, ao preço de $\mathrm{R} \$ 50,00 / \mathrm{MWh}$. Se o preço de curto prazo se elevasse a $R \$ 200,00 / M W h$, este consumidor pagaria $R \$$ 200,00/MWh para cada MWh consumido acima dos 100 MWh contratados. Por outro lado, para o consumo abaixo de $100 \mathrm{MWh}$, o consumidor teria ressarcido do seu custo de energia elétrica a quantia de $R \$ 150,00 / M W h(R \$ 200,00-R \$ 50,00)$ para cada MWh não consumido. No limite, este consumidor poderia receber $R \$ 150,00 x$ $100 \mathrm{MWh}(\mathrm{R} \$ 15.000,00)$, caso reduzisse toda sua carga durante o referido período.

\subsection{EXPERIÊNCIA INTERNACIONAL}

A avaliação de 27 mercados de energia elétrica ao redor do mundo realizada por (BARROSO ET AL., 2005) constata que, em geral, a resposta da demanda aos preços de mercado tem sido relativamente baixa.

No estudo se destaca o mercado espanhol, onde, em geral, a demanda responde aos preços de mercado, sendo possível encontrar tarifas especiais que incentivam a racionalização do consumo.

Os autores destacam também a capacidade de resposta da demanda de alguns países em momentos de crise, como no caso do Brasil, onde a demanda foi reduzida em 20\% durante nove meses de racionamento, entre 2001 e 2002. 
Na Noruega, durante o período de baixa afluência verificado entre os anos de 2003 e 2004 , o consumo reduziu $5 \%$ em resposta aos preços altos. Finalmente, em alguns países como Irlanda e Holanda, existem, ainda que limitados, programas que incentivam a resposta da demanda.

A partir do levantamento de informações a respeito dos programas de incentivo à resposta da demanda adotados nos Estados Unidos, o Berkeley Lab (BARKELEY LAB, 2006) demonstram que estes programas permitem aos consumidores o melhor gerenciamento dos custos de energia e seu uso mais eficiente; reduzem os picos de preços no mercado de energia elétrica; e enviam sinais de preço que refletem de forma mais precisa o verdadeiro custo econômico do uso da eletricidade.

(HEFFNER E GOLDMAN, 2001) conduziram uma avaliação de alguns programas de resposta da demanda implementados nos Estados Unidos, na qual foram realizadas entrevistas com os gestores dos programas. Os seguintes aspectos dos programas foram analisados:

- Motivação da distribuidora ou do operador do mercado em oferecer o programa;

- Natureza do esquema de precificação;

- Detalhes operacionais e resultados;

- Participação dos consumidores e resultados, incluindo a retenção desses consumidores;

- Custos envolvidos nos programas, incluindo hardware e requisitos de comunicação; 
- Necessidade de desenvolvimento de tecnologia.

Os itens 4.8.1, 4.8.2 e 4.8.3 apresentam uma visão geral de programas avaliados pelos autores do referido estudo. Os itens 4.8 .5 e 4.8 .5 destacam os principais aspectos dos programas de resposta da demanda empregados pelo Independent Electricity System Operator - IESO (CA) e pelo PJM Interconection (EUA), respectivamente. Considerando o foco desta pesquisa, destaca-se a implementação de oferta de redução de carga (demand-side bidding) adotada pelo PJM Interconection.

\subsubsection{Boneville Power Administration - BPA}

O Demand Exchange, ou DEMX, é um leilão realizado via internet em que os participantes são alertados sobre os preços do tempo real, de um dia à frente e de dois dias à frente e podem postar suas intenções em cortar carga a um dado preço O DEMX oferece duas opções aos participantes: Voluntary Curtailment Option e PrePurchase Option (ou opção de corte voluntário e opção de pré-compra, em uma tradução livre). Ambos os programas são operados na base do dia seguinte.

A BPA tem como foco consumidores cujo custo de energia elétrica é parcela representativa do total de custos operacionais e possuem alguma flexibilidade de modificação no padrão de consumo.

De acordo com Heffner e Goldman (2001), até abril de 2001 a BPA já havia assinado com 14 consumidores com o potencial de aproximadamente $525 \mathrm{MW}$, tendo recebido mais de 6500 MWh de redução de carga ao longo do programa. Ainda segundo os autores, um percentual superior a $90 \%$ dessas reduções ocorreram em função de preços elevados no mercado atacadista. 


\subsubsection{Cinergy (atual Duke Kentucky)}

Heffner e Goldman (2001) consideram o programa de incentivo à resposta da demanda adotado pela então Cinergy como o mais agressivo dos Estados Unidos. Os autores relatam que a implantação do PowerShare Pricing Program teve como motivação, em grande parte, a experiência da companhia durante o verão de 1999, quando a volatilidade dos preços do mercado de curto prazo atingiu níveis extremos na região centro-oeste dos Estados Unidos. A combinação de elevada temperatura, baixos níveis de chuva, extensa onda de calor e falhas no sistema de geração expôs

a Cinergy e seus consumidores a picos de preços e a problemas severos de segurança do sistema.

O PowerShare Pricing Program oferece aos consumidores duas opções de participação, a Call Option e a Quote Option.

Para participar da CallOption, o consumidor deve ter o potencial mínimo de redução de $500 \mathrm{~kW}$. O consumidor escolhe um preço de exercício, em centavos por kWh, baseado em sua própria estimativa de custos em relação ao corte de carga (como a redução da produção, por exemplo). Quando a projeção de preços para o dia seguinte é superior ao preço de exercício, a Cinergy exerce a opção de corte, notificando o consumidor às 16 horas do dia anterior.

Em contrapartida às reduções de carga, os consumidores recebem da Cinergy créditos de energia toda vez que são solicitados. A penalidade pelo não cumprimento de redução de carga é o pagamento do preço spot (no caso de haver energia disponível) ou uma penalidade, cujo teto é de $\$ 10$ por kWh.

Os consumidores podem participar do programa em diversos níveis e formas. 
- Especificando uma carga firme;

- Identificando um gerador (mínimo $2 \mathrm{MW}$ ) para operar;

- Comprometendo-se com a interrupção de algum processo ou uso final específico;

- Comprometendo-se com uma redução fixa em sua carga;

- Selecionando entre três níveis de freqüência e duração de corte, como descrito na tabela 4.3 .

Tabela 4.3 - Opções oferecidas aos consumidores pelo PowerShare Pricing Program - alternativa CallOption (HEFFNER; GOLDMAN, 2001)

\begin{tabular}{rcccc}
\hline Opção & Duração máxima & Horário & $\begin{array}{c}\text { Solicitações por } \\
\text { ano }\end{array}$ & $\begin{array}{c}\text { Dias consecutivos } \\
\text { por semana }\end{array}$ \\
\hline CallOption $A$ & 8 horas & $\begin{array}{c}\text { Entre } 12: 00 \mathrm{e} \\
20: 00 \mathrm{~h}\end{array}$ & 12 & 3 \\
CallOption $B$ & 4 horas & $\begin{array}{c}\text { Entre } 14: 00 \mathrm{e} \\
18: 00\end{array}$ & 12 & 3 \\
CallOption $C$ & 8 horas & $\begin{array}{c}\text { Entre } 12: 00 \mathrm{e} \\
20: 00\end{array}$ & 4 & 4 \\
\hline
\end{tabular}

\subsubsection{Wabash Valley Power Association (WVPA)}

Como parte do esforço para reduzir custos e a exposição à volatilidade dos preços de curto prazo, a WVPA oferece dois programas de incentivo à resposta da demanda. Para consumidores industriais ou comerciais, um programa de redução voluntária de carga denominado "Customer Payback Plan" e para consumidores residenciais, um programa de controle de aquecimento de água e uso de ar condicionado chamado "It Pays to be COOL - Conserve Our Overall AC Load" (HEFFNER; GOLDMAN, 2001). 
No programa voltado aos consumidores comerciais ou industriais, os participantes recebem U\$250,00 por MWh reduzido, ou gerado via autoprodução, sempre que um "período de gerenciamento de energia" é declarado (HEFFNER; GOLDMAN, 2001). Os autores citam um exemplo em que um consumidor com um gerador de backup com capacidade de $250 \mathrm{~kW}$ opera por 100 horas a pedido da distribuidora. Este consumidor receberia U\$ 6.250,00 pela redução de carga (US\$250,00 x 100 x 250/1.000), mais o conseqüente custo evitado em compra de energia.

Ambos os programas têm como foco o período do verão e são desenhados especificamente como um instrumento de hedge contra a volatilidade dos preços de curto prazo (HEFFNER; GOLDMAN, 2001).

Para participar do Customer Payback Plan o consumidor deve possuir carga superior a 50 kW. Não são necessários equipamentos de medição horária. O consumidor é notificado pela distribuidora às 16 horas do dia anterior ao "período de gerenciamento de energia" (HEFFNER; GOLDMAN, 2001).

Após o evento, a distribuidora afere o montante de energia reduzido pelos participantes. Os métodos de aferição incluem, dependendo do consumidor, a medição direta; a análise da demanda e dos componentes da fatura de energia; a análise de informações dos usos finais armazenadas em dispositivos de coleta de dados (i.e. timers e loggers); e a comparação com uma base histórica de carga. $\mathrm{Na}$ opinião dos autores, este último método depende da colaboração e da confiança entre o consumidor e a distribuidora.

Resultados do programa:

- Residencial: alivio de $30 \mathrm{MW}$ no verão e $20 \mathrm{MW}$ no inverno. 
- Comercial - Industrial: $30 \mathrm{MW}$ de corte voluntário de carga, proporcionados por 250 participantes.

Um destaque do programa de incentivo à resposta da demanda oferecido pela WVPA é a substituição de grandes investimentos em equipamentos de medição (verificado em outros programas) por um desenho relativamente simples, baseado no relacionamento entre a distribuidora e os consumidores participantes do programa.

\subsubsection{Independent Electricity System Operator - IESO, Ontário (Canadá)}

De acordo com o Independent Electricity System Operator - IESO (INDEPENDENT ELECTRICITY SYSTEM OPERATOR, 2007), os grandes consumidores, em sua maioria, estão preparados para modificar seus perfis de consumo em função dos preços de mercado. Segundo IESO, a elasticidade-preço da demanda tem sido um importante benefício da reestruturação do setor elétrico de Ontário.

O IESO oferece aos grandes consumidores, geralmente grandes indústrias capazes de ajustar o consumo de energia elétrica em tempo de atenderem as instruções de despacho a cada cinco minutos, um programa de oferta de redução de carga (demand-side bidding). Estes consumidores participam diretamente do mercado de curto prazo, realizando ofertas horárias de compra de energia .

Segundo o IESO, desde a abertura do mercado, em 2002, duas grandes indústrias representavam sozinhas $65 \mathrm{MW}$. Posteriormente, nove grandes consumidores aderiram ao programa e representam mais de 700 MW (INDEPENDENT ELECTRICITY SYSTEM OPERATOR, 2007). 
De acordo com o IESO, consumidores não despachados diretamente, mas que respondem a preços de curto prazo reduzindo o consumo, somam uma demanda de até $400 \mathrm{MW}$ e contribuem de forma significativa para a redução de picos de preço.

\subsubsection{PJM Interconection}

Denominado PJM Load Response (demand-side response), este mecanismo foi desenhado para prover incentivo aos consumidores a reduzirem carga quando os preços de curto prazo encontram-se elevados, bem como em situações emergenciais (PJM INTERCONECTION, 2009).

Os consumidores finais interessados em participar do PJM Load Response devem ser intermediados por agentes provedores de serviços de redução de carga Curtailment Service Provider - CSP (PJM INTERCONECTION, 2009). Os CSPs são membros especiais do PJM que participam do mercado com a finalidade específica de agregar resposta (redução) da demanda.

A compensação por reduções de carga pode ocorrer por critério emergencial ou econômico (PJM INTERCONECTION, 2009).

- Critério Emergencial (PJM Emergency Load Response):

(i) redução de consumo - os consumidores são compensados por reduções voluntárias de consumo durante eventos emergenciais.

(ii) redução de capacidade - o modelo prevê um mecanismo de compensação financeira por reduções de capacidade durante eventos emergenciais. Neste caso, a redução é compulsória. 
(iii) energia e capacidade - os participantes são compensados financeiramente pelas reduções de energia e capacidade durante o evento emergencial. Neste caso, a redução é compulsória.

- Critério econômico (PJM Economic Load Response): permite que a demanda responda aos preços de curto prazo (PJM Locational Marginal Price - LMP) por meio da redução do consumo.

Enquanto em alguns mercados de energia elétrica a resposta da demanda é acionada unicamente em períodos de contingência do sistema elétrico e não participa do processo de determinação do preço de curto prazo, no PJM, além de reduzir carga em períodos emergenciais, a resposta da demanda pode determinar o preço de curto prazo por meio de oferta de redução de carga (demand-side bidding).

Segundo The Brattle Group (2008b), o PJM conta com um dos protocolos mais avançados para a resposta da demanda. A interface em que são encaminhadas as ofertas de redução de carga (eLoadResponse) é diferente da utilizada para o envio de ofertas dos geradores $(e M k t)$. A interface especial acomoda as diferenças de parâmetros entre as ofertas de redução de carga e ofertas de geração. No entanto, para fins de despacho, determinação de preço e contabilização, a oferta de redução de carga é tratada da mesma forma que as ofertas de geração (THE BRATTLE GROUP, 2008b).

Ao efetuar a oferta de redução de carga, os Curtailment Service Providers devem especificar para cada carga, entre outros dados, as seguintes informações: 
- Quantidade, em KW, a ser reduzida.

- Preço de curto prazo (Locational Marginal Price - LMP), em \$/MW, ao qual a carga deverá ser reduzida (strike price).

- Submercado (Pricing Zone).

- Tempo, em minutos, de redução.

- Indicar se a redução de carga é despachável em tempo real.

É condição fundamental para que uma carga participe do processo de determinação do preço de curto prazo a existência de um sistema de medição conectado diretamente com o PJM (PJM INTERCONECTION, 2009).

A verificação da efetiva redução de carga ocorre de acordo com os critérios apresentados na tabela 4.4 .

Tabela 4.4 - Critérios de verificação de redução efetiva de carga

\begin{tabular}{|c|c|}
\hline Emergencial & Econômico \\
\hline $\begin{array}{l}\text { Geração de Backup: o sistema requer a } \\
\text { medição de geração. }\end{array}$ & $\begin{array}{l}\text { Geração de Backup: o sistema requer a } \\
\text { medição de geração. }\end{array}$ \\
\hline $\begin{array}{l}\text { Medição de Consumo: o sistema requer a } \\
\text { medição de consumo a partir da hora }\end{array}$ & $\begin{array}{l}\text { Medição de Consumo: o sistema requer a } \\
\text { medição de todas as horas durante a redução. }\end{array}$ \\
\hline final do processo. & $\begin{array}{l}\text { Base de Cálculo (média histórica de } \\
\text { consumo): o sistema compara a carga medida } \\
\text { com base de cálculo a fim de verificar a } \\
\text { efetiva redução. }\end{array}$ \\
\hline
\end{tabular}




\section{METOdOLOGIA PARA IMPLEMENTAÇÃO DE OFERTA DE REDUÇÃO DE CARGA}

\subsection{CONSIDERAÇÕES GERAIS}

Embora nunca tenha sido de fato efetivada, os estudos iniciais que fundamentaram a criação do mercado atacadista de energia elétrica brasileiro previam a implementação da oferta de redução de carga (COOPERS\&LYBRAND, 1997).

De acordo com a proposta, consumidores de grande porte, capazes de gerenciar sua carga, ofertariam preços perante os quais estariam dispostos a desligar ou a reduzir carga em um dado montante. Previa-se também que os consumidores habilitados a participar do programa teriam que estar conectados à rede elétrica de tal forma que pudessem ser desconectados ou tivessem acordos em vigor que compelissem à redução de sua carga de maneira segura, quando instruídos a isso, enquanto outros consumidores não participantes do Programa de Redução de Carga, situados na mesma região, não sofressem qualquer interrupção no fornecimento.

Os preços das ofertas de redução ou corte de carga seriam incluídos no processo de otimização do despacho e formação dos preços, sendo que, ao atingir o grau máximo de otimização, na margem, seria promovida uma redução de carga anterior à programação de geração adicional, de tal forma que o preço de curto prazo seria fixado ao preço da oferta daquela redução de carga (COOPERS\&LYBRAND, 1997).

Seriam necessários mecanismos de monitoramento, de forma a determinar se a redução de carga instruída foi efetivada, podendo ser aplicadas penalidades nos casos de descumprimento. 
Com base no mecanismo de oferta de redução de carga previsto na referida proposta, este trabalho pretende analisar a viabilidade de sua implantação no modelo de formação de preços atualmente em vigor no setor elétrico brasileiro, bem como, por meio de simulações, analisar a sensibilidade dos preços de curto prazo em relação a ofertas de redução de carga.

\subsection{OPÇÃO DE IMPLEMENTAÇÃO DA OFERTA DE REDUÇÃO DE CARGA PARA O CASO BRASILEIRO}

No modelo institucional vigente, diferentemente do momento em que o consórcio Coopers \& Lybrand estabeleceu sua proposição, todos os consumidores atuantes no mercado livre e, portanto elegíveis para aderir ao Programa de Redução Voluntária de Carga (PRVC), tem que ter contratos de suprimento que cubram $100 \%$ de sua carga.

A aferição de suficiência de lastro é feita através do cálculo de uma média móvel de 12 meses, para cada intervalo de apuração. Durante esse período, pode haver momentos em que o consumidor apresente sobras ou déficits, porém se na média de 12 meses for verificada insuficiência de lastro, haverá a incidência de severas penalidades.

Ponderando então o arranjo institucional vigente, pode-se avançar uma proposta plausível de implementação, que dispensa a instalação de dispositivos de desconexão compulsória da carga a ser reduzida.

Mais especificamente, o consumidor participante do PRVC tem seus contratos registrados na CCEE e, ao oferecer um determinado montante de carga a reduzir, quando o PLD atinge determinado nível, dever-se-á considerar uma redução de 
igual volume em seu total de contratos. Como os geradores, que têm a obrigação da entrega da correspondente energia, têm suas obrigações mantidas, o volume reduzido passa a ser uma disponibilidade sistêmica.

Nesse âmbito de considerações, qualquer consumo a maior em relação ao contrato reduzido passa a ser considerado uma exposição "spot", a ser penalizada pelo pagamento da própria exposição no mercado de curto prazo (sendo que se a redução de carga foi acionada pressupõe-se PLD elevado), como também pela sujeição de penalidade, na janela móvel de 12 meses.

Vale frisar que o Consumidor poderia auferir a mesma vantagem financeira reduzindo voluntariamente o consumo quando o PLD atingisse patamares atraentes, sem necessidade de formalizar uma adesão ao mecanismo de redução de carga, colocando em questão o racional que o levaria a se comprometer com uma redução sem auferir vantagem adicional. Na medida em que uma adesão formal é importante, para que se possa considerar a redução de carga na própria formação do preço (incluindo sua modelagem nas ferramentas computacionais de formação de preços), resta estabelecer alguma forma de incentivo à adesão ao PRVC. Uma alternativa poderia ser uma remuneração fixa, independente de acionamento do compromisso de redução e, portanto, adicional ao benefício decorrente da diferença entre preço "spot" e preço de contrato, para cada MWh disponibilizado para redução - Desde que inferior ao custo marginal decorrente do despacho sem a sua consideração, a oferta de redução de carga resultaria em redução do custo total de suprimento, uma vez que na ausência de redução usinas mais caras seriam despachadas. 
Uma alternativa à redução de contratos seria o acionamento de geração própria (geração de backup), devidamente medida, o que também funcionaria como uma disponibilidade de recurso para o sistema.

\subsection{MECANISMO ATUAL DE FORMAÇÃO DE PREÇOS NO MERCADO BRASILEIRO}

Inicialmente, são apresentados os conceitos principais do modelo formação do preço de curto prazo adotado no mercado brasileiro.

\subsubsection{Planejamento da operação eletroenergética}

Diferentemente de outros mercados estrangeiros que atravessaram o processo de reestruturação, onde o preço de curto prazo é formado por meio do equilíbrio entre oferta e demanda, no Brasil, o preço de curto prazo, ou PLD, é calculado por meio dos modelos computacionais utilizados na operação, refletindo o custo marginal de operação calculado dentro do processo de planejamento da operação do sistema.

O planejamento da operação, por sua vez, tem como objetivo minimizar o custo total de produção em todo o horizonte de estudo (cinco anos). O custo total se constitui na soma dos custos variáveis de todos os recursos utilizados, o que equivale ao custo da geração térmica e, no caso de parte da demanda não ser atendida, o custo do déficit. 


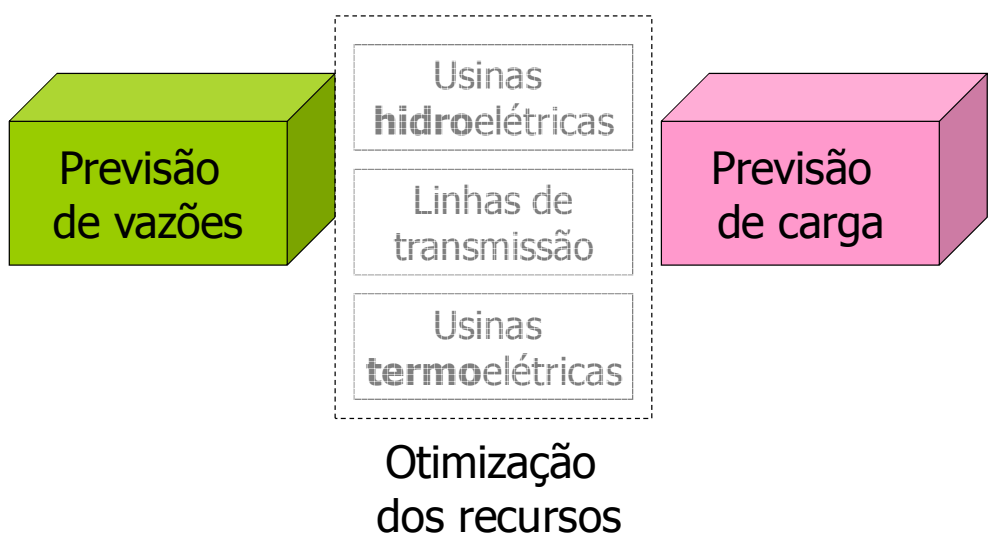

Figura 5.1 - O planejamento da operação eletroenergética ${ }^{19}$.

A presença no sistema brasileiro de grandes reservatórios faz com que uma decisão tomada em determinado momento tenha impactos sobre o futuro. Assim, uma decisão tomada no presente sobre a utilização dos recursos hidrelétricos tem impactos sobre a disponibilidade desse recurso no futuro.

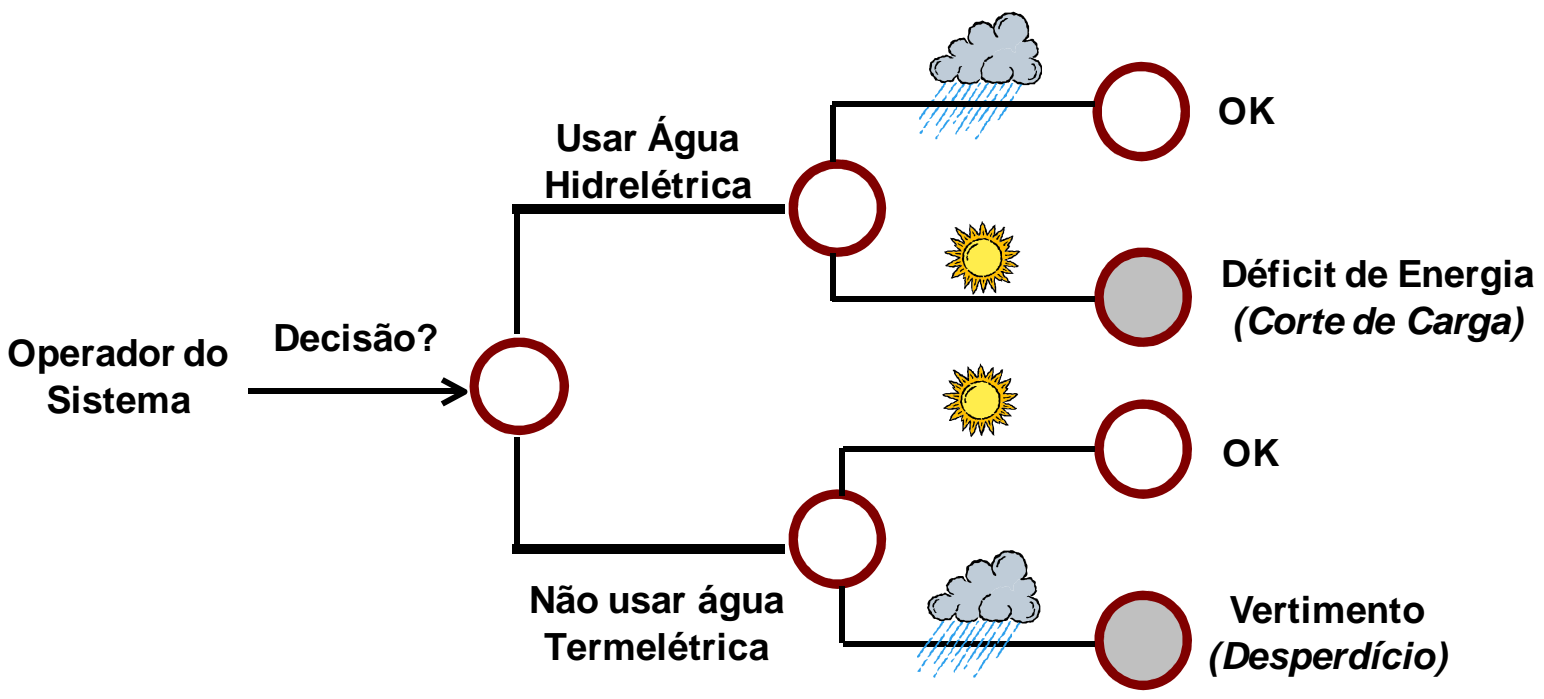

Figura 5.2 - Decisão da utilização dos recursos hidrelétricos no presente versus armazenamento de água ${ }^{20}$.

\footnotetext{
${ }^{19}$ CÂMARA DE COMERCIALIZAÇÃO DE ENERGIA ELÉTRICA. O SIN e os modelos Newave e Decomp utilizados no planejamento da operação energética e no cálculo do PLD. Treinamento aos agentes, 2007, São Paulo. Não publicado.
} 
Dessa forma, o processo de otimização embutido nos modelos computacionais busca realizar uma comparação dos benefícios de utilizar a água no presente com a importância de armazená-la para futura utilização. Dessa comparação obtém-se o custo de oportunidade da água.

O benefício do uso imediato da água é representado pela Função de Custo Imediato (FCl), enquanto o benefício do armazená-la hoje para seu uso no futuro é representado pela Função de Custo Futuro (FCF).

A FCl representa de maneira indireta a geração térmica e os intercâmbios entre as regiões (subsistemas ou submercados). Esta função indica o custo de geração termelétrica necessária para complementar o atendimento da demanda na etapa "t", onde este complemento é a diferença entre a demanda e a energia hidrelétrica produzida.

Por outro lado, a FCF está associada ao custo da geração termelétrica ou déficit no futuro, necessária ao atendimento da demanda nas etapas futuras. Logo, a função de custo futuro permite comparar o custo de utilizar os reservatórios na etapa t ou armazenar água para a utilização futura.

Dessa forma, conclui-se que o uso ótimo da água é aquele que minimiza a soma do custo de geração térmica no presente e o valor esperado do custo de geração até o fim do período de estudo, traduzido pelo ponto de mínimo da curva representada na figura 5.3.

${ }^{20}$ CÂMARA DE COMERCIALIZAÇÃO DE ENERGIA ELÉTRICA. O SIN e os modelos Newave e Decomp utilizados no planejamento da operação energética e no cálculo do PLD. Treinamento aos agentes, 2007, São Paulo. Não publicado. 


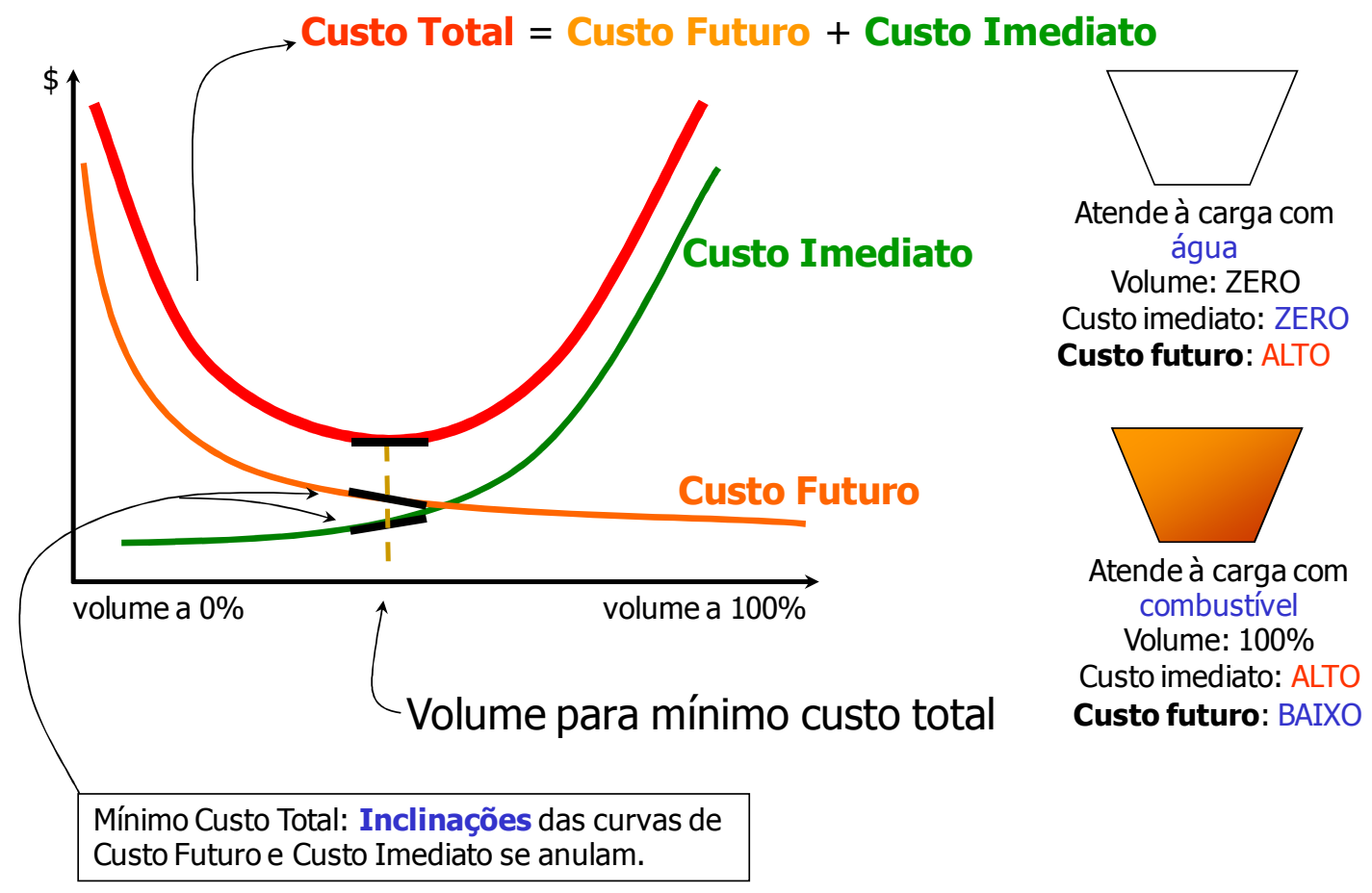

Figura 5.3 - Minimização do custo total de geração ${ }^{21}$.

\subsubsection{Os modelos computacionais NEWAVE e DECOMP}

Os modelos computacionais utilizados no cálculo CMO/PLD são o NEWAVE e o DECOMP, sendo ambos ferramentas desenvolvidas pelo Centro de Pesquisas de Energia Elétrica - CEPEL.

O NEWAVE é utilizado para otimizar a política de operação no horizonte de médio prazo (5 anos), discretizado mensalmente. Tem como objetivo a definição da Função de Custo Futuro.

Já o DECOMP, é o modelo computacional utilizado para horizontes de curto prazo (12 meses) e utiliza a Função de Custo Futuro do NEWAVE como um dado de entrada. O primeiro mês do horizonte de estudo é representado em base semanal e,

${ }^{21}$ CÂMARA DE COMERCIALIZAÇÃO DE ENERGIA ELÉTRICA. O SIN e os modelos Newave e Decomp utilizados no planejamento da operação energética e no cálculo do PLD. Treinamento aos agentes, 2007, São Paulo. Não publicado. 
através de uma árvore de possibilidades de vazões aleatórias e do parque gerador (usinas hidrelétricas e térmicas), determina o despacho por usina que minimiza o custo esperado de operação para a primeira semana do período.

\subsubsection{Determinação do Preço de Liquidação de Diferenças - PLD}

Um dos resultados dos modelos de otimização utilizados para o planejamento da operação é o Custo Marginal de Operação - CMO, o qual é determinado pelo modelo de planejamento e indica o custo adicional que decorreria do atendimento de um incremento de carga em cada submercado, em cada patamar de carga.

A figura 5.4 ilustra a definição do CMO de acordo com o recurso utilizado.

\begin{tabular}{|ccc|}
\hline Recurso & & Custo \\
Água armazenada & $\rightarrow$ & Valor da Água \\
Vertimento turbinável & $\rightarrow$ & Zero \\
Importação de outro submercado & $\rightarrow$ & CMO do submercado \\
Corte de carga & & exportador \\
\end{tabular}

Figura 5.4: Definição do CMO conforme o recurso utilizado.

O Preço de Liquidação de Diferenças - PLD divulgado pela Câmara de Comercialização de Energia Elétrica - CCEE (considerando informações previstas de disponibilidade de geração, vazões afluentes e carga do sistema), é calculado antecipadamente, com periodicidade máxima semanal, por patamar de carga, e tem como base o CMO resultante dos mesmos modelos computacionais utilizados no planejamento da operação, limitado, porém, a um preço máximo e um preço mínimo vigente em cada período de apuração. 
Os dados utilizados no cálculo do PLD são mesmos utilizados no planejamento da operação, a exceção das restrições de transmissão internas a cada submercado e às unidades geradoras em fase de teste, de forma a representar a energia comercializada como igualmente disponível e o $\mathrm{CMO}$ como único em todos os pontos de consumo do submercado.

A figura 5.5 a seguir ilustra a determinação do PLD a partir dos modelos computacionais utilizados no planejamento da operação.

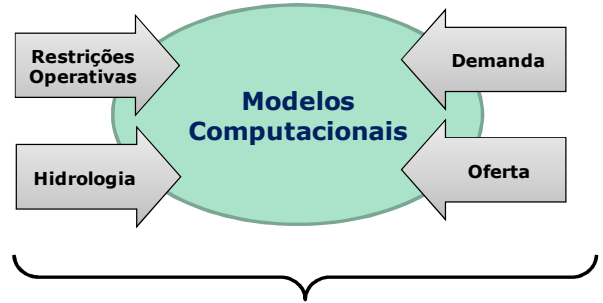

Decisões Operativas

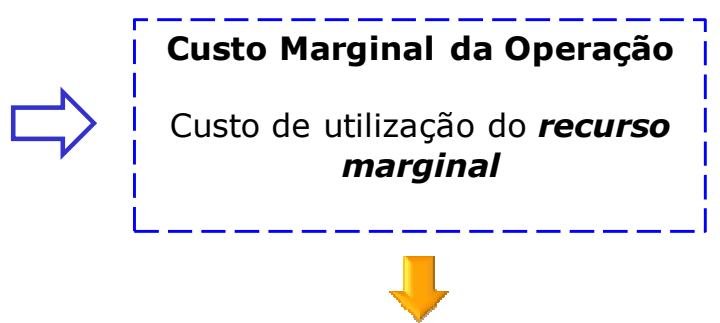

\section{Preço de Liquidação}

Retiradas as restrições internas aos submercados

Figura 5.5 - Processo de planejamento da operação e cálculo do CMO/PLD.

A partir do racionamento de 2001, foi proposta pelo Comitê de Revitalização do Setor Elétrico a introdução de uma curva de alerta, ou Curva de Aversão ao Risco CAR, para as condições de armazenamento de cada subsistema, devendo ser acionada medida preventiva, como o despacho de usinas térmicas fora da ordem de mérito econômico, quando na ocorrência de níveis inferiores à curva.

A figura 5.6 ilustra o despacho e formação de preços a partir da introdução da CAR. 

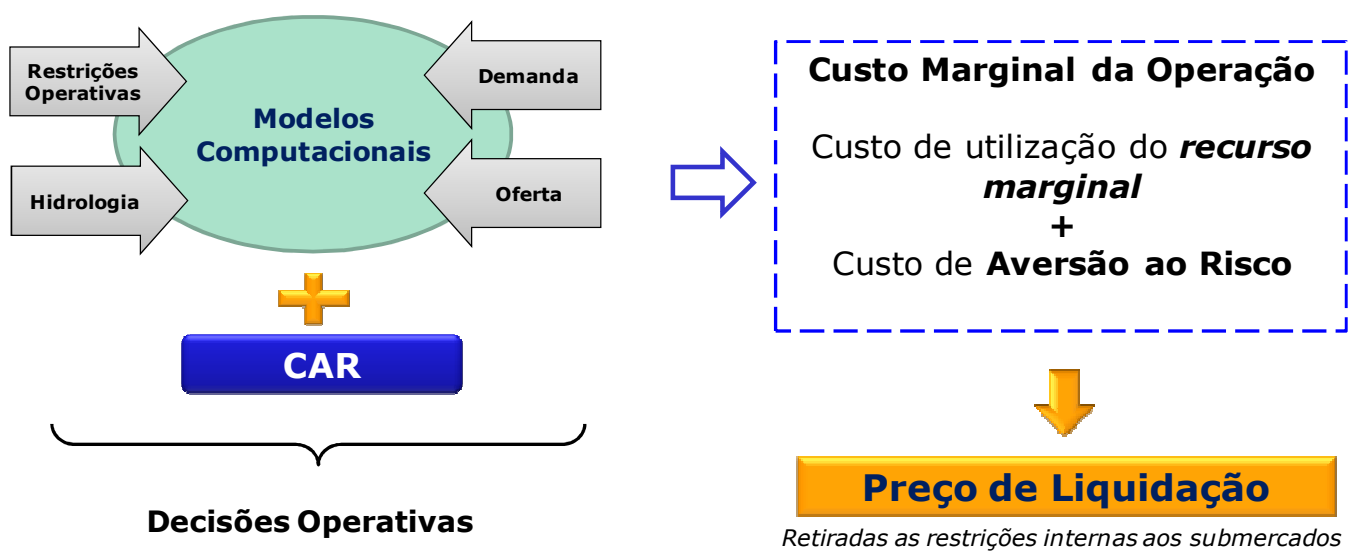

Figura 5.6 - Formação de preços a partir da introdução da CAR.

Posteriormente, no sentido de conferir maior segurança ao suprimento de energia elétrica, foram adotados mecanismos adicionais de segurança operativa para antecipação de despacho termelétrico. Sob essa metodologia, denominada Procedimentos Operativos de Curto Prazo, a operação do sistema passa a ser balizada por níveis-meta de armazenamento que devem ser atingidos no final do período seco de cada ano. Os referidos níveis são estabelecidos previamente pelo Comitê de Monitoramento do Setor Elétrico - CMSE, no âmbito do Ministério de Minas e Energia, podendo o operador lançar mão de despachos térmicos adicionais aos indicados pelo modelo, no sentido de gerenciar o risco de ocorrência de afluências futuras insuficientes, fato que poderia comprometer o atendimento pleno da demanda.

A figura 5.7 ilustra os modelos de despacho e formação de preço após a introdução da CAR e dos Procedimentos Operativos de Curto Prazo. 

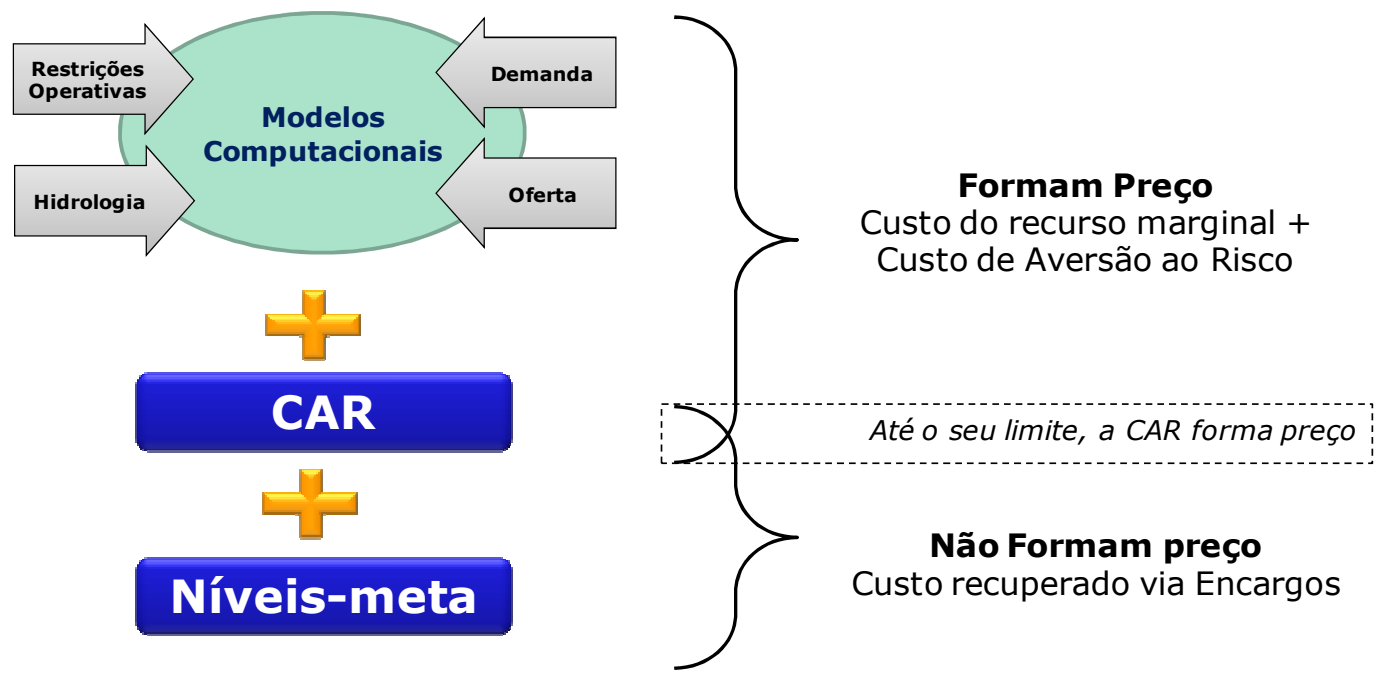

Figura 5.7 - Formação de preços a partir da introdução da CAR e dos níveis-meta.

As usinas termelétricas acionadas em função da aplicação dos Procedimentos Operativos não são consideradas na determinação do PLD. A remuneração do custo adicional do despacho originado da aplicação dos Procedimentos Operativos é realizada por meio do rateio de encargos entre os agentes, com base no consumo verificado.

Embora não determine o PLD, os Procedimentos Operativos afetam sua formação, uma vez que promovem a elevação dos níveis de energia armazenada nos reservatórios. Este efeito se propaga para os períodos subseqüentes ao da decisão de despacho termelétrico.

O gráfico 5.1 apresenta o histórico dos PLD's divulgados pela CCEE durante o período de janeiro de 2003 a julho de 2009 . 


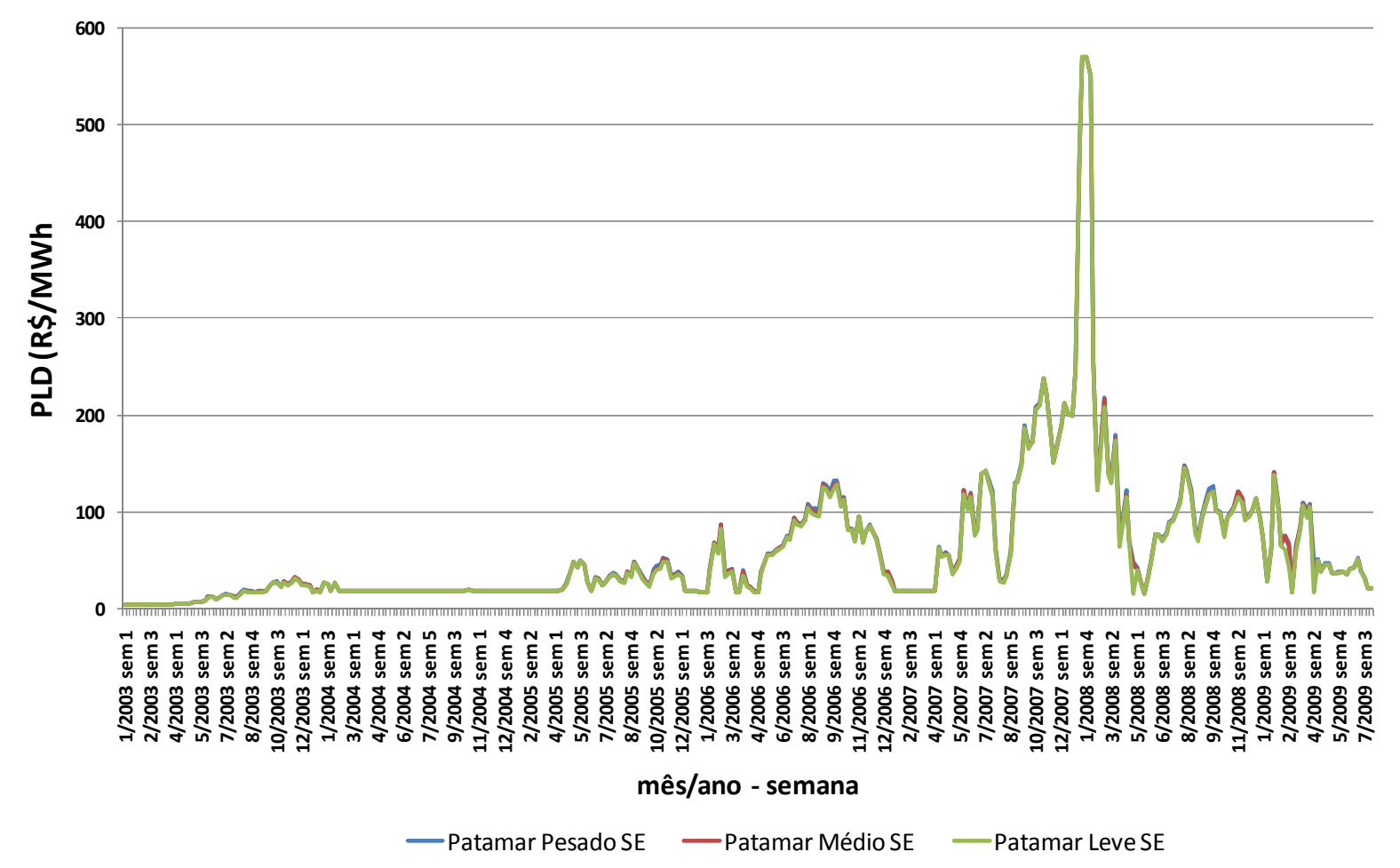

Gráfico 5.1 - Histórico do PLD - período: janeiro de 2003 a março de 2009 (fonte:

CCEE, 2009. Disponível em: <www.ccee.org.br>. Acesso em: 25 de ago. 2009).

\subsection{ESTUDO DE CASO}

O objetivo deste estudo de caso é analisar a sensibilidade do atual modelo de formação de preços, adotado no mercado de energia elétrica brasileiro, à proposta de incorporação da oferta de redução de carga ao processo de formação de preços e definição do despacho do parque hidrotérmico.

Para simular os casos, foram utilizadas as ferramentas computacionais NEWAVE versão 13a e DECOMP versão 15, ambas desenvolvidas pelo Centro de Pesquisas de Energia Elétrica - CEPEL. 
O estudo se divide em três partes. Na primeira, são avaliados os efeitos da incorporação do recurso de redução voluntária de carga no sistema brasileiro a longo prazo. Nesse sentido, foi simulada com o software NEWAVE a introdução de um bloco de usinas termelétricas virtuais, com diferentes custos variáveis unitários, o que representa uma escala de adesão ao PRVC ou "bids". A capacidade de cada térmica representa o montante de adesão ao PRVC e o CVU da respectiva usina sinaliza o preço, em $\mathrm{R} \$ / \mathrm{MWh}$, em que o consumidor estaria disposto a reduzir carga. Os efeitos da introdução do PRVC sobre os CMO's são analisados para os cinco anos do horizonte de estudo (janeiro de 2008 a dezembro de 2012). As simulações foram realizadas para o submercado Sudeste/Centro-Oeste.

A segunda parte do estudo tem por objetivo avaliar os efeitos da adesão conjuntural ao PRVC. Ou seja, enquanto nas simulações anteriores se buscou avaliar o efeito médio da adesão dos agentes, agora se busca avaliar o efeito em conjunturas específicas, rebatendo diretamente no preço do mercado de curto prazo.

Nesse caso, a RVC é representada exclusivamente no modelo DECOMP. Ou seja, é utilizada a Função de Custo Futuro do deck original do NEWAVE, sem a incorporação da RVC, para o cálculo do CMO no modelo DECOMP.

A terceira parte avalia os efeitos da consideração da RVC tanto na construção da Função de Custo Futuro calculada pelo NEWAVE (RVC como recurso "estrutural"), quanto no cálculo efetivo do CMO pelo modelo DECOMP (RVC como recurso estrutural e disponível no curto prazo).

Em todos os casos, adotou-se a $2^{a}$ semana operativa do mês de janeiro de 2008, em função especificamente do elevado $\mathrm{CMO}$ médio verificado neste período, 
equivalente a 475,53 $\mathrm{R} \$ / \mathrm{MWh}$. Evitou-se utilizar a $3^{\text {a }}$ e a $4^{\text {a }}$ semana do referido mês pelo fato de o PLD ter atingido seu patamar máximo nestes períodos, ocorrendo o acionamento de térmicas com custo variável acima do PLD máximo, o que poderia prejudicar a avaliação da sensibilidade total do modelo à RVC, uma vez que a redução no CMO poderia não ser capturada pelos limites do PLD.

O estudo de caso ainda conta com uma avaliação da volatilidade do PLD a partir da introdução da RVC em seu processo de cálculo.

\subsubsection{Avaliação dos efeitos da Redução Voluntária de Carga sobre o PLD no longo prazo}

Para simular os efeitos da adesão ao Programa de Redução Voluntária sobre o PLD no longo prazo, foi utilizado o modelo NEWAVE, o qual simula para um horizonte de cinco anos um conjunto de 2.000 CMO's para cada um dos sessenta meses.

O valor esperado para o PLD de cada mês do horizonte equivalente à média aritmética dos 2.000 CMO's gerados pelo modelo, considerando o efeito do piso e do teto que definem o PLD a partir do CMO.

A incorporação da RVC ao sistema foi representada por meio da introdução de blocos de usinas termelétricas virtuais. Foram simulados dois cenários de adesão ao programa.

- Cenário conservador: adesão de 800 MW de RVC.

- Cenário de referência: adesão total subdividida em quatro blocos de RVC, de 800 MW cada, com distintos patamares de atratividade (preço de adesão). 
Em ambos cenários descritos, o fator de capacidade máximo de todas as usinas é considerado como $100 \%$.

O CVU de cada usina virtual inserida nos modelos computacionais representa a oferta de preço dos consumidores, em $\mathrm{R} \$ / \mathrm{MWh}$, a partir da qual estariam dispostos a reduzir carga.

Importante ressaltar que o objetivo desse estudo é avaliar a capacidade de resposta dos modelos computacionais à metodologia de implementação de oferta de redução de carga aqui proposta. A estimativa dos montantes que seriam eventualmente aderidos ao PRVC deve ser precedida de um estudo aprofundado sobre a elasticidade-preço da demanda, conceito que, embora também tenha sido discutido no decorrer deste trabalho, não se configura como objetivo central. Em outras palavras, os montantes utilizados no estudo de caso são meramente prospectivos, sem nenhuma pretensão de respaldo conceitual e de representatividade de condições reais para os valores de montante e patamar de atratividade utilizados.

O que se objetiva aqui é a avaliação da aplicabilidade da metodologia proposta, da resposta dos modelos computacionais à referida metodologia e dos benefícios obtidos a partir de sua aplicação, como a redução de picos e da volatilidade dos preços de curto prazo.

A tabela 5.1 apresenta os blocos de RVC introduzidos nos modelos de cálculo do preço e as respectivas ofertas em $\mathrm{R} \$ / \mathrm{MWh}$. 
Tabela 5.1 - Usinas termelétricas virtuais introduzidas no NEWAVE para representar a Redução Voluntária de Carga

\begin{tabular}{|c|c|c|}
\hline $\begin{array}{l}\text { Usinas termelétricas virtuais representando a } \\
\qquad \text { RVC }\end{array}$ & Disponibilidade (MW) & $\begin{array}{c}\text { Disposição para } \\
\text { redução de carga } \\
\text { (R\$/MWh) }\end{array}$ \\
\hline $\begin{array}{l}\text { RVC I (representada tanto no cenário } \\
\text { conservador quanto no de referência) }\end{array}$ & $800 \mathrm{MW}$ & $\mathrm{R} \$ 100,00$ \\
\hline RVC II (representada no cenário de referência) & $800 \mathrm{MW}$ & $\mathrm{R} \$ 130,00$ \\
\hline RVC III (representada no cenário de referência) & $800 \mathrm{MW}$ & $\mathrm{R} \$ 150,00$ \\
\hline RVC IV (representada no cenário de referência) & $800 \mathrm{MW}$ & $R \$ 200,00$ \\
\hline
\end{tabular}

\subsubsection{Análise dos resultados - Efeito no horizonte de longo prazo}

Considerando o critério discutido no tópico anterior, os gráficos 5.2 e 5.3 ilustram os resultados obtidos com as simulações do modelo NEWAVE para o deck referente ao mês de janeiro de 2008 (cenário conservador e de referência, respectivamente).

São apresentados os CMO's esperados para o submercado Sudeste/Centro-Oeste patamares de carga pesado, leve e médio - para o período de cinco anos (janeiro de 2008 a dezembro de 2012), resultantes de cada simulação.

São comparados os CMO's calculados com e sem a incorporação da oferta de redução de carga no modelo computacional, tanto para o cenário conservador quanto para o cenário de referência.

O gráfico 5.2 apresenta os CMO's obtidos com a representação do cenário conservador de adesão ao RVC. Estes CMO's são comparados com os CMO's obtidos do modelo NEWAVE sem a incorporação da RVC. 


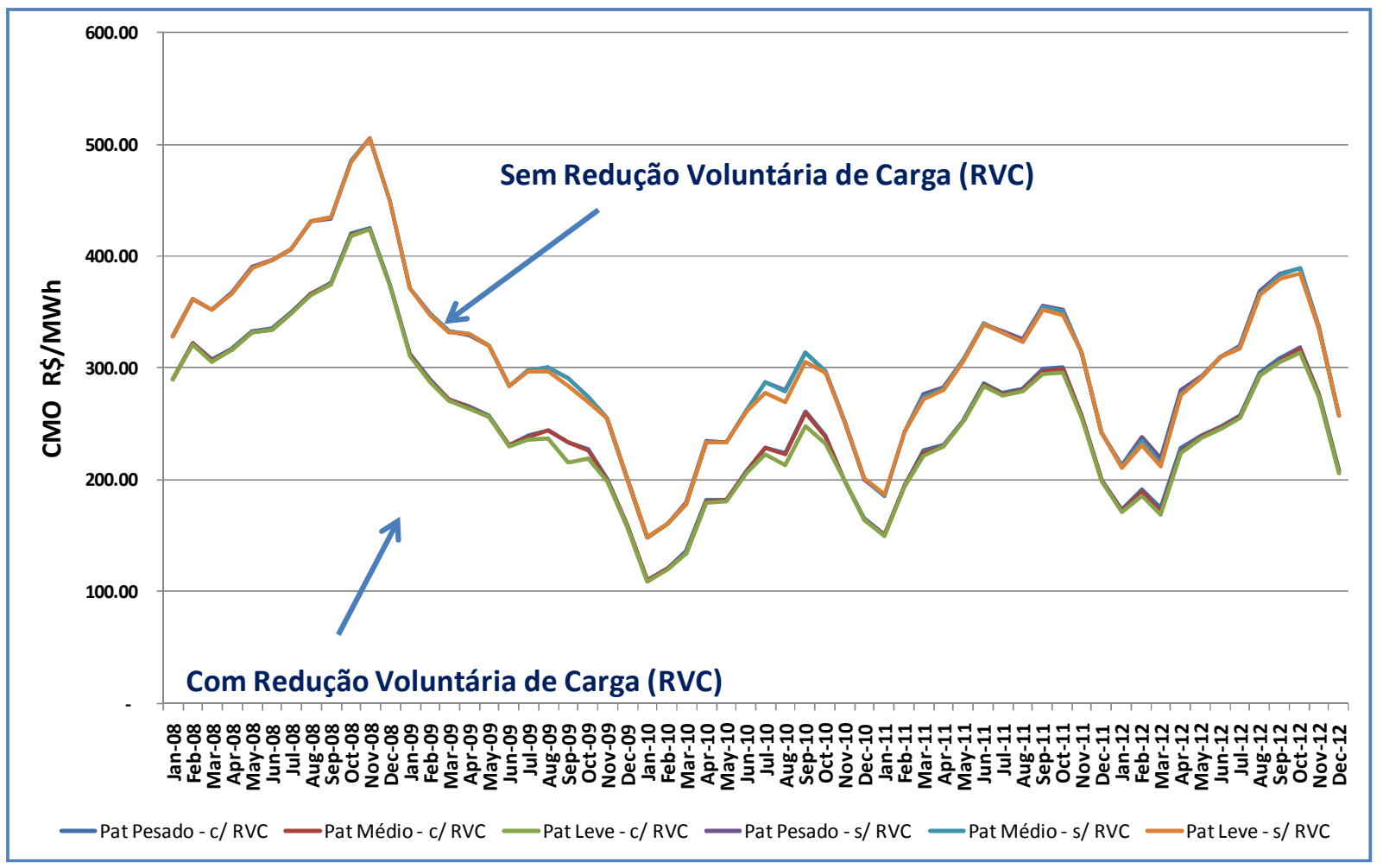

Gráfico 5.2 - Efeitos da introdução da Redução Voluntária de Carga no longo prazo (Cenário conservador - período simulado: janeiro de 2008 a dezembro de 2012)

O gráfico 5.3 apresenta os CMO's obtidos com a representação do cenário de referência de adesão ao RVC. São comparados os CMO's obtidos do modelo NEWAVE com e sem a incorporação da RVC. 


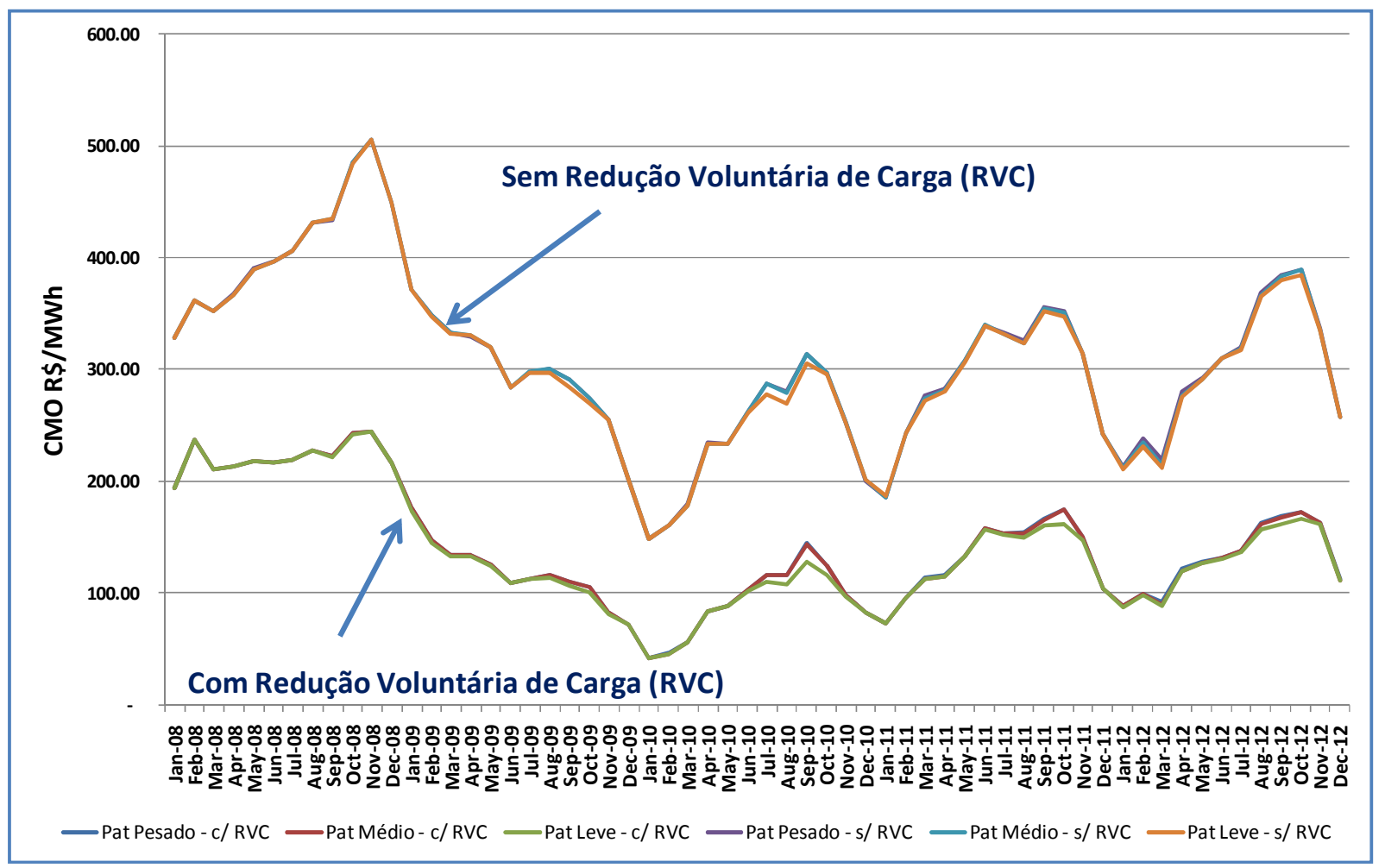

Gráfico 5.3 - Efeitos da introdução da Redução Voluntária de Carga no longo prazo (Cenário de referência - período simulado: janeiro de 2008 a dezembro de 2012)

Observa-se nos gráficos uma importante redução no nível dos CMO,s simulados, quando considerada a Redução Voluntária de Carga. A redução média no CMO em todo o período foi de aproximadamente $\mathrm{R} \$ 54,00 / \mathrm{MWh}$ no cenário conservador e de aproximadamente $R \$ 169,00 R \$ / M W h$ no cenário de referência.

As tabelas 5.2 e 5.3 mostram os valores médios do $\mathrm{CMO}$ obtidos para todo $\mathrm{O}$ período de estudo (cinco anos) e para cada ano, respectivamente. São demonstrados os resultados originais comparados com os resultados dos cenários conservador e de referência. 
Tabela 5.2 - Valores médios de CMO, considerando todo o horizonte de estudo (janeiro de 2008 a dezembro de 2012) ${ }^{22}$

\begin{tabular}{l|ccc}
\hline & $\begin{array}{c}\text { Média do PLD em todo o } \\
\text { horizonte de estudo } \\
\text { (RS/MWh) sem } R V C\end{array}$ & $\begin{array}{c}\text { Média do PLD em todo o } \\
\text { horizonte de estudo } \\
\text { (RS/MWh) com } R V C\end{array}$ & $\begin{array}{c}\text { Média do PLD em todo o } \\
\text { horizonte de estudo } \\
\text { (RȘ/MWh) com RVC }\end{array}$ \\
\hline Patamar Pesado & Cenário Conservador & Cenário de Referência \\
Patamar Médio & 308,85 & 254,34 & 139,50 \\
Patamar Leve & 308,09 & 253,78 & 139,29 \\
\hline
\end{tabular}

Tabela 5.3 - Valores médios anuais dos CMO's simulados, calculados a partir dos valores esperados mensais (média das 2000 séries de cada mês)

\begin{tabular}{l|lllll}
\hline & $\mathbf{2 0 0 8}$ & $\mathbf{2 0 0 9}$ & $\mathbf{2 0 1 0}$ & $\mathbf{2 0 1 1}$ & $\mathbf{2 0 1 2}$ \\
\hline Pat. Pesado - c/ RVC (C. Conservador) & 351,01 & 243,89 & 187,57 & 246,33 & 242,92 \\
Pat. Médio - c/ RVC (C. Conservador) & 350,77 & 243,76 & 187,10 & 245,71 & 241,57 \\
Pat. Leve - c/ RVC (C. Conservador) & 350,68 & 240,71 & 184,39 & 244,58 & 240,62 \\
\hline Pat. Pesado - c/ RVC (C. de Referência) & 222,05 & 119,07 & 92,05 & 132,80 & 131,53 \\
Pat. Médio - c/ RVC (C. de Referência) & 222,04 & 119,00 & 91,90 & 132,59 & 130,91 \\
Pat. Leve - c/ RVC (C. de Referência) & 221,75 & 117,30 & 88,51 & 130,32 & 128,96 \\
\hline Pat. Pesado - s/ RVC & 408,82 & 300,66 & 237,45 & 296,57 & 300,74 \\
Pat. Médio - s/ RVC & 408,39 & 300,39 & 237,11 & 295,60 & 298,97 \\
Pat. Leve - s/ RVC & 408,31 & 298,54 & 234,35 & 294,65 & 297,17 \\
\hline
\end{tabular}

A partir dos histogramas (gráficos 5.4 e 5.5), é possível comparar a distribuição de freqüência dos CMO's gerados pelo NEWAVE, para o período de estudo em questão, com e sem a introdução da RVC, tanto para o cenário conservador quanto para o cenário de referência.

${ }^{22}$ PLD's médios calculados a partir dos valores esperados (média das 2000 séries) de cada mês do horizonte de estudo. 
O gráfico 5.4 apresenta os resultados para o cenário conservador.

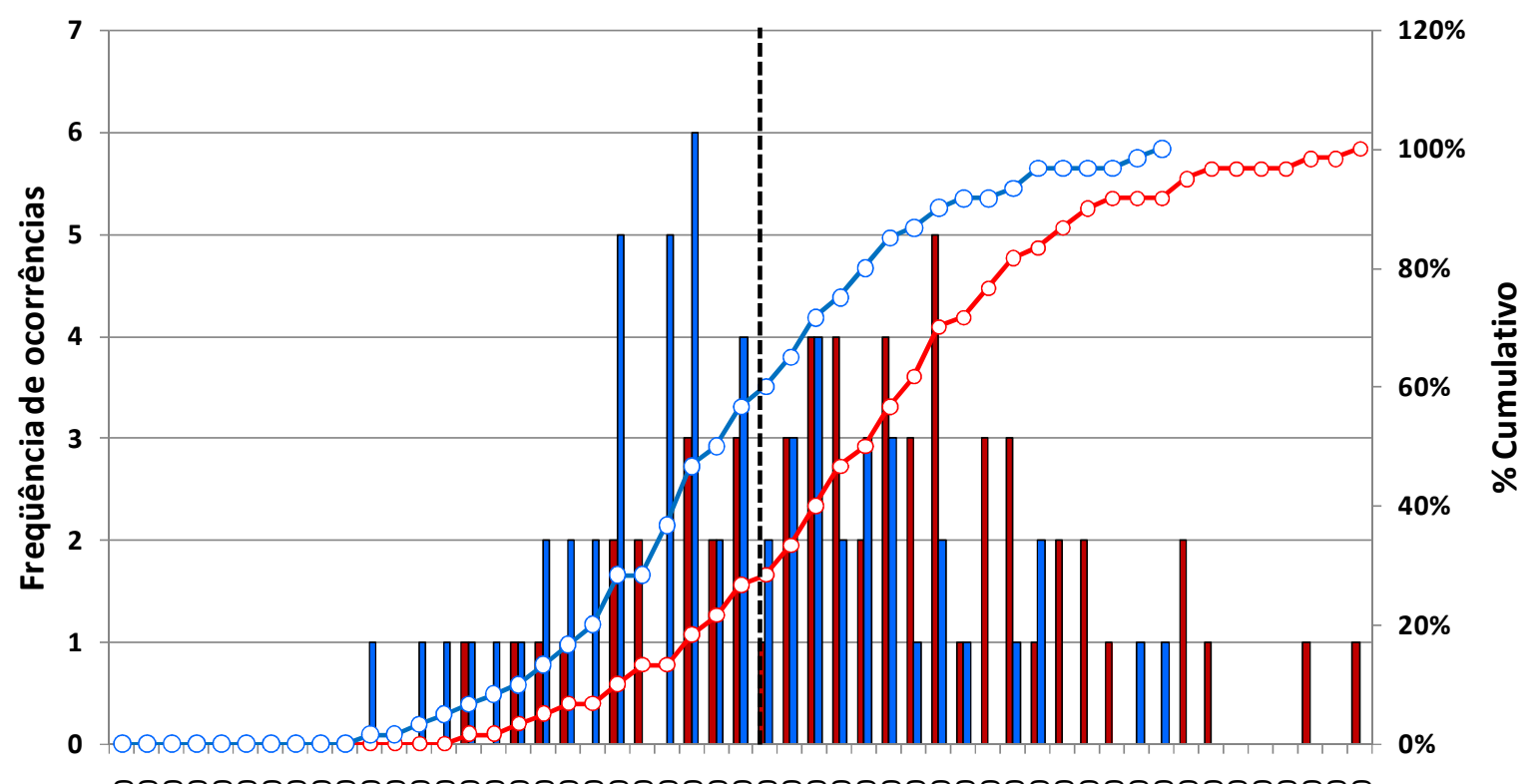

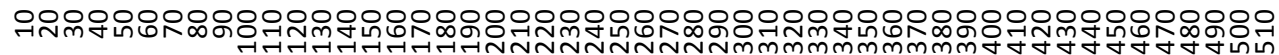

Faixas de Preço R\$/MWh

$\square$ Freqüência Sem RVC $\square$ Freqüência Com RVC $-\infty$ \% cumulativo Sem RVC $-\infty$ \% cumulativo Com RVC

Gráfico 5.4 - Histograma dos CMO's calculados a partir do NEWAVE (com e sem RVC, submercado SE/CO, patamar de carga pesado) - cenário conservador.

É possível observar que a incorporação da RVC reduziu de forma significativa os picos de preços, sendo que o CMO máximo verificado na simulação com RVC foi de $\mathrm{R} \$ 424,67 / \mathrm{MWh}$ no cenário conservador e $\mathrm{R} \$ 244,34 / \mathrm{MWh}$ no cenário de referência, contra $R \$ 505,60$ na versão sem a oferta de redução de carga.

Houve também uma maior concentração de preços em faixas mais baixas, resultado do acionamento da RVC em substituição ao despacho de termelétricas com custos variáveis particularmente elevados. 


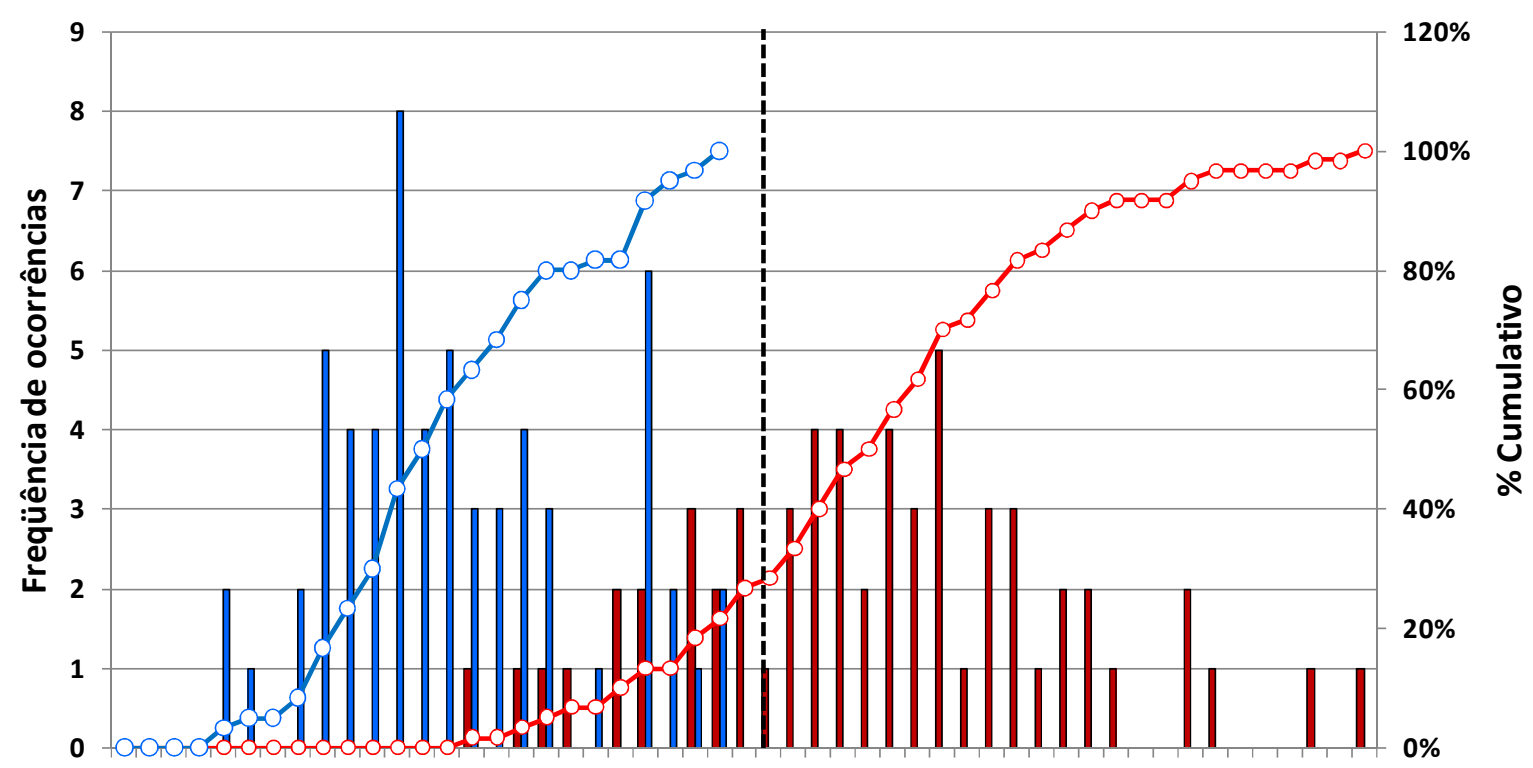

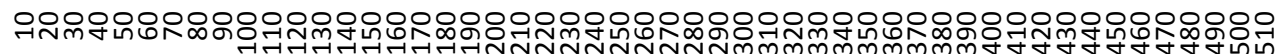

Faixas de Preço R\$/MWh

$\square$ Freqüência Sem RVC $\square$ Freqüência Com RVC - - \% cumulativo Sem RVC - - \% cumulativo Com RVC

Gráfico 5.5 - Histograma dos CMO's calculados a partir do NEWAVE (com e sem RVC, submercado SE/CO, patamar de carga pesado) - cenário de referência.

5.4.1.2. Análise dos resultados - Simulação da RVC no período crítico do Histórico de Vazões

As seqüências hidrológicas menos favoráveis que se tem registro no setor elétrico brasileiro ocorreram no período entre maio de 1951 a novembro de 1956, ciclo conhecido como Período Crítico Histórico da Região Sudeste do Brasil.

Por se tratar de um período extremo de baixa afluência, é importante sua consideração no estudo sobre os efeitos da incorporação da RVC sobre os custos marginais de operação.

A curva do custo do déficit considerada na simulação e vigente durante o ano de 2008 - ano simulado - foi homologada pela Resolução Aneel n 597, de 18 de 
dezembro de 2007. Os valores para os quatro patamares de déficit são apresentados na tabela 5.4 a seguir.

Tabela 5.4: Curva do custo do déficit de energia elétrica (fonte: Res. Homologatória Aneel no 597/2007)

\begin{tabular}{c|c}
\hline Patamares (\% de Redução de Carga $-\mathbf{R C}$ ) & Custo do Déficit (RS $/ \mathbf{M W h}$ ) \\
\hline $\mathbf{0} \%<\mathrm{RC}<\mathbf{5 \%}$ & 944,51 \\
$\mathbf{5 \%}<\mathrm{RC} \leq \mathbf{1 0} \%$ & $2.037,61$ \\
$\mathbf{1 0} \%<\mathrm{RC} \leq \mathbf{2 0} \%$ & $4.257,97$ \\
$\mathbf{R C}>\mathbf{2 0} \%$ & $4.838,69$ \\
\hline
\end{tabular}

O gráfico 5.6 ilustra o resultado das simulações dos custos marginais de operação para o período crítico, com e sem a introdução da RVC (cenário de referência).

Nota-se que, por se tratarem de CMOs - e não PLDs -, os valores encontram-se livres de piso ou teto.

Os resultados expressos no referido gráfico 5.6 apontam a ocorrência de déficit (racionamento) em 24 meses do período crítico para a simulação sem a consideração da oferta de redução de carga, sendo 23 casos até $5 \%$ de déficit e 1 caso entre $5 \%$ e $10 \%$ de déficit.

Depois de introduzida a oferta de redução de carga, conforme metodologia proposta, não houve ocorrência de CMOs iguais ou superiores a nenhum patamar de déficit, implicando que a redução preventiva de carga, para os agentes que aderirem ao mecanismo, pode evitar um racionamento de energia, que de outra forma seria inevitável. 


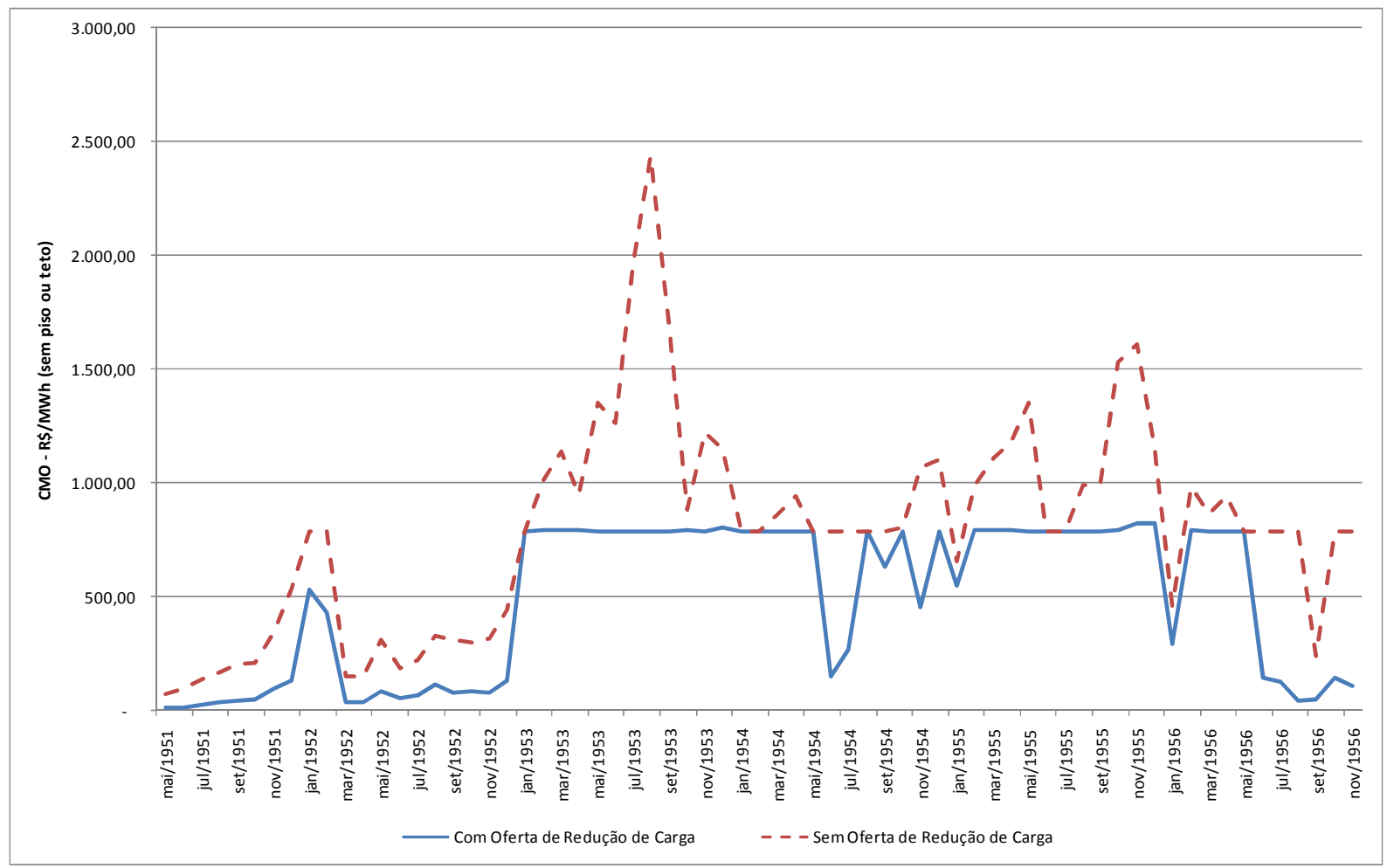

Gráfico 5.6 - Custo Marginal de Operação do Sudeste - série histórica crítica, com e sem RVC - simulação do ano 2008.

Ou seja, na ocorrência de um cenário hidrológico tão desfavorável quanto o ocorrido no período crítico, e dadas as condições de oferta e demanda do ano simulado (2008), a disponibilização da oferta de redução de carga como um recurso adicional para o sistema não só reduziria os patamares dos preços de curto prazo quanto evitaria a ocorrência de déficit de energia elétrica em vinte e quatro meses do período analisado.

A tabela 5.5 ilustra a freqüência de ocorrência de déficits de energia, por patamar de déficit, dentro do período simulado (período crítico). 
Tabela 5.5 - Freqüência de ocorrência de déficits para as séries simuladas (com e sem oferta de redução de carga)

\begin{tabular}{c|ccc}
\hline $\begin{array}{c}\text { Patamares (\% de Redução de } \\
\text { Carga - RC) }\end{array}$ & $\begin{array}{c}\text { Custo do Déficit } \\
\text { (RS/MWh) }\end{array}$ & $\begin{array}{c}\text { Ocorrências de } \\
\text { Déficits por patamar } \\
\text { de RC (Sem ORC) }\end{array}$ & $\begin{array}{c}\text { Ocorrências de } \\
\text { Déficits por patamar } \\
\text { de RC (Com ORC) }\end{array}$ \\
\hline $\mathbf{0 \% < R C < 5 \%}$ & 944,51 & $\mathbf{2 3}$ & 0 \\
$\mathbf{5 \%}<\mathrm{RC} \leq \mathbf{1 0 \%}$ & $2.037,61$ & 1 & 0 \\
$\mathbf{1 0 \%}<\mathrm{RC} \leq \mathbf{2 0} \%$ & $4.257,97$ & 0 & 0 \\
$\mathrm{RC}>\mathbf{2 0} \%$ & $4.838,69$ & 0 & 0 \\
\hline
\end{tabular}

\subsubsection{Cálculo do PLD considerando a Redução de Carga no modelo de curto prazo (DECOMP)}

Esta parte do estudo de caso tem por objetivo avaliar a capacidade de resposta do modelo DECOMP à metodologia proposta de oferta de redução de carga.

A simulação foi realizada sob duas condições. Na primeira, utiliza-se a função de custo futuro gerada pelo modelo NEWAVE sem a incorporação da RVC, ou seja, a oferta de redução de carga, representada pelas usinas termelétricas virtuais, é incluída exclusivamente no modelo DECOMP. O objetivo de se testar esta hipótese é avaliar a resposta do cálculo dos preços da RVC apenas como um recurso conjuntural, no horizonte de curto prazo.

A segunda condição avaliada corresponde à hipótese em que a RVC também seria representada no modelo de longo prazo (NEWAVE). Ou seja, nesse caso, a função de custo futuro que alimenta o DECOMP também foi calculada com a incorporação da RVC.

A tabela 5.6 apresenta os resultados das simulações com o modelo DECOMP para o cenário conservador. 
Tabela 5.6 - Resultados das simulações (PLDs calculados com o modelo DECOMP com e sem a incorporação da RVC - Janeiro/08) - Cenário Conservador

\begin{tabular}{l|ccc}
\hline & $\begin{array}{c}\text { Condição Original } \\
\text { Sem RVC (PLDs } \\
\text { originais) }\end{array}$ & $\begin{array}{c}\text { Condição 1 } \\
\text { RVC somente no } \\
\text { Decomp }\end{array}$ & $\begin{array}{c}\text { Condição 2 } \\
\text { RVC no Newave (FCF) e } \\
\text { no Decomp }\end{array}$ \\
\hline Patamar Pesado & 475,53 & 432,40 & $\mathbf{4 2 1 , 7 1}$ \\
Patamar Médio & 473,30 & 432,40 & $\mathbf{4 2 1 , 7 1}$ \\
Patamar Leve & 472,21 & 432,40 & $\mathbf{4 1 9 , 3 1}$ \\
\hline
\end{tabular}

A tabela 5.7 apresenta os resultados das simulações com o modelo DECOMP para o cenário de referência.

Tabela 5.7 - Resultados das simulações (PLDs calculados com o modelo DECOMP com e sem a incorporação da RVC - Janeiro/08) - Cenário de Referência

\begin{tabular}{l|ccc}
\hline & $\begin{array}{c}\text { Condição Original } \\
\text { Sem RVC (PLDs } \\
\text { originais) }\end{array}$ & $\begin{array}{c}\text { RVC somente no } \\
\text { Decomp }\end{array}$ & $\begin{array}{c}\text { RVC no Newave (FCF) e } \\
\text { no Decomp }\end{array}$ \\
\hline Patamar Pesado & 475,53 & 432,40 & $\mathbf{2 8 5 , 8 3}$ \\
Patamar Médio & 473,30 & 432,40 & $\mathbf{2 8 5 , 8 3}$ \\
Patamar Leve & 472,21 & 432,40 & $\mathbf{2 8 5 , 8 3}$ \\
\hline
\end{tabular}

Com base nos resultados apresentados na tabela 5.5, nota-se que a inclusão da RVC exclusivamente no modelo de curto prazo (DECOMP) não foi suficiente para provocar mudanças significativas no PLD, ao menos quando comparada à variação verificada na segunda condição (com a representação também no modelo de longo prazo). Isso se deve ao fato de que, uma vez que o modelo de formação de preços leva em consideração um período de vários anos, a representação de variações de 
curto prazo tende a ser incapaz de influenciar significativamente os preços calculados.

Esses resultados sugerem que, na implantação da metodologia de oferta de redução de carga na formação do PLD, deve-se levar em consideração a eventual necessidade de comprometimento por parte da carga com horizontes mais extensos, de forma que as reduções voluntárias possam ser representadas não só no modelo de curto prazo (DECOMP) como também no de longo prazo (i.e. na função de custo futuro calculada pelo NEWAVE).

O referido comprometimento poderia ser obtido, por exemplo, no momento da adesão do consumidor ao PRVC, como um pré-requisito do programa.

\subsubsection{Efeitos da Redução Voluntária de Carga sobre a volatilidade do PLD}

\subsubsection{Definição de volatilidade}

A volatilidade é um parâmetro freqüentemente utilizado como forma de mensurar o risco relacionado a um ativo financeiro como uma ação, um índice de bolsa de valores ou ainda os preços de curto prazo em mercados de energia elétrica. Um ativo considerado arriscado é aquele que possui maior chance de perda, enquanto um ativo mais seguro é aquele em que a probabilidade de perda é menor, e este conceito está intrinsecamente relacionado à volatilidade.

Esta variável mostra a intensidade e a freqüência das oscilações dos preços (ou cotações) do ativo considerado.

$\mathrm{Na}$ análise de séries temporais, a volatilidade é utilizada para indicar a incapacidade de prever valores futuros com base em valores históricos. A volatilidade histórica corresponde ao desvio padrão dos logaritmos naturais dos retornos (variação do 
preço entre períodos consecutivos). Seu cálculo consiste em: (i) calcular logaritmo natural de $P_{i} / P_{i-1}$ para cada período, onde $P_{i}$ é o preço no período i e $P_{i-1}$ é o preço no período anterior; (ii) calcular o desvio padrão dos valores calculados no item (i).

5.4.3.2. Análise dos resultados - Efeito sobre a volatilidade nos preços de curto prazo

A fim de avaliar o efeito da incorporação da oferta de redução de carga sobre a volatilidade do PLD, foram comparados os resultados do cálculo da volatilidade histórica dos valores esperados para o CMO no período de janeiro de 2008 a dezembro de 2012, obtidos das simulações com o modelo NEWAVE com e sem a incorporação da RVC.

A tabela 5.8 apresenta os valores esperados para o CMO (média das 2.000 séries sintéticas para cada mês do horizonte de estudo) com e sem a incorporação da oferta de redução de carga (cenário de referência).

Na seqüência, o gráfico 5.7 apresenta as variações percentuais dos preços entre os períodos consecutivos $\left(\mathrm{P}_{\mathrm{i}} / \mathrm{Pi}_{\mathrm{i}-1}-1\right)$. Observa-se uma maior amplitude de variação na série com a redução voluntária de carga.

Nota-se, no cenário considerado, que a introdução da oferta de redução de carga provocou um sensível aumento da volatilidade do PLD. Estes resultados são apresentados na tabela 5.7. 
Tabela 5.8 - CMO's médios por patamar de carga (com e sem a oferta de redução

de carga)

\begin{tabular}{|c|c|c|c|c|c|c|}
\hline \multirow{4}{*}{$\begin{array}{l}\text { jan } / 08 \\
\text { fev/08 }\end{array}$} & \multicolumn{3}{|c|}{ Com RVC } & \multicolumn{3}{|c|}{ Sem RVC } \\
\hline & Pesado & Médio & Leve & Pesado & Médio & Leve \\
\hline & 194,27 & 194,27 & 194,26 & 327,99 & 327,99 & 327,99 \\
\hline & 236,95 & 236,95 & 236,95 & 361,54 & 361,50 & 361,50 \\
\hline $\mathrm{mar} / 08$ & 211,04 & 211,03 & 211,03 & 352,12 & 351,37 & 351,37 \\
\hline $\mathrm{abr} / 08$ & 213,04 & 213,04 & 213,04 & 367,34 & 366,47 & 366,47 \\
\hline $\mathrm{mai} / 08$ & 218,29 & 218,20 & 218,20 & 390,04 & 388,82 & 388,82 \\
\hline jun /08 & 217,22 & 217,19 & 217,19 & 396,29 & 395,69 & 395,69 \\
\hline jul/08 & 218,94 & 218,94 & 218,93 & 405,98 & 405,88 & 405,88 \\
\hline ago/08 & 227,55 & 227,54 & 227,54 & 431,05 & 430,86 & 430,86 \\
\hline set/08 & 222,72 & 222,72 & 221,03 & 434,12 & 434,11 & 433,95 \\
\hline out $/ 08$ & 243,30 & 243,30 & 241,90 & 484,70 & 484,28 & 483,41 \\
\hline nov/08 & 244,34 & 244,34 & 244,34 & 505,60 & 505,09 & 505,09 \\
\hline dez/08 & 216,99 & 216,99 & 216,56 & 449,13 & 448,64 & 448,64 \\
\hline jan/09 & 175,57 & 175,56 & 173,47 & 371,68 & 371,34 & 370,72 \\
\hline fev/09 & 147,61 & 147,28 & 145,44 & 349,16 & 348,05 & 346,71 \\
\hline $\mathrm{mar} / 09$ & 134,54 & 134,29 & 133,48 & 333,25 & 332,54 & 331,37 \\
\hline abr/09 & 134,29 & 134,17 & 132,99 & 330,04 & 329,95 & 329,78 \\
\hline $\mathrm{mai} / 09$ & 126,28 & 126,27 & 125,28 & 319,84 & 319,67 & 319,49 \\
\hline jun/09 & 109,23 & 109,20 & 108,67 & 283,86 & 283,82 & 283,22 \\
\hline jul/09 & 112,77 & 112,73 & 112,38 & 297,67 & 297,61 & 296,27 \\
\hline ago/09 & 116,92 & 116,88 & 114,40 & 300,77 & 300,59 & 296,85 \\
\hline set/09. & 110,91 & 110,90 & 106,78 & 290,85 & 290,79 & 283,05 \\
\hline out/09 & 105,92 & 105,91 & 100,85 & 274,33 & 274,21 & 269,35 \\
\hline nov/09 & 82,54 & 82,52 & 81,89 & 255,47 & 255,14 & 254,78 \\
\hline dez/09 & 72,26 & 72,25 & 71,96 & 200,99 & 200,95 & 200,92 \\
\hline $\mathrm{jan} / 10$ & 42,20 & 42,16 & 42,12 & 148,51 & 148,40 & 148,24 \\
\hline fe $v / 10$ & 46,59 & 46,30 & 46,25 & 160,76 & 160,33 & 159,92 \\
\hline $\mathrm{mar} / 10$ & 56,52 & 56,33 & 56,27 & 179,11 & 178,08 & 177,84 \\
\hline $\mathrm{abr} / 10$ & 84,04 & 83,95 & 83,90 & 234,63 & 233,82 & 233,66 \\
\hline $\mathrm{mai} / 10$ & 88,45 & 88,38 & 88,30 & 233,17 & 232,92 & 232,83 \\
\hline jun $/ 10$ & 103,12 & 103,09 & 101,75 & 261,91 & 261,88 & 260,57 \\
\hline jul/10 & 116,17 & 116,08 & 110,66 & 287,70 & 287,60 & 277,42 \\
\hline ago/10 & 116,47 & 116,30 & 107,74 & 279,87 & 279,39 & 269,21 \\
\hline set $/ 10$ & 144,88 & 144,41 & 128,83 & 313,82 & 313,20 & 304,56 \\
\hline out $/ 10$ & 124,87 & 124,61 & 115,96 & 296,90 & 296,74 & 295,26 \\
\hline nov/10 & 98,00 & 97,93 & 97,07 & 252,46 & 252,43 & 252,13 \\
\hline dez/10 & 83,29 & 83,26 & 83,26 & 200,60 & 200,56 & 200,56 \\
\hline jan/11 & 73,31 & 73,30 & 73,27 & 186,09 & 186,08 & 186,04 \\
\hline fev/11 & 96,58 & 96,34 & 96,12 & 243,40 & 242,76 & 242,48 \\
\hline $\mathrm{mar} / 11$ & 113,54 & 113,20 & 112,91 & 276,87 & 273,78 & 271,52 \\
\hline$a b r / 11$ & 115,92 & 115,70 & 115,59 & 283,04 & 281,01 & 280,37 \\
\hline $\mathrm{mai} / \mathbf{1 1}$ & 133,16 & 133,01 & 132,57 & 308,22 & 307,32 & 306,80 \\
\hline jun /11 & 158,69 & 158,66 & 157,33 & 339,54 & 339,46 & 338,38 \\
\hline jul/11 & 153,32 & 153,21 & 151,86 & 332,59 & 332,07 & 331,75 \\
\hline ago/11 & 154,42 & 153,77 & 149,89 & 325,34 & 323,41 & 322,67 \\
\hline set/11 & 166,27 & 165,91 & 161,07 & 355,22 & 354,02 & 352,27 \\
\hline out/11 & 174,65 & 174,38 & 162,31 & 351,72 & 350,91 & 347,41 \\
\hline nov/11 & 149,74 & 149,65 & 146,89 & 314,37 & 314,15 & 314,09 \\
\hline dez/11 & 104,03 & 103,98 & 103,97 & 242,46 & 242,21 & 242,08 \\
\hline jan/12 & 88,43 & 88,30 & 87,91 & 212,84 & 212,18 & 210,82 \\
\hline fev/12 & 99,97 & 99,22 & 98,00 & 237,80 & 234,37 & 230,99 \\
\hline
\end{tabular}




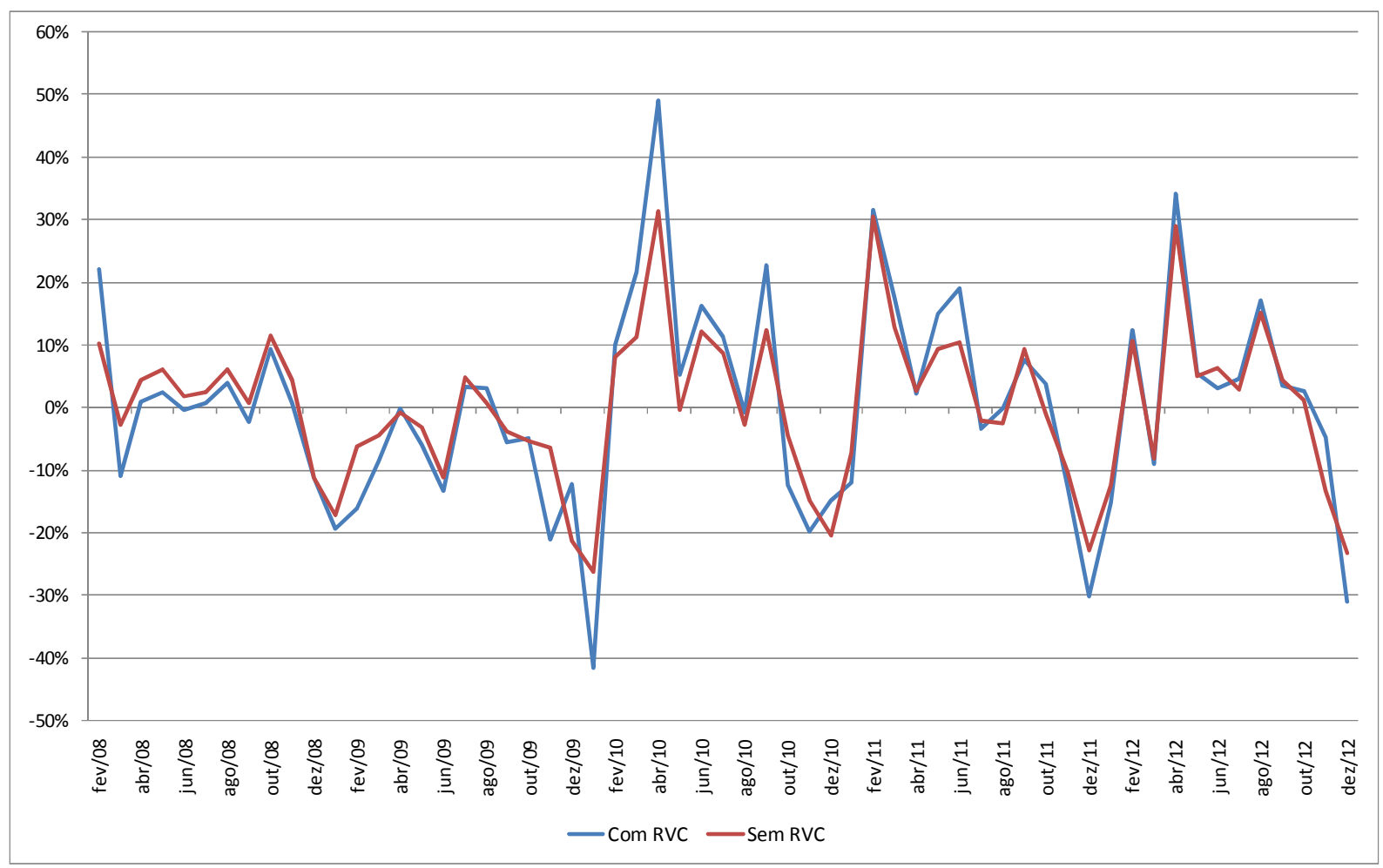

Gráfico 5.7 - Variação percentual do PLD entre períodos consecutivos (com e sem a introdução da oferta de redução de carga).

Tabela 5.9 - Volatilidade do PLD para as séries simuladas com e sem a introdução da RVC.

\begin{tabular}{lcc}
\hline & $\begin{array}{c}\text { Volatilidade } \\
\text { sem } R V C\end{array}$ & $\begin{array}{c}\text { Volatilidade } \\
\text { com } R \text { RVC }\end{array}$ \\
Cenário de Referência \\
\hline Patamar Pesado & $12 \%$ & $\mathbf{1 7 \%}$ \\
Pat Médio & $12 \%$ & $17 \%$ \\
Pat Leve & $12 \%$ & $16 \%$ \\
\hline
\end{tabular}

Cabe ressaltar que, embora tenha provocado um aumento da volatilidade do PLD sob a ótica da variabilidade percentual do preço -, a introdução da oferta de redução de carga reduziu sensivelmente a amplitude das variações em $\mathrm{R} \$ \mathrm{MWh}$ (gráfico 5.8), o que se traduz em menor risco de preço para os agentes. 


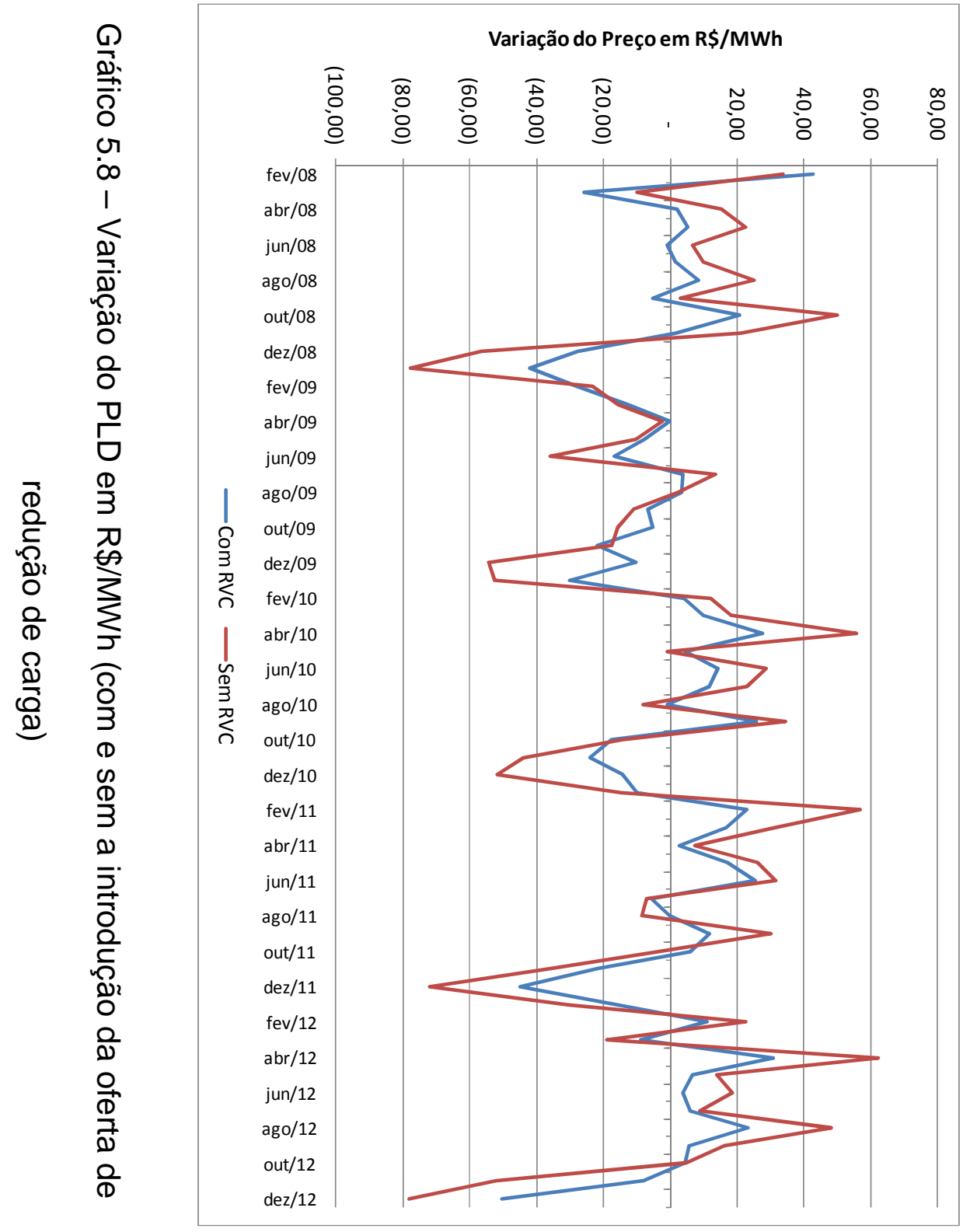

$\vec{\circ}$ 


\section{CONCLUSÕES E TRABALHOS FUTUROS}

\subsection{CONCLUSÕES}

Este trabalho teve como tema central a análise dos efeitos da resposta da demanda aos preços de curto prazo em mercados de energia elétrica.

O reconhecimento no desenho de mercados da importância da reação da demanda aos preços é de fundamental importância para que sejam introduzidos mecanismos que incentivem os consumidores a modificarem seus padrões de consumo em função das condições de mercado (i.e. disponibilidade de recursos).

Ao longo deste trabalho, foram enumerados vários benefícios que a resposta da demanda pode agregar aos mercados de energia elétrica, tais como, (i) a mitigação de poder de mercado por parte dos agentes geradores; (ii) a redução da volatilidade dos preços de curto prazo; (iii) o aumento da confiabilidade do suprimento e, principalmente, (iv) o melhor aproveitamento dos recursos produtivos.

Muitos mercados de energia elétrica estrangeiros já adotam variados tipos de programas de incentivo à resposta da demanda, tendo sido observados importantes resultados, sobretudo em mercados com parque gerador predominantemente termelétrico, nos quais a redução de carga em função dos preços promove diminuição direta da necessidade de investimento em capacidade nova, exclusiva para $o$ atendimento de picos de demanda.

Nos mercados com predominância hidrelétrica, como o caso brasileiro, a reação da demanda toma importância no que diz respeito à mitigação da insuficiência de oferta de energia - por exemplo, em situações em que o nível dos reservatórios se 
encontra abaixo do necessário para ao atendimento da carga - e não de capacidade, como em sistemas térmicos.

Ao analisar a experiência internacional, nota-se que os mercados de energia elétrica maduros, de uma forma geral, adotam algum tipo de programa de incentivo à resposta da demanda. Muitos deles motivados pela predominância termelétrica de suas matrizes, o que torna a reação da demanda crucial para que se evite o acionamento de usinas caras, especificamente em períodos de pico de carga.

Com relação aos diversos mecanismos de resposta da demanda analisados na experiência internacional, é possível identificar soluções viáveis, relativamente simples e com resultados positivos.

Em sistemas com forte componente hidrelétrica como o brasileiro, os déficits de oferta estão normalmente associados à insuficiência de energia, e não de capacidade, o que torna abordagem do problema relativamente diferente.

Os resultados obtidos nas simulações realizadas levam à conclusão de que a implementação da metodologia de oferta de redução de carga aqui proposta, denominada Programa de Redução Voluntária de Carga (RVC), poderia contribuir para a redução tanto de picos de preços, uma vez que o acionamento de termelétricas de custos variáveis elevados seria evitado. Este último aspecto é traduzido como um melhor aproveitamento dos recursos de produção, o que se reflete também em maior segurança para o sistema, reduzindo o risco de racionamento e da necessidade de investimento em expansão da oferta. 


\subsection{TRABALHOS FUTUROS}

Considerando a importância da participação da demanda na formação dos preços de curto prazo e levando em conta os benefícios que pode trazer para o mercado de energia elétrica, sugere-se para trabalhos futuros 0 aprofundamento das investigações levadas a termo nessa oportunidade, contemplando também a possibilidade de aprimoramento da metodologia de incorporação da resposta de demanda ao modelo de formação de preços adotado no Brasil, de forma a promover o aumento de eficiência do mercado e beneficiando a sociedade com maior segurança de abastecimento e menor necessidade de investimento na expansão da oferta.

Uma investigação acerca dos volumes disponíveis de redução de carga entre os diversos setores da economia, bem como dos respectivos preços a partir dos quais os consumidores estariam dispostos a reduzir carga, contribuiria sobremaneira para o aprimoramento do estudo.

Nesse sentido, uma abordagem baseada na analise da matriz insumo-produto pode fornecer informações importantes sobre o custo da energia não suprida para cada setor da economia, o que poderia indicar a disponibilidade marginal dos consumidores em reduzir carga ou o quanto estariam dispostos a pagar para evitarem a interrupção do consumo. Esta metodologia é base para o cálculo do custo do déficit atualmente utilizado no setor elétrico e merece ser investigada em trabalhos futuros que abordem a questão da resposta da demanda aos preços de energia elétrica.

Outra abordagem à estimativa do potencial de resposta da demanda aos preços de curto prazo seria o desenvolvimento de pesquisa junto a grandes consumidores, em 
que poderiam ser identificados diversos níveis de disposição de oferta de redução, em $\mathrm{R} \$ / \mathrm{MWh}$, de acordo com a característica de cada consumidor e setor de da economia.

Dada sua representatividade no consumo total, o ambiente regulado (mercado cativo) também deve ser considerado em estudos que busquem o aumento da resposta da demanda aos preços de curto prazo. Mecanismos que possibilitem a transmissão imediata do sinal econômico do PLD a uma parte específica do ambiente regulado pode ser de grande importância para o mercado de energia elétrica, evitando o uso ineficiente dos recursos - aumento do consumo em períodos em que os preços do mercado de curto prazo encontram-se elevados e vice-versa. Ressalta-se que, nesse ambiente (regulado), pode-se também considerar a participação de inúmeros consumidores que disponibilizariam geração própria (backup) em substituição à redução de carga.

Por fim, cabe ainda a realização de levantamento das possíveis mudanças regulatórias que seriam necessárias para a adoção dos mecanismos de resposta da demanda propostos neste trabalho. 


\section{REFERÊNCIAS BIBLIOGRÁFICAS}

AGÊNCIA NACIONAL DE ENERGIA ELÉTRICA. Nota Técnica ㄲo 118/2003. Regulamentação da curva do Custo do Déficit de energia elétrica e do limite máximo do preço de mercado de curto prazo. Brasília, nov. 2003.

ANDERSEN, F. M. et al. Analyses of Demand Response in Denmark. Denmark: Riso National Laboratory, 2006.

ARAÚJO, J. L. Modelos de formação de preços na regulação de monopólios. Econômica, v.3, n.1., p. 35-66, 2001.

BARROSO, L. A., et. al. Classification of electricity market models worldwide. CIGRÉ, paper 102, 2005. Disponível em: < http://www.cigre-c5.org/Site/Publications /download/2005\%20San\% 20Antonio\%20-\%20TF\%20C5-2\%201ID45VER59.pdf>. Acesso em: 21 de janeiro de 2009.

BERKELEY LAB. Demand response program design preferences of large customers: focus group from four states. Jun. 2006. Disponível em:

$<$ http://eetd.lbl.gov/ea/EMS/reports/ 60610.pdf>. Acesso em: 20 de mar. 2009.

BERKELEY LAB. Estimating demand response market potential among large commercial and industrial customers: a scoping study. Jan. 2007. Disponível em: $<$ http://eetd.lbl.gov/ea/emp/ reports/61498.pdf>. Acesso em 20 de mar. 2009.

BJORNER, T. B., et. al. Industrial companies demand for electricity: evidence from a micropanel. Energy Economics. 2001.

BORENSTEIN, S. The long-run efficiency of real-time electricity pricing. Center for the Study of Energy Markets. Paper CSEMWP-133R, 2005. Disponível em: $<$ http://repositories.cdlib.org/ucei/csem/CSEMWP-133R $>$. Acesso em 15 de agosto de 2008.

CARELLI, E. Análise de práticas anticompetitivas por meio do método de Cournot na geração de energia elétrica no Brasil: período 1998 a 2005. 114 p. Tese (Doutorado) - Universidade Federal de Santa Catarina, Florianópolis, 2005.

CAVALCANTI, R. Avaliação do comportamento estratégico de geradores hidrelétricos em sistemas hidrotérmicos. 160 p. Tese (Doutorado) - Universidade Federal de Santa Catarina, Florianópolis, 2006. 
COMITÊ DE REVITALIZAÇÃO DO MODELO DO SETOR ELÉTRICO. Relatório de Progresso no 2. 2002.

COOPERS\&LYBRAND. Etapa VII - Projeto de Reestruturação do Setor Elétrico Brasileiro: relatório Consolidado Etapa. v. 2, 1997.

DAVID, P. A. et. al. Contratação e Aversão ao Risco no Despacho Competitivo da Geração. XVII SNPTE, out. 2003.

DECKER, I. C. et. al. Identificação da Viabilidade Prática de Modelos Loose-Pool em Sistemas Hidrotérmicos. In: II Citenel - Congresso de Inovação Tecnológica em Energia Elétrica, 2003, Salvador. Anais do II Citenel, Vols. I e II, 2003. v. II. p. 679-687.

ENERGY AND ENVIRONMENTAL ECONOMICS, INC. A survey of Time-of-Use (TOU) pricing and demand-response (DR) programs. San Francisco, CA, nov. 2006.

ESCRIBANO, Á.; PEÑA, J. I.; VILLAPLANA, P. Modeling electricity prices: international evidence. Madrid, jun. 2002. Disponível em: <http://docubib.uc3m.es/ WORKINGPAPERS/WE/we022708. pdf>. Acesso em: 3 de fev. 2008.

EVANS, J.; GREEN, R. Why did British electricity prices fall after 1998? 2005. Disponível em: < ftp://ftp.bham.ac.uk/pub/RePEc/pdf/2005netaprices.pdf>. Acesso em: 10 de fev. 2008.

HEFFNER, G. C.; GOLDMAN, C. A. Demand responsive programs: an emerging resource for competitive electricity markets? Jun. 2001. Disponível em: < http://repositories.cdlib.org/lbnl/ LBNL-48374/>. Acesso em: 5 de jan. 2009.

HULL, J. Introdução aos mercados futuros e de opções. Prentice Hall. 2005.

HUNT, S. Making competition work in electricity. Nova York: Wiley. 2002.

INDEPENDET ELECTRICITY SYSTEM OPERATOR. Apresenta informações sobre o programa de resposta da demanda implementado em Ontário, CA. Disponível em: $<$ http://www.theimo. com/imoweb/marketsAndPrograms/demandResponse3.asp $>$. Acesso em: 10 de nov. 2007.

INSTITUTO BRASILEIRO DE AVALIAÇÕES E PERÍCIAS DE ENGENHARIA. Apresenta recursos e atividades desenvolvidas. Disponível em: < http://www.ibapepb.jpa.com.br/glossario.htm>. Acesso em: 16 de jul. 2008. 
JANNUZZI, G. d.; SWISHER, J. N. Planejamento integrado de recursos energéticos. Autores Associados. 1997.

KNOOW NET. Apresentauma enciclopédia sobre ciências econômicas e empresariais. Disponível em: < http://www.knoow.net/cienceconempr/cee.htm>. Acesso em: 16 de ago. de 2009.

LAFFERTY, R. et. al. Demand responsiveness in electricity markets. Jan. 2001. Disponivel em: <http://www.naseo.org/committees/energyproduction/documents/ demand responsiveness in electricity markets.pdf $>$. Acesso em: 27 ago. 2008.

MATTOS, L. B. Uma estimativa da demanda industrial de energia elétrica: 19742002. Out. 2004. Disponível em: <http://ageconsearch.umn.edu/bitstream/43986/2/ Artigo\%2010\% 20(04.124).pdf>. Acesso em: 15 de jun. 2009.

NEW ZEALAND. Electricity Commission. Issues Paper. Survey of Market Performance. New Zeland, 2007.

NORTH AMERICAN ENERGY STANDARDS BOARD. Demand response discussion for the 2007 long-term reliability assessment. Fev. 2007. Disponível em: < http://www.naesb.org/pdf2/ dsmee052407w4.pdf >. Acesso em: 02 de jun. de 2009.

OLIVEIRA, A. M. Estratégia ótima de oferta de preços no mercado de curto prazo em sistemas com predominância hidrelétrica. 2003. Tese (Doutorado) Pontifícia Universidade Católica do Rio de Janeiro, Rio de Janeiro, 2003.

PATRICK, R. H.; WOLAK, F. A. Using customer demands under spot market prices for service design and analysis. Jun. 2001. Disponível em: <http://www.rci. rutgers.edu/ rpatrick/ EPRIr01.pdf>. Acesso em: 03 de set. 2008.

PINDICK, R. S.; RUBINFELD, D. L. Microeconomia. São Paulo: Pearson Prentice Hall. 2005.

PJM INTERCONECTION. Apresenta informações sobre a operação do mercado do PJM. Disponível em: <www.pjm.com>. Acesso em: 03 de dez. 2009.

ROWLANDS, I. H. Demand response in Ontario: exploring the issues. Toronto, CA, ago. 2008. (A report prepared for the Independent Electricity System Operator IESO). Disponível em: <http://www.ieso.ca/imoweb/pubs/marketreports/omo/2009/ demand response.pdf $>$. Acesso em: 20 de jan. 2009. 
SANTOS, P. E. Tarifa de distribuição para unidades consumidoras e microgeração considerando a elasticidade-preço das cargas. 2008. Tese (Doutorado) - Universidade Federal de Itajubá, Itajubá, 2008.

SIDDIQUI, A. S. Price-Elastic Demand in Deregulated Electricity Markets.

Lawrence Berkeley National Laboratory. Paper LBNL-51533. Bekeley, mai. 2003.

SILK, J. I.; JOUTZ, F. L. Short and long-run elasticities in US residential electricity demand: a co-integration approach. Energy Economics. 1997.

SILVA, E. L. Formação de Preços em Mercados de Energia Elétrica. Porto Alegre: Sagra Luzzato, 2001

STOFT, S. Power System Economics. (s.n.): Wiley. 2002.

THE BRATTLE GROUP. Load Management Informational and rulemaking proceeding. Disponível em: <http://www.energy.ca.gov/load management/ documents/2008-06-10 workshop/presentations/4(\%20A.Faruqui)\%20\%20Demand\%20Response A\%20Long\%20 View\%20(06-03-08).pdf>. Acesso em: 02 de jun. 2009.

THE BRATTLE GROUP. Quantifying the benefits of dynamic pricing in the mass market. jan. 2008a. Disponível em: <http://www.edisonfoundation.net/iee/ reports/QuantifyingBenefitsDynamicPricing.pdf>. Acesso em junho de 2009.

THE BRATTLE GROUP. Demand-side bidding in wholesale electricity markets. Jun. 2008b. Disponível em:<http://www.brattle.com/ documents/UploadLibrary/ Upload732.pdf>. Acesso em dezembro de 2009.

TIPPING, J. P. The analysis of spot price stochasticity in deregulated wholesale electricity markets. 2007. Tese (PhD) - University of Canterbury, New Zealand, mar. 2007.

U.S.A. Federal Energy Regulatory Commission. Federal Energy Regulatory Commission - Glossary. 2008. Disponível em: < http://www.ferc.gov/industries/ electric/indus-act/demand-response/2008/survey/glossary.pdf>. Acesso em: 21 de ago. 2008.

U.S.A. U. S. Department of Energy. A report to the United States Congress pursuant to Section 1252 of The Energy Policy Act of 2005. Benefits of demand response in electricity markets and recommendations for achieving them. U.S.A., fev. 2006. 
Disponível em: < http://eetd.lbl.gov/ea/EMP/reports/congress-1252d.pdf >. Acesso em: 12 de nov. 2008.

VINHAES, E. A. Estrutura de governança e comportamento estratégico em sistemas elétricos reestruturados: uma abordagem institucional do poder de mercado na indústria de energia elétrica brasileira. 2003. Tese (Doutorado) Universidade Federal de Santa Catarina, Florianópolis, Santa Catarina. Fev. 2003.

VON DER FEHR, N. H; WOLAK, F. A. Power sector reforms in Brazil: some issues. Jan. 2003. Disponível em: <ftp://zia.stanford.edu/pub/papers/ vonderfehrwolak.pdf >. Acesso em: 15 de mai. 2008.

WOLAK, F. A. An empirical analysis of the impact of hedge contracts on bidding behavior in a competitive electricity market. Mar. 1999a. Disponível em: $<$ http://faculty-gsb.stanford.edu/wilson/archive/E542/classfiles/Wolak Hedges Australia.pdf>. Acesso em 10 de nov. 2007.

WOLAK, F. A. Market design and price behavior in restructured electricity markets: an international comparison. 1999b. Disponível em: <ftp://zia.stanford. edu/pub/papers/taiwan. pdf>. Acesso em: 24 de out. 2008.

WOLAK, F. A., PATRICK, R. H. The Impact of Market Rules and Market Structure on the Price Determination Process in the England and Wales Electricity Market. 1997. Disponível em: < http://www.ucei.berkeley.edu/ucei/PDF/pwp047.pdf >. Acesso em: 10 de jan. 2008. 


\section{GLOSSÁRIO}

Custo de oportunidade - Custo associado às oportunidades perdidas por não alocar os recursos da empresa na melhor alternativa de uso

Custo marginal - Ou custo incremental, é o aumento de custo ocasionado pela produção de uma unidade adicional de produto.

Custo marginal de expansão - Ou custo marginal de longo prazo, é o custo de atendimento ao diferencial de carga considerando obras adicionais no sistema.

Day-ahead market - Mercado do dia seguinte (mercados de energia elétrica).

Demanda residual - Participação do produtor no atendimento da demanda total.

Excedente do consumidor - Diferença entre o montante que o consumidor estaria disposto a pagar por determinada quantidade de um bem e o montante que efetivamente paga.

Excedente do produtor - Diferença entre o preço que o produtor recebe e o custo de produção por unidade.

Hedge - Instrumento que visa proteger operações financeiras contra o risco de grandes variações de preço de determinado ativo

Lucro variável - Soma dos lucros de cada unidade adicional produzida por uma empresa, isto é, o lucro descontado o custo fixo.

Mercado cativo - Mercado em que o consumidor (cativo) adquire energia elétrica diretamente com a distribuidora local, com tarifa regulada.

Mercado de Curto Prazo (MCP) - Segmento onde são comercializadas as diferenças entre os montantes de energia elétrica contratados e registrados pelos agentes e os montantes de geração ou consumo efetivamente verificados e atribuídos aos respectivos agentes.

Mercado livre - Mercado em que o consumidor negocia livremente a compra de energia elétrica diretamente com o(s) produtor(es) ou comercializador(es).

Patamar de carga - Classificação das horas do mês, de acordo com o perfil de carga definido pelo Operador Nacional do Sistema Elétrico - ONS, podendo ser: leve (horários de baixo consumo), médio (horários de consumo médio) ou pesado (horários em que se verificam picos de consumo). 
Poder de mercado - Capacidade tanto do vendedor quanto do comprador de influenciar o preço de uma mercadoria.

Preço de curto prazo - Preço pelo qual é valorada a energia comercializada no Mercado de Curto Prazo.

Preço spot - Preço de curto prazo.

Price maker (formador de preço) - Firma com capacidade de influenciar o preço por meio da modificação de sua produção.

Price taker (tomador de preço) - Firma sem capacidade de influenciar o preço por meio da modificação de sua produção.

Real-time market - Mercado em tempo real (mercados de energia elétrica), onde são transacionadas as diferenças entre os volumes ofertados no day-ahead market e a operação real do sistema.

Receita marginal - Variação na receita resultante do aumento da produção em uma unidade. 


\section{APÊNDICE A - REDUÇÃO DO ACOPLAMENTO ENTRE DESPACHO FÍSICO E FORMAÇÃO DE PREÇOS - A PROPOSTA DO COMITÊ DE REVITALIZAÇÃO}

O Comitê de Revitalização do Setor Elétrico foi instituído pela Resolução № 18, de 22 de junho de 2001, da Câmara de Gestão da Crise de Energia - GCE, com o objetivo de propor medidas corretivas para as deficiências do modelo do setor elétrico então em vigor. A premissa básica para os trabalhos desenvolvidos no âmbito do Comitê de Revitalização é que as soluções deveriam preservar os pilares básicos de funcionamento do modelo do setor, ou seja:

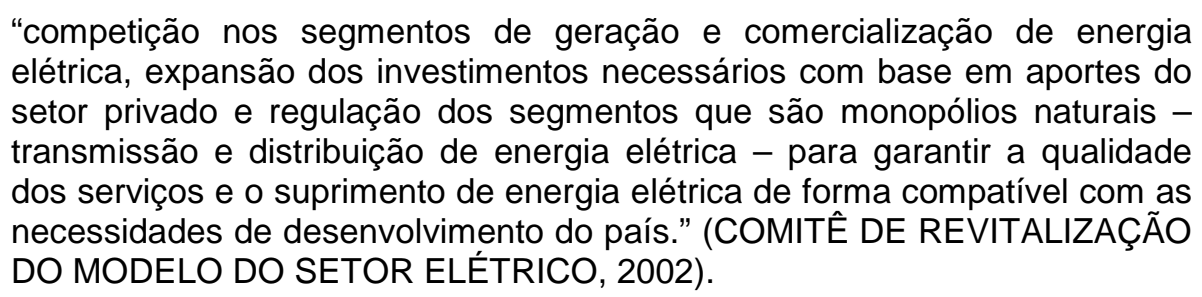

Um dos temas abordados pelo Comitê diz respeito à verificação quanto à viabilidade de se substituir o processo de uso do custo marginal de operação como variável proxy $^{23}$ dos preços por um mecanismo de oferta de quantidade e preços mais aderente aos fundamentos de mercado. Neste sentido, o Comitê propôs um esquema de oferta de preços o qual se baseia no desacoplamento entre o despacho comercial (onde os agentes exprimem suas disposições a produzir ao operador do mercado) e o despacho físico (onde o operador do sistema elétrico realiza a operação ótima dos reservatórios).

23 Variável proxy: Variável utilizada para substituir outra de difícil mensuração e que se presume guardar com ela relação de pertinência. 
Este desacoplamento seria possibilitado por meio da criação de uma Conta de Direitos de Enegia (CDE) para cada gerador hidrelétrico do sistema, a qual o agente gerenciaria em função de suas expectativas em relação aos riscos e oportunidades.

Uma CDE seria equivalente a uma parte, em MW médios, da energia armazenada nos reservatórios do sistema, sendo que em cada estágio o somatório das CDE's de todos os geradores deve ser igual à energia fisicamente armazenada no sistema.

Para cada estágio, a energia afluente do sistema (controlável e não-controlável) é repartida para os geradores hidrelétricos, proporcionalmente às suas energias asseguradas, creditando-se as parcelas em suas respectivas contas, em procedimento análogo à distribuição de direitos do Mecanismo de Realocação de Energia (MRE) atualmente existente.

Limitando-se ao saldo da CDE em cada submercado, cada gerador hidrelétrico informaria pares quantidade-preço para cada submercado, sendo que a parcela referente à energia não controlável (fio d'água) seria automaticamente ofertada pela Tarifa de Energia de Otimização - TEO e os créditos associados à energia controlável seriam ofertados de acordo com a estratégia do gerador (OLIVEIRA, 2003).

Os agentes de geração termelétricos também ofertariam pares quantidade-preço, limitando-se às suas respectivas capacidades de produção.

O despacho comercial e a formação do preço seriam realizados a partir do empilhamento das ofertas individuais dos agentes, em ordem crescente de preço ofertado e não a partir de custos marginais calculados centralizadamente. O preço de liquidação do mercado seria definido pelo preço de equilíbrio, ou seja, pela 
interseção da curva de oferta informada pelos geradores com curva de demanda, considerada inelástica e determinística (DECKER ET AL., 2003). Desta forma, o preço de liquidação seria equivalente ao preço ofertado do último recurso necessário para o atendimento da demanda.

No despacho físico, a otimização do sistema continuaria sendo resolvida por modelos computacionais. Todavia a curva de oferta dos agentes elaborada nas etapas anteriores seria utilizada como função de custo futuro, independente das afluências recentes. Estas não necessitariam ser consideradas na função de custo futuro, pois a tendência hidrológica já teria sido internalizada pelos agentes na formulação de suas ofertas de preço. Assim, a otimização seria realizada para um único estágio, e não mais para vários, como atualmente.

Ressalta-se que o objetivo da utilização de vários estágios é exatamente o de se obter a função de custo futuro, que será utilizada como base para as decisões de despacho do primeiro estágio.

Preservando o limite global de produção hidrelétrica informado pelos agentes - na função custo futuro -, respeitando o balanço oferta/demanda, o princípio de conservação da massa e a otimização da operação das usinas hidrelétricas em cascata, e ainda levando em conta os limites de transmissão e demais aspectos do sistema possíveis de serem representadas nos modelos, o operador realiza 0 despacho físico do sistema.

Quanto à remuneração dos geradores, cabe ressaltar que esta se daria pelo despacho comercial. Portanto, o volume ofertado por uma usina não necessariamente teria que ser igual à sua produção física. 
OLIVEIRA, 2003 observa que, como resultado do desacoplamento entre despacho comercial e despacho físico, o "os direitos de armazenamento de cada gerador hidrelétrico para o próximo período poderão estar armazenados fisicamente em qualquer reservatório do sistema." 